\title{
Syntheses and Transformations of $\alpha$-Aminobenzylnaphthol Derivatives
}

PhD Thesis

\section{István Szatmári}

Institute of Pharmaceutical Chemistry, University of Szeged

Szeged, Hungary 
The test of a first rate intelligence is the ability to hold two opposed ideas in the mind at the same time, and still retain the ability to function. One should, for example, be able to see that things are hopeless and yet be determined to make them otherwise.

(F. Scott Fitzgerald) 


\section{CONTENTS}

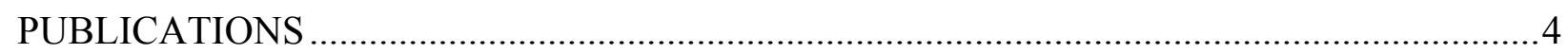

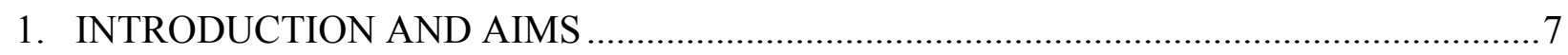

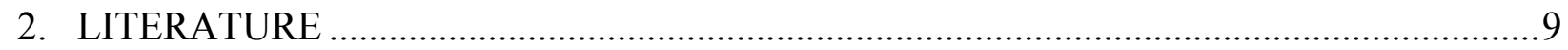

2.1. Syntheses of $\alpha$-aminobenzylnaphthol derivatives ...............................................

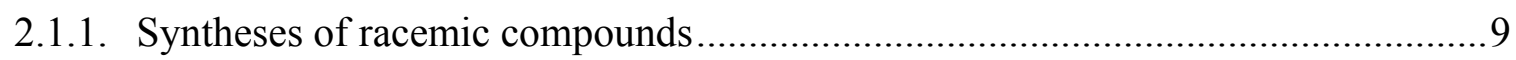

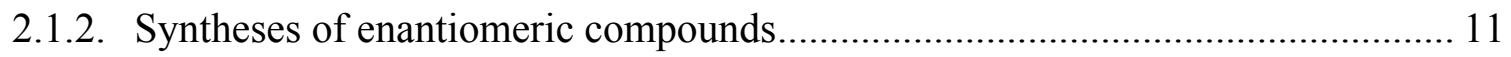

2.1.2.1. Resolution of the racemates by separation of the diastereomers................ 11

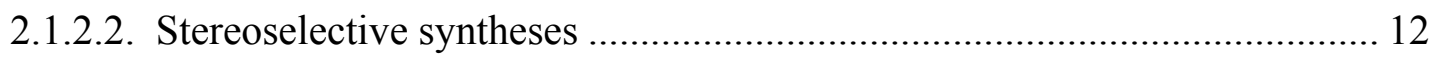

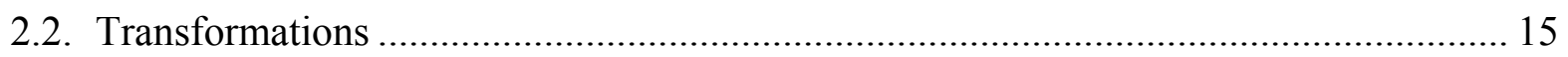

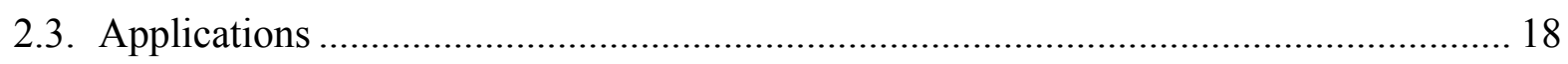

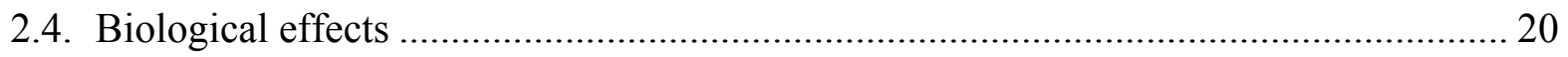

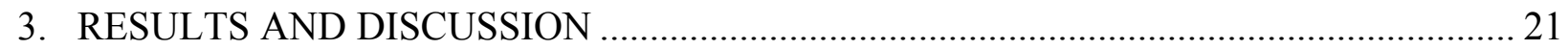

3.1. Syntheses and ring-chain tautomerism of 1,3-diarylnaphth[1,2-e][1,3]oxazines ......... 21

3.2. Syntheses and ring-chain tautomerism of 3-alkyl-1-arylnaphth[1,2-e][1,3]oxazines.... 34

3.3. Syntheses and ring-chain tautomerism of 2,4-diarylnaphth[2,1-e][1,3]oxazines ......... 37

3.4. Transformations of $\alpha$-aminobenzylnaphthol derivatives ....................................... 41

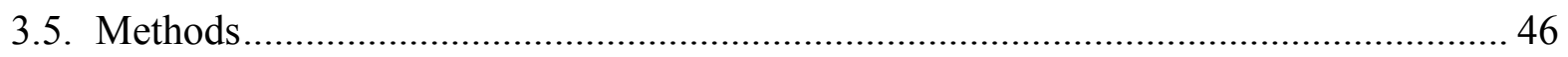

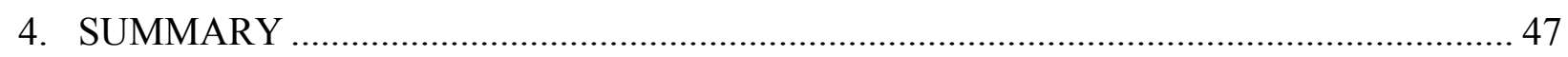

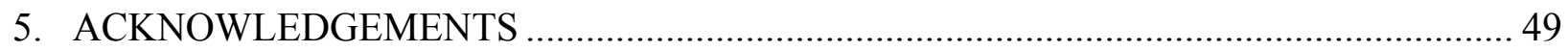

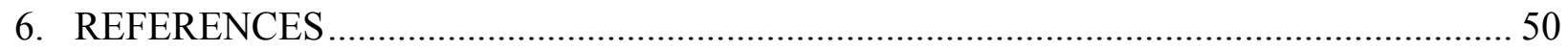

\section{ANNEX}




\section{PUBLICATIONS}

\section{Papers}

I. István Szatmári, Tamás A. Martinek, László Lázár, Ferenc Fülöp

Substituent effects in the ring-chain tautomerism of 1,3-diaryl-2,3-dihydro- $1 H$-naphth[1,2-e][1,3]oxazines.

Tetrahedron 2003, 59, 2877-2884.

II. István Szatmári, Tamás A. Martinek, László Lázár, Andreas Koch, Erich Kleinpeter, Ferenc Fülöp

Substituent effects in the ring-chain tautomerism of 1-aryl-2,3-dihydro- $1 H$-naphth$[1,2-e][1,3]$ oxazines.

Annals of West University of Timisoara 2003, 3, 175-182.

III. István Szatmári, Tamás A. Martinek, László Lázár, Andreas Koch, Erich Kleinpeter, Kari Neuvonen, Ferenc Fülöp

Stereoelectronic effects in ring-chain tautomerism of 1,3-diarylnaphth[1,2-e][1,3]oxazines and 3-alkyl-1-arylnaphth[1,2-e][1,3]oxazines.

J. Org. Chem. 2004, 69, 3645-3653.

IV. István Szatmári, Tamás A. Martinek, László Lázár, Ferenc Fülöp

Substituent effects in the ring-chain tautomerism of 2,4-diaryl-3,4-dihydro- $2 H$-naphth$[2,1-e][1,3]$ oxazines.

Eur. J. Org. Chem. 2004, 2231-2238.

V. István Szatmári, Ferenc Fülöp

Syntheses and transformations of 1-( $\alpha$-aminobenzyl)-2-naphthol derivatives.

Curr. Org. Synth. 2004, 1, 155-165.

VI. István Szatmári, Anasztázia Hetényi, László Lázár, Ferenc Fülöp

Transformation reactions of Betti base analogue aminonaphthols.

$J$. Heterocyclic Chem. (in press).

VII. Matthias Heydenreich, Andreas Koch, László Lázár, István Szatmári, Reijo Sillanpää, Erich Kleinpeter, Ferenc Fülöp

Synthesis and stereochemical studies of 1- and 2-phenyl-substituted 1,3-oxazino$[4,3-a]$ isoquinoline derivatives.

Tetrahedron 2003, 59, 1951-1959. 


\section{Conference lectures}

VIII. László Lázár, István Szatmári, Tamás A. Martinek, Ferenc Fülöp

Substituent effects on the ring-chain tautomerism of naphthalene-condensed

2-aryl-1,3-oxazines.

XIXth European Colloquium on Heterocyclic Chemistry

Aveiro, Portugal, 19-22 July, 2000, Abstr.: 124.

IX. Szatmári István

Szubsztituenshatások tanulmányozása naftalinnal kondenzált 2-aril-1,3-oxazinok gyürülánc tautomériájában.

V. Clauder Ottó Emlékverseny

Budapest, 2000. szeptember 21-23., Abstr.: 11.

X. Szatmári István, Martinek Tamás, Lázár László, Fülöp Ferenc

Szubsztituenshatások tanulmányozása naftalinnal kondenzált 2-aril-1,3-oxazinok gyürülánc tautomériájában.

MKE Vegyészkonferencia

Hajdúszoboszló, 2001. június 27-29., Abstr.: 115.

XI. Szatmári István, Lázár László, Martinek Tamás, Andreas Koch, Erich Kleinpeter, Fülöp Ferenc

A Betti-bázis alkalmazásai heterociklusok szintézisére.

MTA Heterociklusos Kémiai Munkabizottság Elöadóülése

Balatonszemes, 2002. május 23-24.

XII. István Szatmári, László Lázár, Tamás Martinek, Andreas Koch, Erich Kleinpeter, Ferenc Fülöp

Substituent effects on ring-chain tautomerism of naphthalene-condensed 1,3-oxazines.

$9^{\text {th }}$ Blue Danube Symposium on Heterocyclic Chemistry

Tatranská Lomnica, Slovak Republic, June 16-20, 2002, Abstr.: PO 134.

XIII. Ferenc Fülöp, István Szatmári, László Lázár, Tamás Martinek, Andreas Koch, Erich Keinpeter

Ring-chain tautomerism of regioisomeric naphthalene-condensed 1,3-oxazines.

XXth European Colloquium on Heterocyclic Chemistry

Stockholm, Sweden, August 18-21, 2002, Abstr.: 94.

XIV. Szatmári István

Szubsztituenshatások tanulmányozása naftalinnal kondenzált diaril-szubsztituált

1,3-oxazinok gyürü-lánc tautomériájában.

$X X V$. Kémiai Elöadói Napok

Szeged, 2002. október 28-30., Abstr.: 163.

\section{Szatmári István}

Szubsztituenshatások tanulmányozása naftalinnal kondenzált diaril-szubsztituált 1,3-oxazinok gyürü-lánc tautomériájában.

„A szegedi ifjú szerves kémikusok támogatásáért” alapitvány elöadóülése

Szeged, 2003. január 16. 
XVI. Szatmári István, Martinek Tamás, Lázár László, Fülöp Ferenc

Szubsztituenshatások tanulmányozása naftalinnal kondenzált 2,4-diaril-szubsztituált 1,3-oxazinok gyürü-lánc tautomériájában.

MKE Vegyészkonferencia

Hajdúszoboszló, 2003. június 26-28., Abstr.: 152.

XVII. István Szatmári, Tamás A. Martinek, László Lázár, Andreas Koch, Erich Kleinpeter, Ferenc Fülöp

Substituent effects in the ring-chain tautomerism of 1,3-diaryl-2,3-dihydro- $1 H$-naphth[1,2-e][1,3]oxazines and 3-alkyl-1-aryl-2,3-dihydro-1H-naphth[1,2-e][1,3]oxazines.

$11^{\text {th }}$ Physical Chemistry Conference (ROMPHYSCHEM)

Timisoara, Romania, September 2-5, 2003, Abstr.: 43. 


\section{INTRODUCTION AND AIMS}

One hundred years ago, Betti reported a straightforward synthesis of 1-( $\alpha$-aminobenzyl)-2naphthol (the Betti base, I: Y = H), ${ }^{1-5}$ starting from 2-naphthol, benzaldehyde and ammonia. The Betti procedure can be interpreted as a specification of the Mannich condensation, in which formaldehyde is replaced by an aromatic aldehyde, secondary amine by ammonia and the $\mathrm{C}-\mathrm{H}$ acid by an electron-rich aromatic compound such as 2-naphthol. The preparation of substituted Betti base derivatives by the modified Mannich reaction has subsequently become of considerable importance because a $\mathrm{C}-\mathrm{C}$ bond is formed under mild experimental conditions. In the past decade, interest in the chemistry of the Betti base has intensified. Preparation of the enantiomers of the Betti base and its $\mathrm{N}$-substituted derivatives is of significance since they can serve as chiral catalysts.

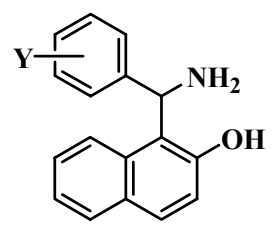

I

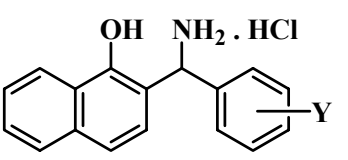

II<smiles>NCc1c(O)ccc2ccccc12</smiles>

VI

$\mathrm{Y}=\mathrm{NO}_{2}(m) ; \mathrm{Br}(m) ; \mathrm{NO}_{2}(p) ; \mathrm{Br}(p) ; \mathrm{Cl}(p)$;

$\mathrm{H} ; \mathrm{F}(p) ; \mathrm{Me}(p) ; \mathrm{OMe}(p)$

$\mathrm{Y}=\mathrm{NO}_{2}(m) ; \mathrm{Br}(m) ; \mathrm{Br}(p) ; \mathrm{Cl}(p) ; \mathrm{H} ;$

$\mathrm{Me}(p) ; \mathrm{OMe}(p)$

The ring-chain tautomeric interconversion of $\mathrm{N}$-unsubstituted 1,3-O,N-heterocycles and the corresponding hydroxyalkylimines can often be exploited advantageously in different areas of organic synthesis, and also in physical, medicinal and peptide chemistry. ${ }^{6-8}$ From quantitative studies on such equilibria, it has been concluded that the tautomeric ratios for oxazolidines and tetrahydro-1,3-oxazines bearing a substituted phenyl group at position 2 can be characterized by an aromatic substituent dependence: ${ }^{6}$

$$
\log \mathrm{K}_{\mathrm{X}}=\rho \sigma^{+}+\log \mathrm{K}_{\mathrm{X}=\mathrm{H}}
$$

where $\mathrm{K}_{\mathrm{X}}$ is the [ring]/[chain] ratio and $\sigma^{+}$is the Hammett-Brown parameter of substituent $\mathrm{X}$ on the 2-phenyl group. The scope and limitations of Eq. 1 have been thoroughly studied from the aspects of the applicability of this equation in the case of complex tautomeric mixtures containing several types of open and/or cyclic forms, and the influence of the steric and/or electronic effects of the substituents at positions other than 2 on the parameters in Eq. $1 .^{8-11}$ Previous quantitative investigations on the ring-chain tautomeric equilibria of some 1,3- $Y, N$ heterocyclic model compounds $(\mathrm{Y}=O, N R)$ did not result in precise mathematical formulae with which to characterize the effects of substituents at positions other than 2 , or were restricted to the recording of the substituent-induced changes in the parameters in Eq. 1. ${ }^{12-14}$ 
My $\mathrm{PhD}$ work focused on the syntheses of $\alpha$-aminobenzylnaphthol derivatives (I, II and VI) and, by transformation to different substituted 1,3-diaryl- (III), 3-alkyl,1-aryl- (IV) and 2,4diarylnaphthoxazines $(\mathbf{V})$, study of the double substituent effects on the ring-chain tautomeric equilibria.<smiles>c1ccc(C2N[C@H](c3ccccc3)c3c(ccc4ccccc34)O2)cc1</smiles>

III-B<smiles>[X]c1cccc(N=C(c2ccccc2)c2c(O)ccc3ccccc23)c1</smiles>

III-A

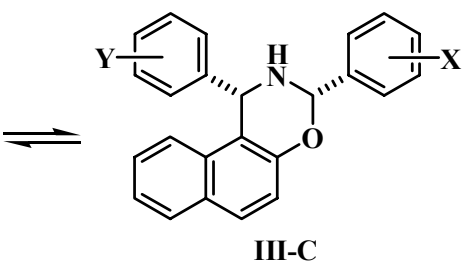

III-C

$\mathrm{Y}=\mathrm{NO}_{2}(m) ; \mathrm{Br}(m) ; \mathrm{NO}_{2}(p) ; \mathrm{Br}(p) ; \mathrm{Cl}(p) ; \mathrm{H} ; \mathrm{F}(p) ; \mathrm{Me}(p) ; \mathrm{OMe}(p)$

$\mathrm{X}=\mathrm{NO}_{2}(p) ; \mathrm{Br}(m) ; \mathrm{Br}(p) ; \mathrm{Cl}(p) ; \mathrm{H} ; \mathrm{Me}(p) ; \mathrm{OMe}(p)$<smiles>[R]C1=N[C@H](c2ccc[Y]([H])c2)c2c(ccc3ccccc23)O1</smiles>

IV-B<smiles>[R]C=NC(c1ccccc1)c1c(O)ccc2ccccc12</smiles>

IV-A<smiles>[R]C1N[C@H](c2ccccc2)c2c(ccc3ccccc23)O1</smiles>

IV-C

$\mathrm{Y}=\mathrm{NO}_{2}(m) ; \mathrm{Br}(m) ; \mathrm{NO}_{2}(p) ; \mathrm{Br}(p) ; \mathrm{Cl}(p) ; \mathrm{H} ; \mathrm{F}(p) ; \mathrm{Me}(p) ; \mathrm{OMe}(p)$ $\mathrm{R}=\mathrm{Me} ; \mathrm{Et} ; \operatorname{Pr} ; i \operatorname{Pr} ; t \mathrm{Bu}$<smiles>c1ccc(C2NC(c3ccccc3)c3ccc4ccccc4c3O2)cc1</smiles>

V-B<smiles>[X]c1cccc(C=NC(c2ccccc2)c2ccc3ccccc3c2O)c1</smiles>

V-A<smiles>[X]c1cccc([C@@H]2N[C@H](c3ccccc3)c3ccc4ccccc4c3O2)c1</smiles>

V-C

$\mathrm{Y}=\mathrm{NO}_{2}(m) ; \mathrm{Br}(m) ; \mathrm{Br}(p) ; \mathrm{Cl}(p) ; \mathrm{H} ; \mathrm{Me}(p) ; \mathrm{OMe}(p)$

$\mathrm{X}=\mathrm{NO}_{2}(p) ; \mathrm{Br}(m) ; \mathrm{Br}(p) ; \mathrm{Cl}(p) ; \mathrm{H} ; \mathrm{Me}(p) ; \mathrm{OMe}(p)$

A further aim was to study the synthetic applicability of $\alpha$-aminobenzylnaphthol derivatives (I: $\mathrm{Y}=\mathrm{H}$; II: $\mathrm{Y}=\mathrm{H}$; and $\mathbf{V I})$ in some other ring-closure reactions. 


\section{LITERATURE}

\subsection{Syntheses of $\alpha$-aminobenzylnaphthol derivatives}

\subsubsection{Syntheses of racemic compounds}

The chemistry of the Betti bases started at the beginning of the 20th century, when Betti reported the synthesis of 1-( $\alpha$-aminobenzyl)-2-naphthol. The reaction was performed with 2naphthol (1), benzaldehyde and ammonia (in a ratio of 1:2:1) to obtain 1,3-diphenyl-2,3-dihydro$1 H$-naphth[1,2-e][1,3] oxazine (2a). The subsequent acidic hydrolysis and basification with $\mathrm{NH}_{4} \mathrm{OH}$ gave the desired aminonaphthol 3a (Scheme 1). ${ }^{1-4}$

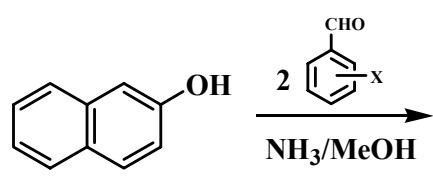

1<smiles>c1ccc(C2NC(c3ccccc3)c3c(ccc4ccccc34)O2)cc1</smiles>

2a-f

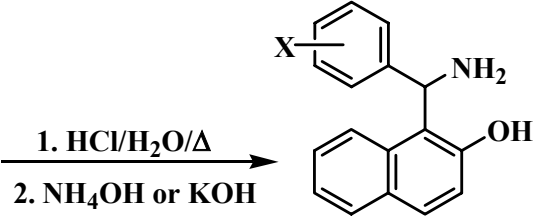

3a-f $\mathrm{X}=\mathrm{H}: \mathbf{a} ; \mathrm{Cl}(o): \mathbf{b} ; \mathrm{Cl}(m): \mathbf{c} ; \mathrm{Cl}(p): \mathbf{d} ; \mathrm{Me}(p): \mathbf{e} ; \mathrm{OMe}(p): \mathbf{f}$

\section{Scheme 1}

The general applicability of the Betti condensation has been tested by using chlorosubstituted benzaldehydes. The resulting aminonaphthols $\mathbf{3 b}, \mathbf{3 c}$ and $\mathbf{3 d}$ (Scheme 1) were found to be less stable than 3a. The sequence of stability was $\mathrm{X}=\mathrm{H}>\mathrm{Cl}(m)>\mathrm{Cl}(o)>\mathrm{Cl}(p) .{ }^{15} \mathrm{Some}$ further aminonaphthol analogues, $\mathbf{3 e}$ and $\mathbf{3 f}$, were prepared in order to study the stability of these compounds with respect to acidic hydrolysis. ${ }^{16}$ In these early papers, compounds 2 a-f were described as naphthoxazines, but in later publications it was pointed out that in $\mathrm{CDCl}_{3} \mathbf{2} \mathbf{2}-\mathbf{f}$ participate in a three-component tautomeric mixture containing two epimeric naphthoxazines besides the Schiff base. ${ }^{17,18}$

The reaction of 2-naphthol (1) with benzylidene( $p$-methoxyaniline) in methanol led to the formation of 1-[ $\alpha$-(p-methoxyanilino)benzyl]-2-naphthol (4, Scheme 2$).{ }^{19}$ The results can be interpreted as an extension of the Betti reaction because benzylidene( $p$-methoxyaniline) serves as an aldehyde source in the reaction, while primary amines were used instead of ammonia.

In a study of the diazotization of 2-naphthol (1) with amines, by induction with microwave irradiation in the absence of solvent, replacement of the aromatic amine by benzylamine led to the formation of $\alpha$-(2-hydroxy-1-naphthyl)dibenzylamine (5) instead of the expected benzylazo2-naphthol (Scheme 2). ${ }^{20}$ 
<smiles>COc1ccc(NC(c2ccccc2)c2c(O)ccc3ccccc23)cc1</smiles>

4

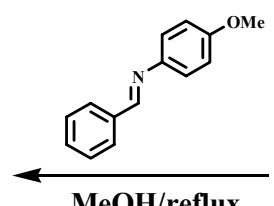

$\mathrm{MeOH} /$ reflux<smiles>Oc1ccc2ccccc2c1</smiles>

1<smiles>Oc1ccc2ccccc2c1C(NCc1ccccc1)c1ccccc1</smiles>

5

Scheme 2

The extension of the Betti reaction, when the electron-rich aromatic compound 2-naphthol (1) was replaced by the less reactive 1-naphthol (6), was performed by Hanumanthu et al. 1-Naphthol (6) with benzylidene( $p$-methoxyaniline) in methanol led to the formation of 2-[ $\alpha-(p-$ methoxyanilino)benzyl]-1-naphthol (7) (Scheme 3). ${ }^{19}$ Some further secondary and tertiary 2-( $\alpha$ aminobenzyl)-1-naphthol derivatives 8 were prepared by the reactions of 2-bromo-2-( $\alpha$ bromobenzyl)-1-tetralone (9) with primary or secondary amines (Scheme 3). ${ }^{21}$ Compounds 8 were synthesized by the same authors using classical Mannich condensation (e.g. 1-naphthol, benzaldehyde and amines) (Scheme 3). ${ }^{21}$<smiles>Oc1cccc2ccccc12</smiles>

6<smiles>[Tl]NCNCCc1ccccc1</smiles><smiles>[R]N([R])C(c1ccccc1)c1ccc2ccccc2c1O</smiles>

8

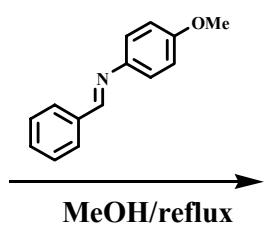

MeOH/reflux

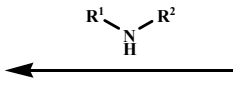

9

$\mathrm{R}^{1}, \mathrm{R}^{2}=\mathrm{H}, \mathrm{C}_{6} \mathrm{H}_{11} ; \mathrm{Me}, \mathrm{C}_{6} \mathrm{H}_{11}$; $-\left(\mathrm{CH}_{2}\right)_{5}-;-\left(\mathrm{CH}_{2}\right)_{2}-\mathrm{O}-\left(\mathrm{CH}_{2}\right)_{2}-$<smiles>COc1ccc(NC(c2ccccc2)c2ccc3ccccc3c2O)cc1</smiles>

7<smiles>O=C1c2ccccc2CCC1(Br)C(Br)c1ccccc1</smiles>

Scheme 3

The Betti condensation was extended by using secondary amines, ${ }^{22,23}$ resulting in 10, or cyclic amines, ${ }^{22-25}$ resulting in $\mathbf{1 1}$ as the $N, N$-disubstituted derivatives of the Betti base (Scheme 4). 
<smiles>[X]c1ccc(C(c2c(O)ccc3ccccc23)N([R])[R])cc1</smiles>

10

$\mathrm{X}=\mathrm{H} ; p \mathrm{OMe}$

$\mathrm{R}^{1}=\mathrm{Me} ; \mathrm{Et} ; n \mathrm{Pr}$ $\mathrm{R}^{2}=\mathrm{Me} ; \mathrm{Et} ; n \mathrm{Pr}$

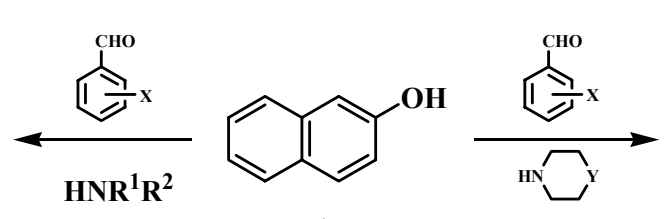

1<smiles>[X]c1ccc(C(c2c(O)ccc3ccccc23)N2CC[IH]CC2)cc1</smiles>

11

$$
\begin{gathered}
\mathrm{X}=p \mathrm{Cl} ; \mathrm{H} ; p \mathrm{OMe}, \mathrm{Y}=-\mathrm{CH}_{2^{-}} \\
\mathrm{X}=\mathrm{H} ; 3,4-\mathrm{OMe} ; p \mathrm{OMe} ; p \mathrm{NMe}_{2}, \mathrm{Y}=\mathrm{O}
\end{gathered}
$$

\section{Scheme 4}

In contrast with the conventional Mannich procedure, aminomethylations using methylene iminium salts, which function as highly reactive Mannich reagents, furnish basic advantages, because they generally provide superior yields, while the reactions are faster and require milder conditions. This strategy was first applied by Risch et al. ${ }^{26}$ to prepare 12 and $\mathbf{1 4}$ (Scheme 5), and was extended by Saidi et al. ${ }^{27}$ the iminium salts being prepared in situ in $5 \mathrm{M}$ ethereal lithium perchlorate to obtain 13 and $\mathbf{1 5}$ (Scheme 5).<smiles>[R]N([R])C(c1ccccc1)c1c(O)ccc2ccccc12</smiles>

12

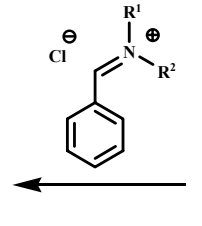<smiles>Oc1ccc2ccccc2c1</smiles>

1

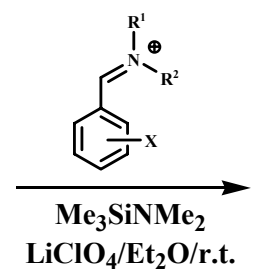

$\mathrm{LiClO}_{4} / \mathrm{Et}_{2} \mathrm{O} /$ r.t.<smiles>[X]c1ccc(C(c2c(O)ccc3ccccc23)N([R])[R])cc1</smiles>

13

$\mathrm{R}^{1}, \mathrm{R}^{2}=\mathrm{Me}, \mathrm{Me}: \mathbf{a} ;-\left(\mathrm{CH}_{2}\right)_{5^{-}}: \mathbf{b}$

$$
\begin{gathered}
\mathrm{X}=m \mathrm{NO}_{2} ; 2,4-\mathrm{di}-\mathrm{Cl} ; p \mathrm{Cl} ; p \mathrm{CN} ; \mathrm{H} \\
\mathrm{R}^{1}, \mathrm{R}^{2}=\mathrm{Me}, \mathrm{Me} ;-\left(\mathrm{CH}_{2}\right)_{4}^{-} ;-\left(\mathrm{CH}_{2}\right)_{5}- \\
-\left(\mathrm{CH}_{2}\right)_{2}-\mathrm{O}-\left(\mathrm{CH}_{2}\right)_{2-}^{-}
\end{gathered}
$$<smiles>CN(C)C(c1ccccc1)c1ccc2ccccc2c1O</smiles>

14

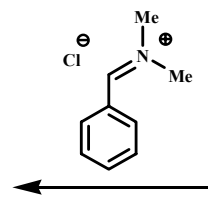<smiles>Oc1cccc2ccccc12</smiles>

6

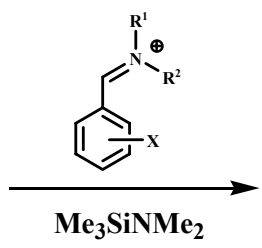

$\mathrm{LiClO}_{4} / \mathrm{Et}_{2} \mathrm{O} /$ r.t.<smiles>[X]c1ccc(C(c2ccc3ccccc3c2O)N([R])[R])cc1</smiles>

15

$$
\begin{gathered}
\mathrm{X}=2,4-\mathrm{di}-\mathrm{Cl} ; p \mathrm{Cl} \\
\mathrm{R}^{1}, \mathrm{R}^{2}=-\left(\mathrm{CH}_{2}\right)_{4^{-}} ;-\left(\mathrm{CH}_{2}\right)_{2}-\mathrm{O}-\left(\mathrm{CH}_{2}\right)_{2}-
\end{gathered}
$$

Scheme 5

\subsubsection{Syntheses of enantiomeric compounds}

\subsubsection{Resolution of the racemates by separation of the diastereomers}

The first resolution of 1-( $\alpha$-aminobenzyl)-2-naphthol was performed by diastereomeric salt formation with tartaric acid by Betti. ${ }^{28,29}$ Naso et al. reported the resolution of 3a through treatment of the racemic compound with an equivalent amount of $(2 R, 3 R)$-tartaric acid in a $95 \%$ 
ethanol-methanol mixture (6:1). Fractional crystallization afforded the less soluble salt (+)-3a, and its absolute configuration was found to be $(S)$ (determined by X-ray diffraction analysis of its hydrobromide salt, 3a.HBr). ${ }^{30}$ The $N, N$-dimethylamino derivative of $\mathbf{3 a}$ was resolved in a similar manner. The diastereomeric salts obtained from the racemate and $(2 R, 3 R)$-tartaric acid were separated by fractional crystallization from acetone. ${ }^{30}$ The $N$-butyl derivative of $\mathbf{3 a}$ could be resolved by using an equivalent amount of $(2 R, 3 R)$-tartaric acid in acetone. ${ }^{31}$<smiles>N[C@H](c1ccccc1)c1c(O)ccc2ccccc12</smiles>

3a<smiles>CN(C)[C@H](c1ccccc1)c1c(O)ccc2ccccc12</smiles><smiles>CCCCNC(c1ccccc1)c1c(O)ccc2ccccc12</smiles>

\subsubsection{Stereoselective syntheses}

Palmieri reported an enantioselective synthesis of $\left(1 R, 1^{\prime} R\right)-\mathbf{1 7} \mathbf{a}$ under solvent-free conditions, starting from benzaldehyde, 2-naphthol (1) and $(R)$-1-phenylethylamine. Of the two possible diastereomers, the diastereomeric excess (de) of the $(R, R)$ isomer was found to be $98 \%{ }^{32}$ Since 17 a could be obtained in excellent yield and de, the reaction was later extended to substituted benzaldehydes and to obtain $\left(1 R, 1^{\prime} R\right)-16$, 2-naphthol being replaced by 1-naphthol (Scheme 6 and Table 1). ${ }^{33}$

A variety of such aminonaphthols were prepared by Palmieri et al., (R)-1phenylethylamine being replaced by other chiral amines. The de values and the reaction conditions are given in Table $1 .^{34}$<smiles>CC(N[C@H](c1ccccc1)c1ccc2ccccc2c1O)c1ccccc1</smiles>

16

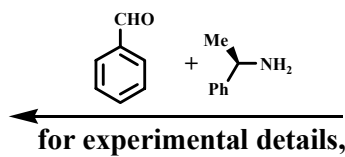
see Table 1<smiles>Oc1cccc2ccccc12</smiles>

6

1
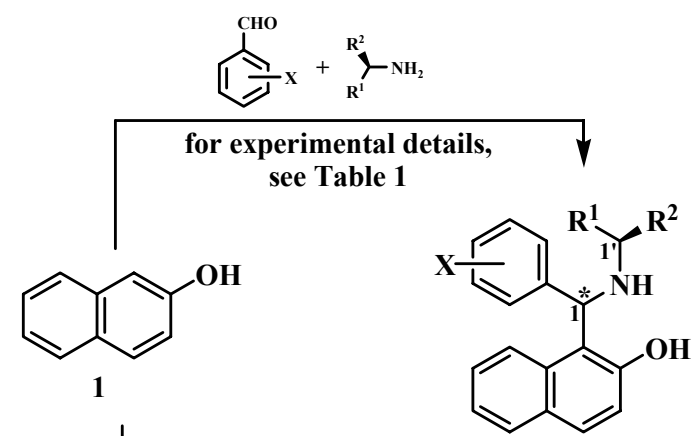

17

for experimental details, see Table 2

Scheme 6 
Table 1. Reaction conditions for the aminoalkylation of 1- or 2-naphthol with enantiopure amines and substituted benzaldehydes

\begin{tabular}{||c|c|c|c|c|c|c||}
\hline \hline $\mathrm{X}$ & $\mathrm{R}^{1}$ & $\mathrm{R}^{2}$ & Main product & Conditions & $\begin{array}{c}\text { Yield } \\
(\%)\end{array}$ & de (\%) \\
\hline- & - & - & $\left(1 R, 1^{\prime} R\right)-\mathbf{1 6}$ & $60^{\circ} \mathrm{C}, 8 \mathrm{~h}$ & 50 & $41^{\mathrm{a}}$ \\
$\mathrm{H}$ & $\mathrm{Ph}$ & $\mathrm{Me}$ & $\left(1 R, 1^{\prime} R\right)-\mathbf{1 7 a}$ & $60^{\circ} \mathrm{C}, 8 \mathrm{~h}$ & 93 & $98^{\mathrm{b}}$ \\
$p \mathrm{Me}$ & $\mathrm{Ph}$ & $\mathrm{Me}$ & $\left(1 R, 1^{\prime} R\right)-\mathbf{1 7 b}$ & $60^{\circ} \mathrm{C}, 8 \mathrm{~h}$ & 72 & $92^{\mathrm{a}}$ \\
$p \mathrm{OMe}$ & $\mathrm{Ph}$ & $\mathrm{Me}$ & $\left(1 R, 1^{\prime} R\right)-\mathbf{1 7 c}$ & $60^{\circ} \mathrm{C}, 14 \mathrm{~h}$ & 66 & $61^{\mathrm{a}}$ \\
$p \mathrm{Cl}$ & $\mathrm{Ph}$ & $\mathrm{Me}$ & $\left(1 R, 1^{\prime} R\right)-\mathbf{1 7 d}$ & $60^{\circ} \mathrm{C}, 7 \mathrm{~h}$ & 72 & $62^{\mathrm{a}}$ \\
$m \mathrm{NO}{ }_{2}$ & $\mathrm{Ph}$ & $\mathrm{Me}$ & $\left(1 R, 1^{\prime} R\right)-\mathbf{1 7 e}$ & $60^{\circ} \mathrm{C}, 14 \mathrm{~h}$ & 86 & $50^{\mathrm{a}}$ \\
$o \mathrm{OMe}$ & $\mathrm{Ph}$ & $\mathrm{Me}$ & $\left(1 S, 1^{\prime} R\right)-\mathbf{1 7 f}$ & $60^{\circ} \mathrm{C}, 9 \mathrm{~h}$ & 75 & $50^{\mathrm{c}}$ \\
$\mathrm{H}$ & $-\mathrm{CH}_{2}-\mathrm{OH}$ & $\mathrm{Ph}$ & $\left(1 S, 1^{\prime} R\right)-\mathbf{1 7 g}$ & $60^{\circ} \mathrm{C}, 8 \mathrm{~h}$ & 66 & $56^{\mathrm{c}}$ \\
$\mathrm{H}$ & $1-$ naphthyl & $\mathrm{Me}$ & $\left(1 R, 1^{\prime} R\right)-\mathbf{1 7 h}$ & $60^{\circ} \mathrm{C}, 14 \mathrm{~h}$ & 80 & $60^{\mathrm{c}}$ \\
\hline \hline
\end{tabular}

${ }^{\mathrm{a}}$ Data from ref. 33. ${ }^{\mathrm{b}}$ Data from ref. $32 .{ }^{\mathrm{c}}$ Data from ref. 34

The diastereoselectivity of the reaction was explained by the asymmetric transformation of the second kind induced by the preferential crystallization. ${ }^{33}$ The diastereoselectivity of the reaction was interpreted by Palmieri et al. as given in Scheme 7. It was assumed that an aldiminium-type complex (A) is initially formed through protonation of the $\mathrm{C}=\mathrm{N}$ nitrogen. In the first step of this Friedel-Crafts reaction, the rate-limiting stage of the whole reaction, the formation of the arenium $\sigma$-complex $u l-(R e, S i)-(R, R)-\mathbf{1 7 a}-\sigma(\mathbf{C})$ proceeds through a sixmembered transition state $u l-(R e, S i)-(R, R)-\mathbf{1 7 a - T S}(\mathbf{B})$, as shown in Scheme 7. The relative stability of the transition state 17a-TS, calculated for all four possible combinations, at the semiempirical PM3 level, accorded with the stereoselectivity observed for this Mannich reaction. ${ }^{34}$

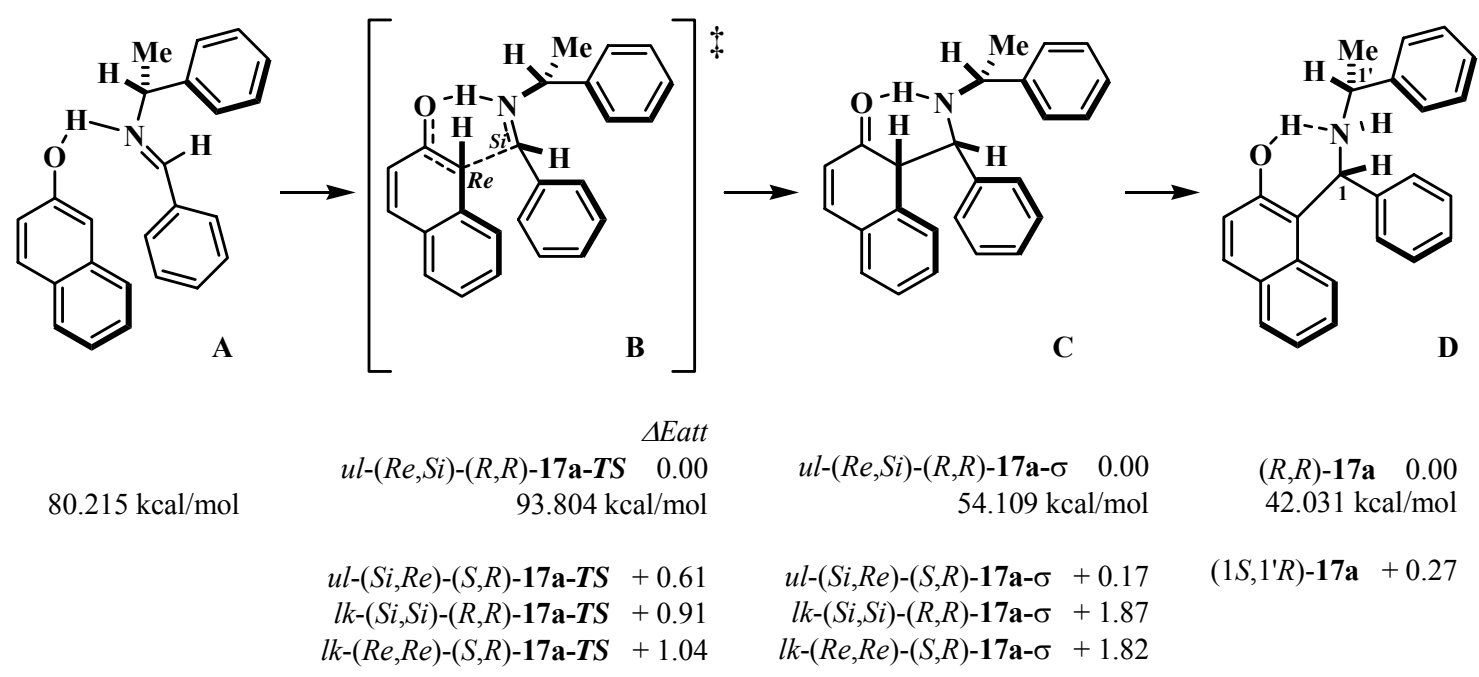

Scheme 7

The mechanism and diastereoselectivity of the reactions of 2-naphthol (1) and chiral imines, which involve donor-acceptor interactions, were also investigated by Boga et al. Table 2 lists the yields, de values and experimental conditions. Those authors assumed the presence of 
kinetic control at low temperature, and re-equilibration (by thermodynamic control) at high temperature. ${ }^{35}$

Saidi et al. reported a one-pot, three-component Mannich reaction of 2-naphthol (1) with imines prepared in situ in $5 \mathrm{M}$ ethereal lithium perchlorate at room temperature. Under these conditions, secondary aminonaphthols could be obtained in high yields with high diastereoselectivities (Scheme 6, Table 2). ${ }^{36}$

Table 2. Reaction conditions for the aminoalkylation of 2-naphthol with chiral imines

\begin{tabular}{||c|c|c|c|c|c|c|c|c||}
\hline \hline $\mathrm{X}$ & $\mathrm{R}^{1}$ & $\mathrm{R}^{2}$ & Main product & Catalyst & Solvent & Conditions & $\begin{array}{c}\text { Yield } \\
(\%)\end{array}$ & $\begin{array}{c}\text { de } \\
(\%)\end{array}$ \\
\hline $\mathrm{H}$ & $\mathrm{Me}$ & $\mathrm{Ph}$ & $\left(1 R, 1^{\prime} S\right)-\mathbf{1 7 a}$ & - & $\mathrm{CH}_{2} \mathrm{Cl}_{2}$ & $20^{\circ} \mathrm{C}, 1 \mathrm{~d}$ & 75 & $0^{\mathrm{a}}$ \\
$\mathrm{H}$ & $\mathrm{Me}$ & $\mathrm{Ph}$ & $\left(1 S, 1^{\prime} S\right)-\mathbf{1 7 a}$ & - & $\mathrm{CH}_{2} \mathrm{Cl}_{2}$ & $20^{\circ} \mathrm{C}, 10 \mathrm{~d}$ & 95 & $70^{\mathrm{a}}$ \\
$\mathrm{H}$ & $\mathrm{Me}$ & $\mathrm{Ph}$ & $\left(1 R, 1^{\prime} S\right)-\mathbf{1 7 a}$ & $\mathrm{Et}_{3} \mathrm{~N}$ & $\mathrm{CH}_{2} \mathrm{Cl}_{2}$ & $20{ }^{\circ} \mathrm{C}, 10 \mathrm{~d}$ & 50 & $0^{\mathrm{a}}$ \\
$\mathrm{H}$ & $\mathrm{Me}$ & $\mathrm{Ph}$ & $\left(1 S, 1^{\prime} S\right)-\mathbf{1 7 a}$ & $\mathrm{CH}_{3} \mathrm{SO}_{3} \mathrm{H}$ & $\mathrm{CH}_{2} \mathrm{Cl}_{2}$ & $20^{\circ} \mathrm{C}, 10 \mathrm{~d}$ & 87 & $60^{\mathrm{a}}$ \\
$\mathrm{H}$ & $\mathrm{Me}$ & $\mathrm{Ph}$ & $\left(1 R, 1^{\prime} S\right)-\mathbf{1 7 a}$ & - & $\mathrm{CH}_{2} \mathrm{Cl}_{2}$ & $-20^{\circ} \mathrm{C}, 7 \mathrm{~d}$ & 50 & $20^{\mathrm{a}}$ \\
$\mathrm{H}$ & $\mathrm{Me}$ & $\mathrm{Ph}$ & $\left(1 R, 1^{\prime} S\right)-\mathbf{1 7 a}$ & - & $\mathrm{THF}$ & $20^{\circ} \mathrm{C}, 3 \mathrm{~d}$ & 84 & $20^{\mathrm{a}}$ \\
$\mathrm{H}$ & $\mathrm{Ph}$ & $\mathrm{Me}$ & $\left(1 R, 1^{\prime} R\right)-\mathbf{1 7 a}$ & $\mathrm{LiClO}_{4} / \mathrm{TMSCl}^{\mathrm{c}}$ & $\mathrm{Et}_{2} \mathrm{O}$ & r.t., $6 \mathrm{~h}$ & 75 & $98^{\mathrm{b}}$ \\
$p \mathrm{Cl}$ & $\mathrm{Ph}$ & $\mathrm{Me}$ & $\left(1 R, 1^{\prime} R\right)-\mathbf{1 7 d}$ & $\mathrm{LiClO}_{4} / \mathrm{TMSCl}$ & $\mathrm{Et}_{2} \mathrm{O}$ & r.t., $6 \mathrm{~h}$ & 78 & $98^{\mathrm{b}}$ \\
$m \mathrm{NO}$ & $\mathrm{Ph}$ & $\mathrm{Me}$ & $\left(1 R, 1^{\prime} R\right)-\mathbf{1 7 e}$ & $\mathrm{LiClO}_{4} / \mathrm{TMSCl}$ & $\mathrm{Et}_{2} \mathrm{O}$ & r.t., $6 \mathrm{~h}$ & 70 & $80^{\mathrm{b}}$ \\
$2,4-\mathrm{di}-\mathrm{Cl}$ & $\mathrm{Ph}$ & $\mathrm{Me}$ & $\left(1 R, 1^{\prime} R\right)-\mathbf{1 7 i}$ & $\mathrm{LiClO}_{4} / \mathrm{TMSCl}$ & $\mathrm{Et}_{2} \mathrm{O}$ & r.t., $6 \mathrm{~h}$ & 70 & $90^{\mathrm{b}}$ \\
$p \mathrm{CN}$ & $\mathrm{Ph}$ & $\mathrm{Me}$ & $\left(1 R, 1^{\prime} R\right)-\mathbf{1 7 j}$ & $\mathrm{LiClO}_{4} / \mathrm{TMSCl}$ & $\mathrm{Et}_{2} \mathrm{O}$ & r.t., $6 \mathrm{~h}$ & 72 & $90^{\mathrm{b}}$ \\
$p \mathrm{Br}$ & $\mathrm{Ph}$ & $\mathrm{Me}$ & $\left(1 R, 1^{\prime} R\right)-\mathbf{1 7 k}$ & $\mathrm{LiClO}_{4} / \mathrm{TMSCl}$ & $\mathrm{Et}_{2} \mathrm{O}$ & r.t., $6 \mathrm{~h}$ & 60 & $86^{\mathrm{b}}$ \\
$p \mathrm{OMe}$ & $\mathrm{Ph}$ & $\mathrm{Me}$ & $\left(1 R, 1^{\prime} R\right)-\mathbf{1 7 c}$ & $\mathrm{LiClO}_{4} / \mathrm{TMSCl}$ & $\mathrm{Et}_{2} \mathrm{O}$ & r.t., $6 \mathrm{~h}$ & 55 & $50^{\mathrm{b}}$ \\
\hline
\end{tabular}

${ }^{\mathrm{a}}$ Data from ref. 35. ${ }^{\mathrm{b}}$ Data from ref. 36. ${ }^{\mathrm{c}}$ Trimethylsilyl chloride

Chan et al. reported a new, one-step synthesis of (1S,1'S)-18 starting from 2-naphthol (1), benzaldehyde and $(S)-(-)-N$ - $\alpha$-dimethylbenzylamine. This was the first example of a straightforward asymmetric synthesis of an optically active tertiary aminonaphthol via Mannich aminoalkylation of 2-naphthol (Scheme 8). ${ }^{37}$

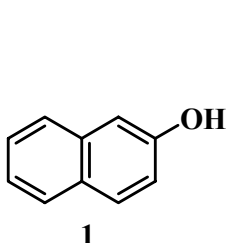

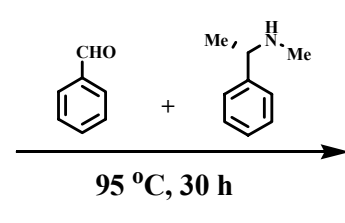

Scheme 8<smiles>[Y4]C(c1ccccc1)N([C@H](C)c1ccccc1)[C@H](c1ccccc1)c1c(O)ccc2ccccc12</smiles>

$\left(1 S, 1^{\prime} S\right)-\mathbf{1 8}$ 


\subsection{Transformations}

In spite of the great reaction possibility resulting from the two functional groups in the Betti base, relatively few publications have appeared on this field. Desai et al. used the racemic Betti base for the transformation into 4-thiazolidinones 20. The first step was the preparation of the Schiff bases 19 with substituted benzaldehydes, but the tautomeric capability of the condensation products was not discussed at all. Compounds 19 were then treated with mercaptoacetic acid to obtain 2-aryl-3-[ $\alpha$-(2-hydroxy-1-naphthyl)benzyl]-4-thiazolidinones (20), which exerted antimycobacterial and antibacterial activity (Scheme 9). ${ }^{38}$<smiles>NC(C=O)c1c(O)ccc2ccccc12</smiles>

3a

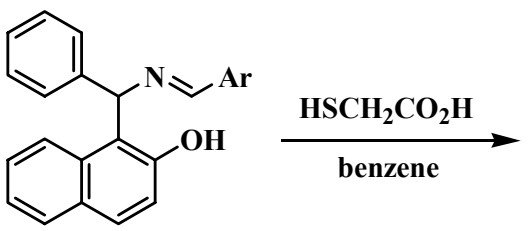

19<smiles>O=C1CSC([AlH2])N1C(c1ccccc1)c1c(O)ccc2ccccc12</smiles>

20

$\mathrm{Ar}=\mathrm{C}_{6} \mathrm{H}_{5}: \mathbf{a} ; 2-\mathrm{OH}-\mathrm{C}_{6} \mathrm{H}_{4}: \mathbf{b} ; 4-\mathrm{OH}-\mathrm{C}_{6} \mathrm{H}_{4}: \mathbf{c} ; 4-\mathrm{Cl}_{-} \mathrm{C}_{6} \mathrm{H}_{4}: \mathbf{d} ; 4-\mathrm{OMe}-\mathrm{C}_{6} \mathrm{H}_{4}: \mathbf{e} ; 5-\mathrm{Br}, 2-\mathrm{OH}-\mathrm{C}_{6} \mathrm{H}_{3}: \mathbf{f}$; 3,5-di-Br,2-OH-C $\mathrm{C}_{6} \mathrm{H}_{2}: \mathbf{g} ; 3,4-\mathrm{CH}_{2} \mathrm{O}_{2}-\mathrm{C}_{6} \mathrm{H}_{3}: \mathbf{h} ; 4-\mathrm{NO}_{2}-\mathrm{C}_{6} \mathrm{H}_{4}: \mathbf{i} ; 3-\mathrm{NO}_{2}-\mathrm{C}_{6} \mathrm{H}_{4}: \mathbf{j} ; 4-\mathrm{Me}_{-} \mathrm{C}_{6} \mathrm{H}_{4}: \mathbf{k}$

\section{Scheme 9}

Hanumanthu et al. achieved the synthesis of 1,3-diphenyl-2-( $p$-methoxyphenyl)-2,3dihydro- $1 H$-naphth[1,2-e][1,3]oxazines

(21) and 2,4-diphenyl-3-(p-methoxyphenyl)-3,4dihydro-2 $H$-naphth[2,1-e][1,3]oxazines (22) by the reactions of 1-[ $\alpha$-( $p$-methoxyanilino)benzyl]2-naphthol (4) and 2-[ $\alpha$-(p-methoxyanilino)benzyl]-1-naphthol (7) either with benzaldehyde or with benzylidene $\left(p\right.$-methoxyaniline) in acetic acid (Scheme 10). ${ }^{19}$<smiles>COc1ccc(NC(c2ccccc2)c2c(O)ccc3ccccc23)cc1</smiles>

4<smiles>COc1ccc(NC(c2ccccc2)c2ccc3ccccc3c2O)cc1</smiles>

7

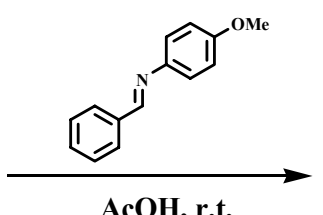

АcOH, r.t.

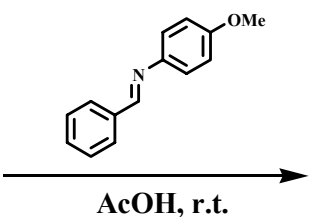

AcOH, r.t.<smiles>COc1ccc(N2C(c3ccccc3)Oc3ccc4ccccc4c3C2c2ccccc2)cc1</smiles>

21<smiles>COc1ccc(N2C(c3ccccc3)Oc3c(ccc4ccccc34)C2c2ccccc2)cc1</smiles>

22

Scheme 10 
Treatment of $(S)-(+)-\mathbf{3 a}$ with $\mathrm{NaOH} / \mathrm{MeI}$ led to the trimethyl derivative $(S)-(-)-\mathbf{2 3}$ (Scheme 11). ${ }^{30}$ In order to prove the $(S)$ configuration of the $(+)-25$ produced, Palmieri et al. treated $(S)$ $(+)$-3a with $n$-butanal, yielding the oxazine (-)-24, which was reduced with $\mathrm{NaBH}_{4}$ to $(+)-25$ (Scheme 11). ${ }^{31}$<smiles>COc1ccc2ccccc2c1[C@@H](c1ccccc1)N(C)C</smiles>

$(S)-(-)-23$

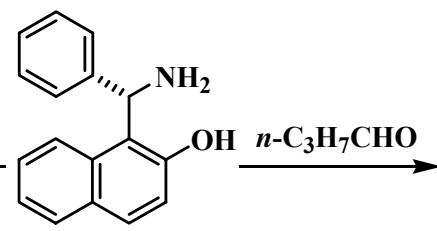

$(S)-(+)-3 \mathbf{a}$

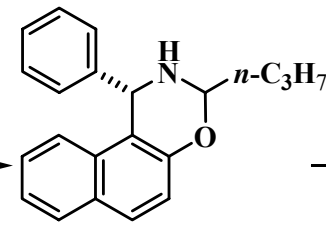

$(S)-(-)-24$

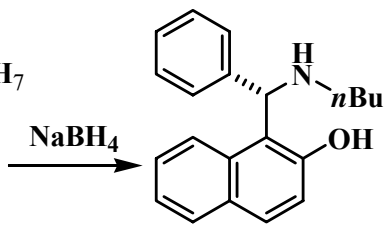

$(S)-(+)-25$

\section{Scheme 11}

The enantiomers of the Betti base derivatives are not only good chiral ligands in asymmetric syntheses, but can also be applied as simple starting materials in the enantioselective syntheses of other chiral inductors.

A simple preparation of $\left(1 S, 1^{\prime} S\right)$-18 starting from $\left(1 S, 1^{\prime} S\right)$-17a is its direct $N$-methylation with paraformaldehyde; this was first carried out by Wang et al. (Scheme 12). ${ }^{39}$ Palmieri et al. reported the syntheses of $\left(1 R, 1^{\prime} R\right)-\mathbf{1 8}$ and a wide group of tertiary aminonaphthols $\mathbf{2 6}$ and $\mathbf{2 8}$ by reduction or alkylation of $27^{40}$ with organometallic reagents (Scheme 12). ${ }^{34}$<smiles>[X]c1ccc([C@H](N[C@@H](C)c2ccccc2)c2c(O)ccc3ccccc23)cc1</smiles>

$17 \mathbf{a}, 17 \mathrm{~b}$ $\mathrm{X}=\mathrm{H}: \mathbf{a} ; \mathrm{Me}: \mathbf{b}$<smiles>[Y]c1ccc([C@H](c2c(O)ccc3ccccc23)N(C)[C@H](C)c2ccccc2)cc1</smiles>

$\mathrm{X}=\mathrm{H}: \mathbf{1 8} ; \mathrm{CH}_{3}: \mathbf{2 6}$

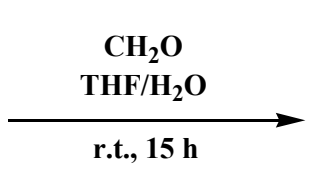<smiles>[X]c1ccc([C@H]2c3c(ccc4ccccc34)OCN2[C@@H](C)c2ccccc2)cc1</smiles>

$27 \mathrm{a}, 27 \mathrm{~b}$ $\mathrm{X}=\mathrm{H}: \mathbf{a} ; \mathrm{Me}: \mathbf{b}$

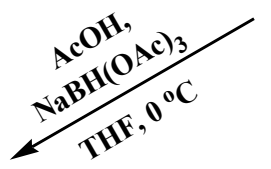<smiles>[R]CN(C(C)c1ccccc1)[C@H](c1ccccc1)c1c(O)ccc2ccccc12</smiles>

28a-f

$\mathrm{R}^{1}=\mathrm{CH}_{3}: \mathbf{a} ; \mathrm{CH}_{2}-\mathrm{C}_{6} \mathrm{H}_{5}: \mathbf{b} ; n-\mathrm{C}_{4} \mathrm{H}_{9}: \mathbf{c}$; $\mathrm{C}_{6} \mathrm{H}_{5}: \mathbf{d} ; \mathrm{CH}_{2}-\mathrm{CH}=\mathrm{CH}_{2}: \mathbf{e} ; \mathrm{CH}=\mathrm{CH}_{2}: \mathbf{f}$

\section{Scheme 12}

The syntheses of $(R)$ - and $(S)-1-[\alpha-(1$-azacycloalkyl)benzyl]-2-naphthol 30 were attained by $\mathrm{Hu}$ et al. via selective $N$-cyclizations of $(R)-(-)$ and $(S)-(+)$ Betti bases with dials in the 
presence of $\mathrm{NaBH}_{3} \mathrm{CN}$ to give naphthalene-condensed 1-azacycloalka[2,1-b]oxazines 29, followed by selective cleavage of the C-O bonds with $\mathrm{LiAlH}_{4}$ (Scheme 13). ${ }^{41,42}$

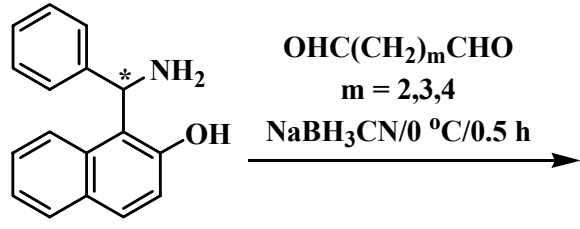

3a<smiles>c1ccc([C@@H]2C3=C(NCCC3)Oc3ccc4ccccc4c32)cc1</smiles>

29

$\mathrm{n}=1: \mathbf{a} ; 2: \mathbf{b} ; 3: \mathbf{c}$

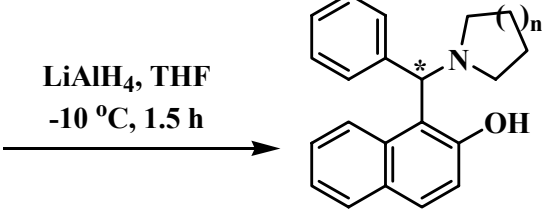

30

$\mathrm{n}=1: \mathbf{a} ; 2: \mathbf{b} ; 3: \mathbf{c}$

\section{Scheme 13}

Ding et al. described the synthesis of a new type of chiral aminophosphine ligands from $\left(1 R, 1^{\prime} R\right)-\mathbf{1 7} \mathbf{a}$ as starting material, formed by asymmetric 1-aminoalkylation of 2-naphthol (1) with $(R)-1$-phenylethylamine and benzaldehyde (Schemes 14 and 15). ${ }^{43}$<smiles>C[C@H](NC(c1ccccc1)c1c(O)ccc2ccccc12)c1ccccc1</smiles>

$\left(1 R, 1^{\prime} R\right)-\mathbf{1 7} \mathbf{a}$

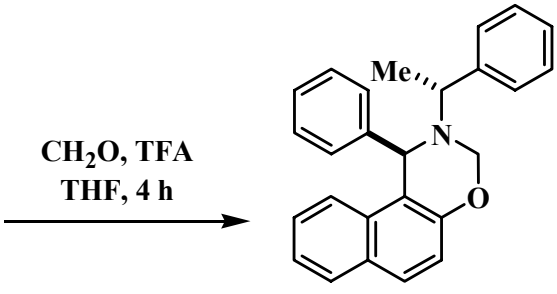

$\left(1 R, 1^{\prime} R\right)-\mathbf{3 1}$

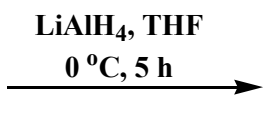<smiles>C[C@H](c1ccccc1)N(C)C(c1ccccc1)c1c(O)ccc2ccccc12</smiles>

$\left(1 R, 1^{\prime} R\right)-32$

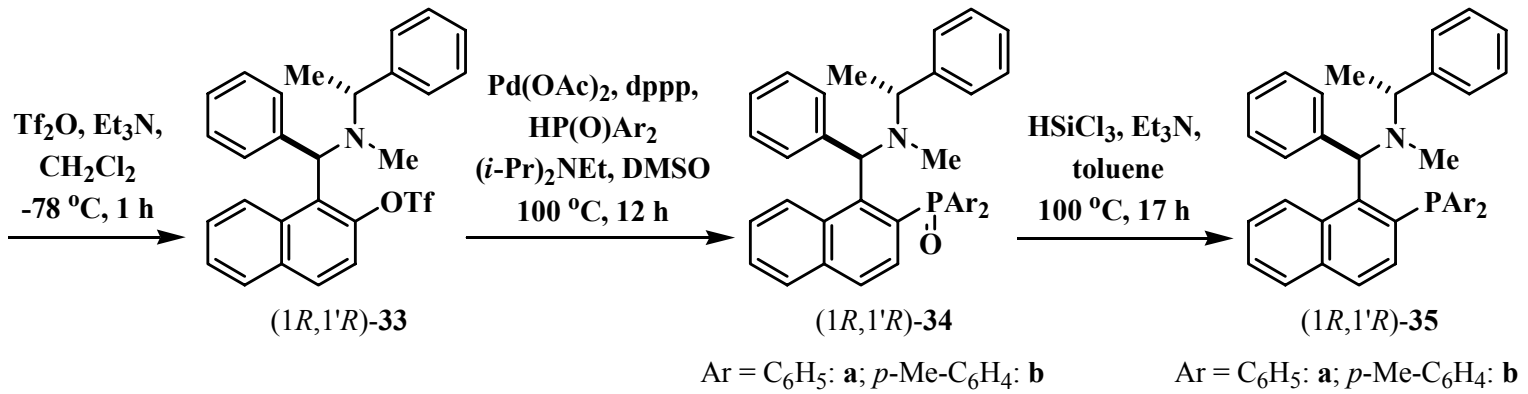

$\mathrm{Tf}_{2} \mathrm{O}=$ trifluoromethanesulfonic anhydride; $\mathrm{dppp}=1,3$-bis(diphenylphosphino)propane

\section{Scheme 14}




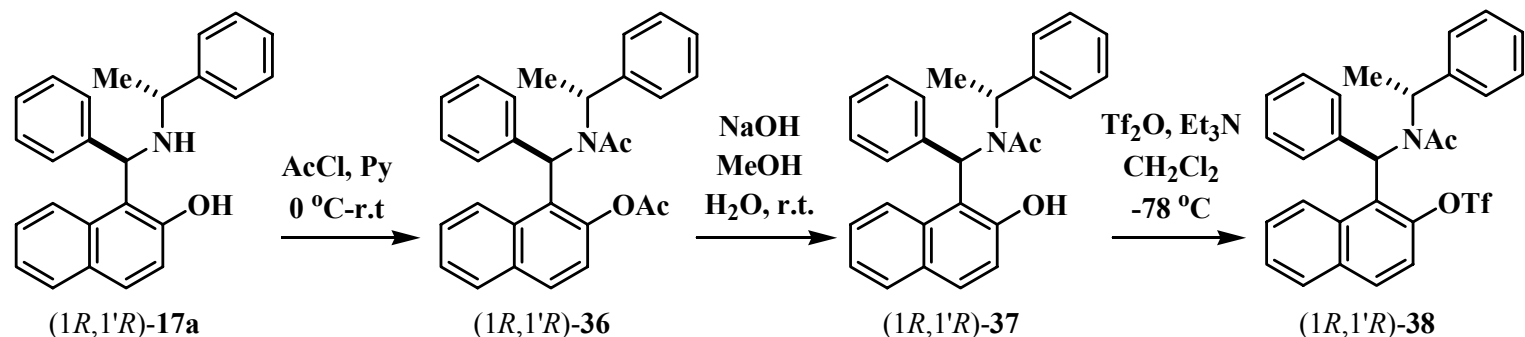

$\left(1 R, 1^{\prime} R\right)-\mathbf{1 7} \mathbf{a}$

$\left(1 R, 1^{\prime} R\right)-\mathbf{3 6}$

$\left(1 R, 1^{\prime} R\right)-\mathbf{3 7}$

$\left(1 R, 1^{\prime} R\right)-\mathbf{3 8}$

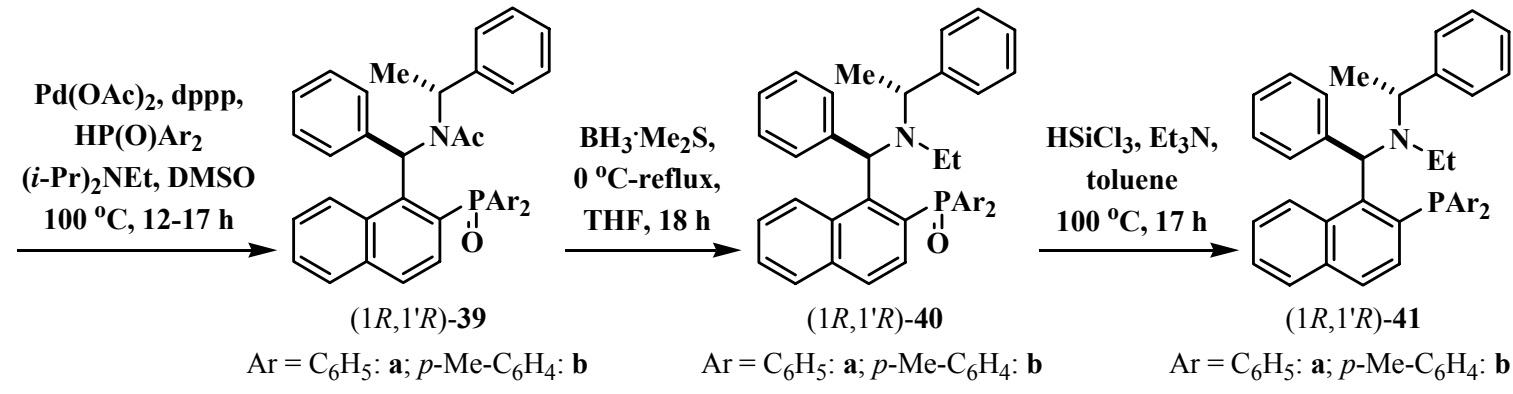

$\mathrm{Tf}_{2} \mathrm{O}=$ trifluoromethanesulfonic anhydride; $\mathrm{dppp}=$ 1,3-bis(diphenylphosphino)propane

Scheme 15

\subsection{Applications}

The first resolution of 3a was reported by Betti. Enantiomers of 3a were used for the resolution of 2-(p-anisyl)propanal ${ }^{44}$ and glyceraldehyde ${ }^{45}$ and to discriminate between aldohexoses and ketohexoses. ${ }^{46}$ However, in spite of the availability and low cost of the Betti base, there was a long silence over this optically active material. This was broken by Naso et al., who described a detailed protocol for resolution of the two isomers, ${ }^{30}$ with their application as chiral ligands in the enantioselective addition of diethylzinc to aryl aldehydes (Scheme 16). ${ }^{31}$ As indicated in Table 3, depending on the chiral ligand and the aryl aldehyde, the products were obtained in high enantiopurity (up to $>99 \%$, Table 3, entries 1-4). ${ }^{31}$ Since the dimethylsubstituted Betti base 12a resulted in higher ee values in the enantioselective alkylation of benzaldehydes, attention focused on the preparation and examination of secondary ${ }^{32,34,39}$ (Table 3, entries 5-10) and tertiary ${ }^{34,39}$ (Table 3, entries 11-17) amine derivatives of these aminonaphthols. Hu et al. tested $N$-cycloalkylaminonaphthols (30) as chiral ligands; the best results are listed in Table 3 (entries 18-25). ${ }^{41}$

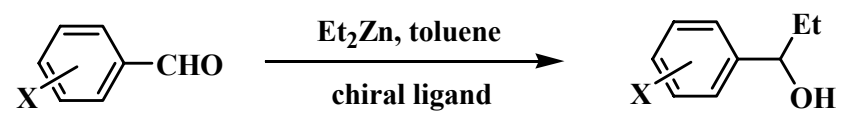

Scheme 16 
Table 3. The reaction conditions and results of enantioselective addition of diethylzinc to aromatic aldehydes, using chiral ligands derived from the Betti base

\begin{tabular}{|c|c|c|c|c|c|c|c|}
\hline Entry & Ligand & Mol \% & $X$ & Conditions & Yield (\%) & ee $(\%)$ & Config. \\
\hline 1 & $(R)-\mathbf{3 a}$ & 13.3 & $\mathrm{H}$ & r.t., $24 \mathrm{~h}$ & 85 & $35^{\mathrm{a}}$ & $(S)$ \\
\hline 2 & $(S)-12 \mathbf{a}$ & 13.3 & $\mathrm{H}$ & r.t., $12 \mathrm{~h}$ & 93 & $96^{\mathrm{a}}$ & $(R)$ \\
\hline 3 & $(S)-12 \mathbf{a}$ & 13.3 & 2-Me & r.t., $24 \mathrm{~h}$ & 75 & $>99^{\mathrm{a}}$ & $(R)$ \\
\hline 4 & $(S)-12 \mathbf{a}$ & 13.3 & 4-Me & r.t., $24 \mathrm{~h}$ & 94 & $96^{\mathrm{a}}$ & $(R)$ \\
\hline 5 & $\left(1 R, 1^{\prime} R\right)-\mathbf{1 7} \mathbf{a}$ & 6 & $\mathrm{H}$ & r.t., 4 h & 89 & $87^{\mathrm{b}}$ & $(S)$ \\
\hline 6 & $\left(1 S, 1^{\prime} S\right)-\mathbf{1 7} \mathbf{a}$ & 15 & 4-Me & r.t., $24 \mathrm{~h}$ & 90 & $92^{\mathrm{c}}$ & $(R)$ \\
\hline 7 & $\left(1 S, 1^{\prime} S\right)-\mathbf{1 7} \mathbf{a}$ & 15 & $4-\mathrm{Cl}$ & r.t., $24 \mathrm{~h}$ & 88 & $87^{\mathrm{c}}$ & $(R)$ \\
\hline 8 & $\left(1 S, 1^{\prime} R\right)-\mathbf{1 7 f}$ & 10 & $\mathrm{H}$ & r.t., $4 \mathrm{~h}$ & 81 & $89^{d}$ & $(S)$ \\
\hline 9 & $\left(1 R, 1^{\prime} R\right)-\mathbf{1 7} \mathbf{g}$ & 10 & $\mathrm{H}$ & r.t., $24 \mathrm{~h}$ & 68 & $15^{\mathrm{d}}$ & $(S)$ \\
\hline 10 & $\left(1 R, 1^{\prime} R\right)-\mathbf{1 7 h}$ & 10 & $\mathrm{H}$ & r.t., 4 h & 84 & $81^{\mathrm{d}}$ & $(S)$ \\
\hline 11 & $(1 S, 1 ' S)-\mathbf{1 8}$ & 15 & $\mathrm{H}$ & r.t., $24 \mathrm{~h}$ & 95 & $99.4^{\mathrm{c}}$ & $(R)$ \\
\hline 12 & $\left(1 S, 1^{\prime} S\right)-\mathbf{1 8}$ & 15 & 4-Me & r.t., $24 \mathrm{~h}$ & 96 & $99.8^{c}$ & $(R)$ \\
\hline 13 & $\left(1 S, 1^{\prime} S\right)-\mathbf{1 8}$ & 15 & $4-\mathrm{Cl}$ & r.t., $24 \mathrm{~h}$ & 98 & $96^{c}$ & $(R)$ \\
\hline 14 & $\left(1 S, 1^{\prime} S\right)-\mathbf{1 8}$ & 15 & $4-\mathrm{NO}_{2}$ & r.t., $24 \mathrm{~h}$ & 86 & $99.8^{c}$ & $(R)$ \\
\hline 15 & $\left(1 R, 1^{\prime} R\right)-\mathbf{1 8}$ & 15 & $\mathrm{H}$ & r.t., $2 \mathrm{~h}$ & 90 & $86^{\mathrm{d}}$ & $(S)$ \\
\hline 16 & $\left(1 R, 1^{\prime} R\right)-26$ & 10 & $\mathrm{H}$ & r.t., $5 \mathrm{~h}$ & 97 & $85^{d}$ & $(S)$ \\
\hline 17 & $\left(1 R, 1^{\prime} R\right)-\mathbf{2 8 f}$ & 10 & $\mathrm{H}$ & r.t., $5 \mathrm{~h}$ & 86 & $85^{d}$ & $(S)$ \\
\hline 18 & $(S)-\mathbf{3 0} \mathbf{a}$ & 10 & $\mathrm{H}$ & $0^{\circ} \mathrm{C}, 8 \mathrm{~h}$ & 93 & $99^{d}$ & $(R)$ \\
\hline 19 & $(S)-\mathbf{3 0 b}$ & 10 & $\mathrm{H}$ & $0^{\circ} \mathrm{C}, 8 \mathrm{~h}$ & 95 & $98^{\mathrm{e}}$ & $(R)$ \\
\hline 20 & $(S)-\mathbf{3 0 b}$ & 10 & 4-Me & $0^{\circ} \mathrm{C}, 8 \mathrm{~h}$ & 95 & $98^{\mathrm{e}}$ & $(R)$ \\
\hline 21 & $(S)-\mathbf{3 0 b}$ & 10 & $4-F$ & $0^{\circ} \mathrm{C}, 8 \mathrm{~h}$ & 96 & $98^{\mathrm{e}}$ & $(R)$ \\
\hline 22 & $(S)-30 \mathrm{c}$ & 10 & $\mathrm{H}$ & $0^{\circ} \mathrm{C}, 8 \mathrm{~h}$ & 93 & $73^{e}$ & $(R)$ \\
\hline 23 & $(R)-\mathbf{3 0 a}$ & 10 & $\mathrm{H}$ & $0^{\circ} \mathrm{C}, 8 \mathrm{~h}$ & 91 & $98^{\mathrm{e}}$ & $(S)$ \\
\hline 24 & $(R)-\mathbf{3 0 b}$ & 10 & $\mathrm{H}$ & $0^{\circ} \mathrm{C}, 8 \mathrm{~h}$ & 91 & $98^{\mathrm{e}}$ & $(S)$ \\
\hline 25 & $(R)-\mathbf{3 0 c}$ & 10 & $\mathrm{H}$ & $0^{\circ} \mathrm{C}, 8 \mathrm{~h}$ & 92 & $75^{e}$ & $(S)$ \\
\hline
\end{tabular}

${ }^{\mathrm{a}}$ Data from ref. 31. ${ }^{\mathrm{b}}$ Data from ref. $32 .{ }^{\mathrm{c}}$ Data from ref. 39.

${ }^{\mathrm{d}}$ Data from ref. 34. ${ }^{\mathrm{e}}$ Data from ref. 41

The applicability of the tertiary aminonaphthols was extended by utilizing the addition of alkenylzinc to aldehydes (Scheme 17). ${ }^{37}$ The best results are given in Table 4.
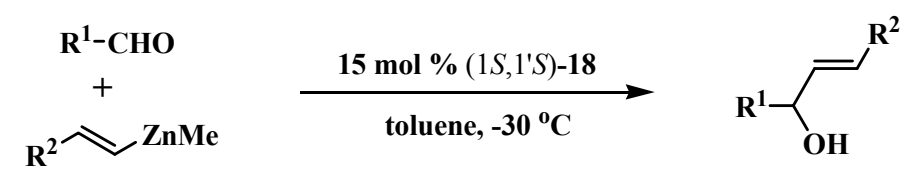

Scheme 17 
Table 4. Results of the enantioselective addition of alkenylzinc to aldehydes, using chiral ligands derived from the Betti base

\begin{tabular}{||c|c|c|c|c||}
\hline \hline $\mathrm{R}^{1}$ & $\mathrm{R}^{2}$ & Yield (\%) & ee (\%) & Config. \\
\hline $\mathrm{Ph}\left(\mathrm{CH}_{2}\right)_{2}$ & $c-\mathrm{C}_{6} \mathrm{H}_{11}$ & 93 & 95 & $(S)$ \\
$n-\mathrm{C}_{4} \mathrm{H}_{9}$ & $o-\mathrm{NO}_{2}-\mathrm{C}_{6} \mathrm{H}_{4}$ & 77 & 98 & $(R)$ \\
$n-\mathrm{C}_{4} \mathrm{H}_{9}$ & $o-\mathrm{Cl}_{2}-\mathrm{C}_{6} \mathrm{H}_{4}$ & 90 & $>99$ & $(R)$ \\
$n-\mathrm{C}_{4} \mathrm{H}_{9}$ & $o-\mathrm{Br}_{2}-\mathrm{C}_{6} \mathrm{H}_{4}$ & 87 & 98 & $(R)$ \\
$n-\mathrm{C}_{4} \mathrm{H}_{9}$ & $m-\mathrm{Br}_{2}-\mathrm{C}_{6} \mathrm{H}_{4}$ & 92 & 94 & $(R)$ \\
\hline
\end{tabular}

Ding et al. tested the asymmetric induction properties of aminophosphine ligands derived from the Betti bases 35 and 41 in the $\operatorname{Pd}(0)$-catalysed allylic substitution of 1,3-diphenylprop-2en-1-yl acetate with dimethyl malonate (Scheme 18). ${ }^{43}$ The main results are listed in Table 5.<smiles>CC(=O)OC(C=Cc1ccccc1)c1ccccc1</smiles>

rac-42

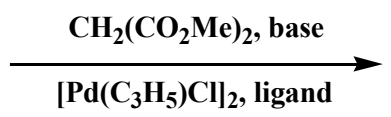

\section{Scheme 18}<smiles>COC(=O)C(C(=O)OC)C(/C=C/c1ccccc1)c1ccccc1</smiles>

$(S)-43$

Table 5. The reaction conditions and the results of the $\operatorname{Pd}(0)$-catalysed asymmetric substitution of $( \pm)-\mathbf{4 2}$, using chiral aminophosphine ligands derived from the Betti base

\begin{tabular}{||c|c|c|c|c||}
\hline \hline Ligand & Solvent & Time (h) & Yield (\%) & ee (\%) \\
\hline 35a & $\mathrm{CH}_{2} \mathrm{Cl}_{2}$ & 24 & 99 & 71.2 \\
35a & $\mathrm{ClCH}_{2} \mathrm{CH}_{2} \mathrm{Cl}$ & 24 & 99 & 72.2 \\
35b & $\mathrm{CH}_{2} \mathrm{Cl}_{2}$ & 24 & 96 & 61.5 \\
41a & $\mathrm{ClCH}_{2} \mathrm{CH}_{2} \mathrm{Cl}$ & 24 & 67 & 70.2 \\
41b & $\mathrm{CH}_{2} \mathrm{Cl}_{2}$ & 24 & 83 & 59.7 \\
\hline
\end{tabular}

\subsection{Biological effects}

Little attention has been paid to the discussed compounds as concerns their biological activity. Desai et al. examined the in vitro antimycobacterial activity of $\mathbf{1 9}$ and $\mathbf{2 0}$ (Scheme 9) against the $\mathrm{H}_{37} \mathrm{R}_{V}$ strain of Mycobacterium tuberculosis in Lowenstein-Jensen egg medium at $0.02 \mathrm{mg} / \mathrm{mL}$. The antibacterial activities of $\mathbf{1 9}$ and $\mathbf{2 0}$ were also tested, and they proved to be active against E. coli and S. aureus. ${ }^{38}$ It was found that $\mathbf{1 9}$ does not possess significant antimycobacterial activity; the presence of a thiazolidine nucleus (20) is necessary for good antituberculotic activity, and the presence of halogen atoms enhances the activity. 


\section{RESULTS AND DISCUSSION}

\subsection{Syntheses and ring-chain tautomerism of 1,3-diarylnaphth[1,2-e][1,3]oxazines}

Betti's classical procedure, ${ }^{5}$ a Mannich-type aminoalkylation reaction of 2-naphthol, was applied to prepare the starting materials for the synthesis of the target compounds. Condensation of 2-naphthol (1) and benzaldehyde or substituted benzaldehydes in the presence of ammonia, and subsequent acidic hydrolysis, gave aminonaphthols 45a-i in good yields (Scheme 19).

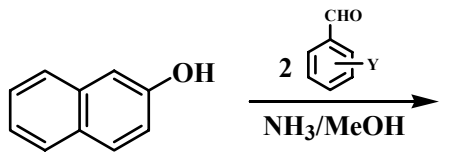

1<smiles>[Y]c1ccc(C2NC(c3ccccc3)c3c(ccc4ccccc34)O2)cc1</smiles>

44a-i

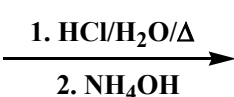<smiles>NC(c1ccccc1)c1c(O)ccc2ccccc12</smiles>

45a-i

$\mathrm{Y}=\mathrm{NO}_{2}(m): \mathbf{a} ; \mathrm{Br}(m): \mathbf{b} ; \mathrm{NO}_{2}(p): \mathbf{c} ; \mathrm{Br}(p): \mathbf{d} ; \mathrm{Cl}(p): \mathbf{e} ; \mathrm{H}: \mathbf{f} ; \mathrm{F}(p): \mathbf{g} ; \mathrm{Me}(p): \mathbf{h} ; \mathrm{OMe}(p): \mathbf{i}$

\section{Scheme 19}

Condensations of aminonaphthols 45a-i with equivalent amounts of aromatic aldehydes resulted in naphthoxazine model compounds 46-54 as crystalline products (Scheme 20). The ${ }^{1} \mathrm{H}$ NMR spectra of 46-54 revealed that, in $\mathrm{CDCl}_{3}$ solution at $300 \mathrm{~K}$, the members a-g of each set of compounds 46-54 participated in three-component ring-chain tautomeric equilibria involving C-3 epimeric naphthoxazines (B and $\mathbf{C})$ besides the open tautomer (A).<smiles>NC(c1ccccc1)c1c(O)ccc2ccccc12</smiles><smiles>c1ccccc1</smiles>

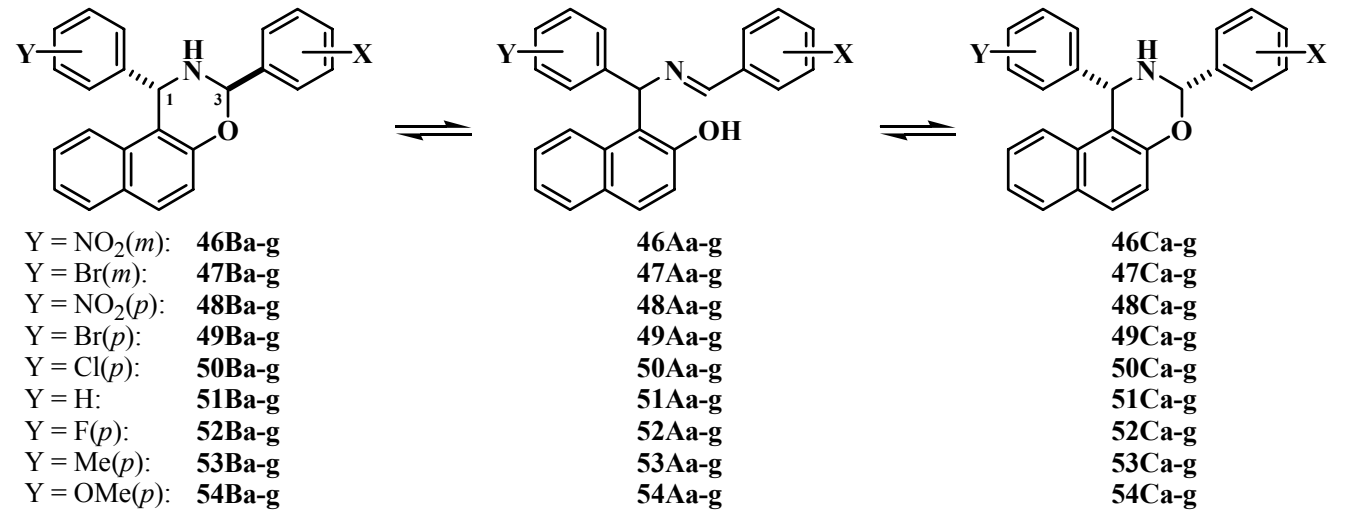

$\mathrm{X}=\mathrm{NO}_{2}(p): \mathbf{a} ; \operatorname{Br}(m): \mathbf{b} ; \operatorname{Br}(p): \mathbf{c} ; \mathrm{Cl}(p): \mathbf{d} ; \mathrm{H}: \mathbf{e} ; \mathrm{Me}(p): \mathbf{f} ; \mathrm{OMe}(p): \mathbf{g}$

Scheme 20 
The intermediate of the Betti reaction was earlier presumed to have a ring-chain tautomeric character. ${ }^{17,18}$ By condensation of the Betti base with aromatic aldehydes, Smith and Cooper prepared 1-phenyl-3-aryl-2,3-dihydro- $1 H$-naphth[1,2-e][1,3]oxazines, and studied their ringchain tautomeric equilibria by means of $60 \mathrm{MHz}{ }^{1} \mathrm{H}$ NMR. ${ }^{17}$ They made the assumption that 1,3diaryl groups prefer pseudo-equatorial and therefore a cis arrangement in the major ring-closed tautomer. In contrast with this assumption, the NOESY measurements of 50a unequivocally showed that the major ring forms in all tautomeric equilibria (46-54) contain the 1,3-diaryl substituents in the trans position (B). In consequence of the very similar NMR spectroscopic characters of 1,3-diaryl-2,3-dihydro- $1 H$-naphth[1,2-e][1,3] oxazines 46-54, determination of the relative configurations of the major and minor ring-closed tautomers was performed only for 50a.

To characterize the effects of the aryl substituent at position 1 on the tautomeric character of this ring system, 1-unsubstituted 3-aryl-2,3-dihydro-1H-naphth[1,2-e][1,3]oxazines (56) were prepared from the readily available ${ }^{47} 1$-aminomethyl-2-naphthol $(\mathbf{5 5}$, synthesized by acidic hydrolysis of the product of 2-naphthol and hexamethylenetetramine) and aromatic aldehydes. In $\mathrm{CDCl}_{3}$ at $300 \mathrm{~K}, \mathbf{5 6 a - g}$ proved to participate in ring-chain tautomeric equilibria (Scheme 21).

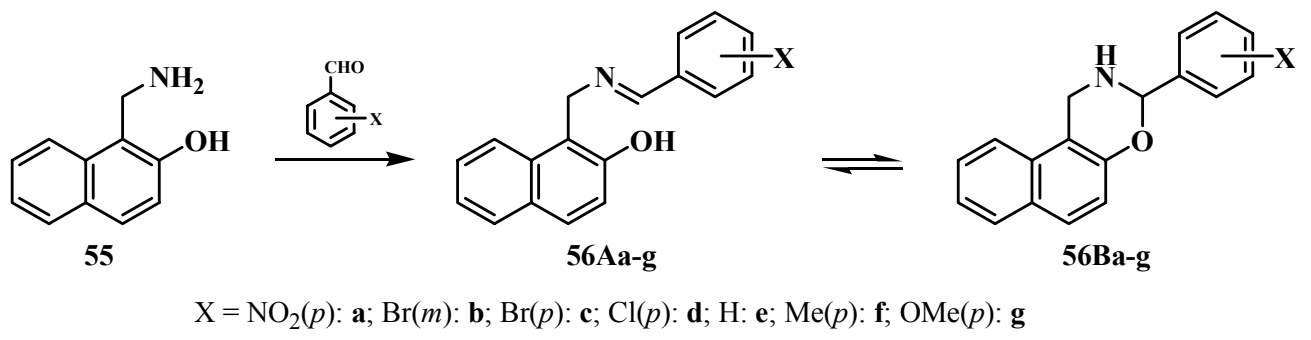

Scheme 21

The proportions of the chain (A) and diastereomeric ring forms (B and $\mathbf{C}$ ) of the tautomeric equilibria of 46-54 and $\mathbf{5 6}\left(\mathrm{K}_{\mathrm{X}}\right)$ were determined by integration of the well-separated $\mathrm{O}-\mathrm{CHAr}-\mathrm{N}$ (ring) and $\mathrm{N}=\mathrm{CHAr}$ (chain) proton singlets or doublets in the ${ }^{1} \mathrm{H}$ NMR spectra.

When Eq. 1 was applied to the $\log \mathrm{K}_{\mathrm{X}}$ values, good linear correlations were obtained $v s$ the Hammett-Brown parameter $\sigma^{+}$of the substituent $X$ on the 3-phenyl group for 46-54 and 56 (Figure 1 and Table 6). 


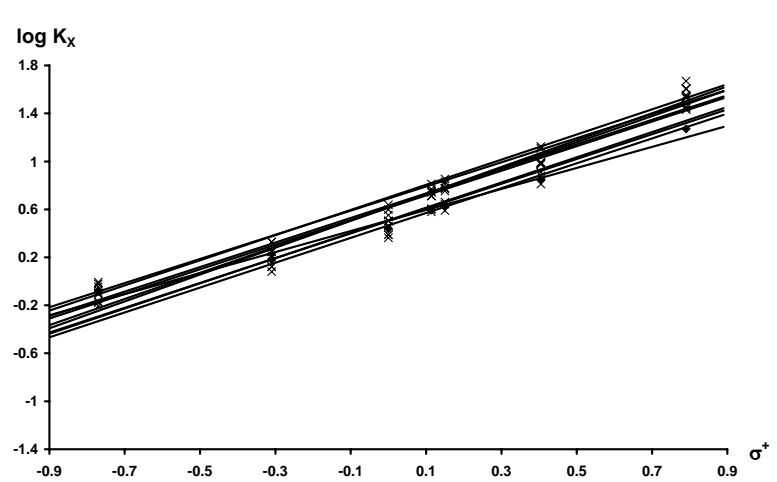

$a$

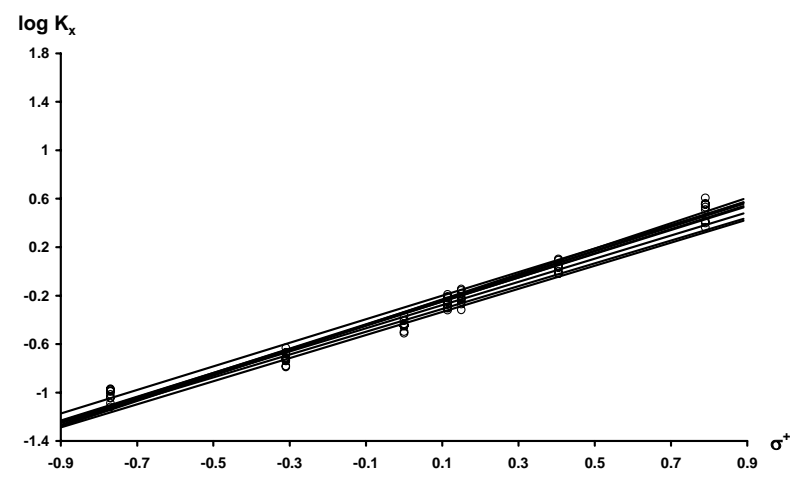

$b$

Figure 1. $a$ : Plots of $\log \mathrm{K}_{\mathrm{X}}$ for 46-54B $(\mathrm{x})$ and 56B $(\diamond)$ vs Hammett-Brown parameter $\sigma^{+}$. $b$ : Plots of $\log \mathrm{K}_{\mathrm{X}}$ for 46-54C ( $\left.\mathrm{\circ}\right) v s$ Hammett-Brown parameter $\sigma^{+}$

The linear regression analysis data in Table 6 show that, as is customary among 2-aryl-1,3$O, N$ heterocycles, the value of $\rho$ is positive in each case, i.e. electron-withdrawing (EW) substituents on the 3-phenyl ring favour the ring-closed tautomer. While the value of $\rho$ for 1unsubstituted 3-aryl-2,3-dihydro-1H-naphth[1,2-e][1,3]oxazines (56: 0.88) is the same (within experimental error) as that for the parent 2-arylperhydro-1,3-oxazines (57: 0.74), the values of $\rho$ for 1,3-diaryl-2,3-dihydro-1H-naphth[1,2-e][1,3]oxazines (46-54: 0.94-1.05) are somewhat higher. The cis or trans arrangement of the 1,3-diaryl substituents in the ring forms of 1,3-diaryl2,3-dihydro-1H-naphth[1,2-e][1,3]oxazines does not seem to influence the value of $\rho$; the plots for the equilibria containing C-3 epimeric ring forms of 46-54 (B-A and C-A) are practically parallel.

To characterize the effects of the substituents and the presence of an annelated ring on the stability of the ring forms, a substitution effect parameter $\left(\mathrm{c}_{\mathrm{s}}\right)$ was calculated as the difference in the intercepts for the given naphthoxazine derivative $(\mathbf{4 6 - 5 4}, \mathbf{5 6})$ and the parent 2-arylperhydro1,3-oxazine (57: $\left.\log \mathrm{K}_{0}=-0.15\right): \mathrm{c}_{\mathrm{s}}=\log \mathrm{K}_{\mathrm{X}=\mathrm{H}}-\log \mathrm{K}_{0}$. This kind of relative ring stability constant was introduced earlier for the saturated 2-aryl-1,3-O,N-heterocycles bearing substituents at positions $4-6 .{ }^{8,9}$ A positive value of $\mathrm{c}_{\mathrm{s}}$ means a more stable ring form relative to the corresponding parent 2-arylperhydro-1,3-O,N-heterocycle. 
Table 6. Linear regression data on compounds 46-54, 56, 2-aryl-3,4,5,6-tetrahydro- $2 H-1,3-$ oxazines (57), 2-aryl-3,4-dihydro- $2 H$-1,3-benzoxazines (58) and 2-aryl-4-phenyl-3,4,5,6tetrahydro- $2 H-1,3$-oxazines $(\mathbf{5 9})$

\begin{tabular}{|c|c|c|c|c|c|}
\hline \multicolumn{6}{|c|}{$\mathrm{X}=\mathrm{NO}_{2}(p) ; \mathrm{NO}_{2}(m) ; \mathrm{Cl}(m) ; \mathrm{Cl}(p) ; \mathrm{H} ; \mathrm{Me}(p) ; \mathrm{OMe}(p) ; \mathrm{NMe}_{2}(p)$} \\
\hline Equilibrium & No. of points & Slope $(\rho)$ & Intercept & $\begin{array}{l}\text { Correlation } \\
\text { coefficient }\end{array}$ & $\mathrm{c}_{\mathrm{s}}^{\mathrm{a}}$ \\
\hline $46 A \rightleftharpoons 46 B$ & 7 & 1.01 & 0.68 & 0.993 & 0.83 \\
\hline $46 \mathrm{~A} \rightleftharpoons 46 \mathrm{C}$ & 7 & 1.05 & -0.34 & 0.997 & -0.19 \\
\hline $47 A \rightleftharpoons 47 B$ & 7 & 1.12 & 0.62 & 0.977 & 0.77 \\
\hline $47 \mathrm{~A} \rightleftharpoons 47 \mathrm{C}$ & 7 & 1.00 & -0.34 & 0.984 & -0.19 \\
\hline $48 \mathrm{~A} \rightleftharpoons 48 \mathrm{~B}$ & 7 & 1.05 & 0.70 & 0.994 & 0.85 \\
\hline $48 \mathrm{~A} \rightleftharpoons 48 \mathrm{C}$ & 7 & 0.97 & -0.29 & 0.992 & -0.14 \\
\hline $49 \mathrm{~A} \rightleftharpoons 49 \mathrm{~B}$ & 7 & 1.02 & 0.63 & 0.987 & 0.78 \\
\hline $49 \mathrm{~A} \rightleftharpoons 49 \mathrm{C}$ & 7 & 1.03 & -0.34 & 0.991 & -0.19 \\
\hline $50 \mathrm{~A} \rightleftharpoons 50 \mathrm{~B}$ & 7 & 1.03 & 0.61 & 0.988 & 0.76 \\
\hline $50 \mathrm{~A} \rightleftharpoons 50 \mathrm{C}$ & 7 & 0.96 & -0.37 & 0.994 & -0.22 \\
\hline $51 \mathrm{~A} \rightleftharpoons 51 \mathrm{~B}$ & 7 & 1.05 & 0.51 & 0.986 & 0.66 \\
\hline $51 \mathrm{~A} \rightleftharpoons 51 \mathrm{C}$ & 7 & 0.98 & -0.35 & 0.983 & -0.20 \\
\hline $52 \mathrm{~A} \rightleftharpoons 52 \mathrm{~B}$ & 7 & 1.09 & 0.62 & 0.985 & 0.57 \\
\hline $52 \mathrm{~A} \rightleftharpoons 52 \mathrm{C}$ & 7 & 1.00 & -0.35 & 0.978 & -0.20 \\
\hline $53 A \rightleftharpoons 53 B$ & 7 & 1.04 & 0.47 & 0.982 & 0.62 \\
\hline $53 \mathrm{~A} \rightleftharpoons 53 \mathrm{C}$ & 7 & 0.95 & -0.43 & 0.993 & -0.28 \\
\hline $54 \mathrm{~A} \rightleftharpoons 54 \mathrm{~B}$ & 7 & 1.03 & 0.50 & 0.985 & 0.65 \\
\hline $54 \mathrm{~A} \rightleftharpoons 54 \mathrm{C}$ & 7 & 0.94 & -0.40 & 0.986 & -0.25 \\
\hline $56 \mathrm{~A} \rightleftharpoons 56 \mathrm{~B}$ & 7 & 0.88 & 0.51 & 0.991 & 0.66 \\
\hline $57 \mathrm{~A} \rightleftharpoons 57 \mathrm{~B}^{\mathrm{b}}$ & 7 & 0.74 & -0.15 & 0.984 & - \\
\hline $58 \mathrm{~A} \rightleftharpoons 58 \mathrm{~B}^{\mathrm{b}}$ & 7 & 0.82 & -0.66 & 0.995 & -0.51 \\
\hline $59 \mathrm{~A} \rightleftharpoons 59 \mathrm{~B}^{\mathrm{c}}$ & 6 & 0.72 & 0.42 & 0.997 & 0.57 \\
\hline $59 \mathrm{~A} \rightleftharpoons 59 \mathrm{C}^{\mathrm{c}}$ & 6 & 0.99 & -1.12 & 0.996 & -0.97 \\
\hline
\end{tabular}

${ }^{\mathrm{a}}$ Relative ring stability constant: see the text. ${ }^{\mathrm{b}}$ Data from ref. $9 .{ }^{\mathrm{c}}$ For compounds $\mathbf{5 9}$ (ref. 13), the tautomeric ratios were remeasured and the linear regression analysis was performed separately for the equilibria involving C-2 epimeric ring forms.

While an annelated benzene ring considerably decreased the stability of the ring form of 2arylperhydro-1,3-oxazine (58: $\left.\mathrm{c}_{\mathrm{s}}=-0.51\right),{ }^{9}$ an annelated naphthalene ring caused a dramatic increase in ring stability $\left(\mathbf{5 6}: \mathrm{c}_{\mathrm{s}}=0.66\right)$. This increased stability of the ring form was observed 
for all naphthoxazines having trans diaryl substituents (46-54 B: $\left.\mathrm{c}_{\mathrm{s}}=0.57-0.85\right)$, while the negative $\mathrm{c}_{\mathrm{s}}$ values for the $\mathrm{cis}$ isomers of these compounds (46-54 C: $\left.\mathrm{c}_{\mathrm{s}}=-0.14--0.28\right)$ indicate that the stabilizing effect of the naphthalene ring is diminished by the unfavourable steric arrangement of the aryl substituents.

\section{Hansch analysis of equilibrium constants}

The influence of the 3-aryl group on the tautomeric equilibria of 1,3-naphthoxazines 46-54 could be described by using Eq. 1. The Hammett-Brown parameter $\sigma^{+}$was found to be inadequate to describe the influence of aryl substituents at position 1. The effect of substituent $\mathrm{Y}$ was therefore divided into two parts: $\sigma_{F}$ (inductive effect) and $\sigma_{R}$ (resonance effect). Since the Hammett-Brown parameter $\sigma^{+}$has proved to be a convenient substituent parameter with which to characterize the influence of substituent $\mathrm{X}$ on tautomeric equilibria, it was used to set up the following Hansch quantitative structure-properties relationship (QSPR) model (Eq. 2):

$$
\mathrm{DV}=\mathrm{k}+\rho_{\mathrm{F}}^{\mathrm{Y}} \sigma_{\mathrm{F}}^{\mathrm{Y}}+\rho_{\mathrm{R}}^{\mathrm{Y}} \sigma_{\mathrm{R}}^{\mathrm{Y}}+\rho^{\mathrm{X}} \sigma^{+\mathrm{X}}
$$

where DV is the dependent variable (log $\mathrm{K}$ or donation energies). However, analogously with that of substituent $\mathrm{Y}$, the influence of substituent $\mathrm{X}$ can also be divided into two parts $\left(\sigma_{\mathrm{F}}\right.$ and $\sigma_{\mathrm{R}}$ ), as represented by Eq. 3. Multiple linear regression analysis of Eqs 2 and 3 was performed by using the SPSS statistical software. A value of 0.05 was chosen as the significance level. ${ }^{48}$

$$
\mathrm{DV}=\mathrm{k}+\rho_{\mathrm{F}}^{\mathrm{Y}} \sigma_{\mathrm{F}}^{\mathrm{Y}}+\rho_{\mathrm{R}}^{\mathrm{Y}} \sigma_{\mathrm{R}}^{\mathrm{Y}}+\rho_{\mathrm{F}}^{\mathrm{X}} \sigma_{\mathrm{F}}^{\mathrm{X}}+\rho_{\mathrm{R}}^{\mathrm{X}} \sigma_{\mathrm{R}}^{\mathrm{X}}
$$

Multiple linear regression analysis of Eqs 2 and 3 with DV as $\log \mathrm{K}$ values led to the results listed in Table 7. As regards substituent $X$, both inductive and resonance effects seem to be significant for equilibria $\mathbf{B}=\mathbf{A}$ and $\mathbf{C}=\mathbf{A}$. On the other hand, substituent $\mathrm{Y}$ does not affect the equilibrium $\mathbf{C}=\mathbf{A}$ at all, and only inductive effects are significant for the equilibrium $\mathbf{B}=\mathbf{A}$. The present results can be interpreted as an extension of the Hammett equation (Eq. 1) and it means that for trans $=$ chain $(\mathbf{B}=\mathbf{A})$ equilibria the equilibrium constants can be described by using a double substituent parameter treatment and a plane can be fitted to the data points with data error $r=0.980$ (Figure 2). 


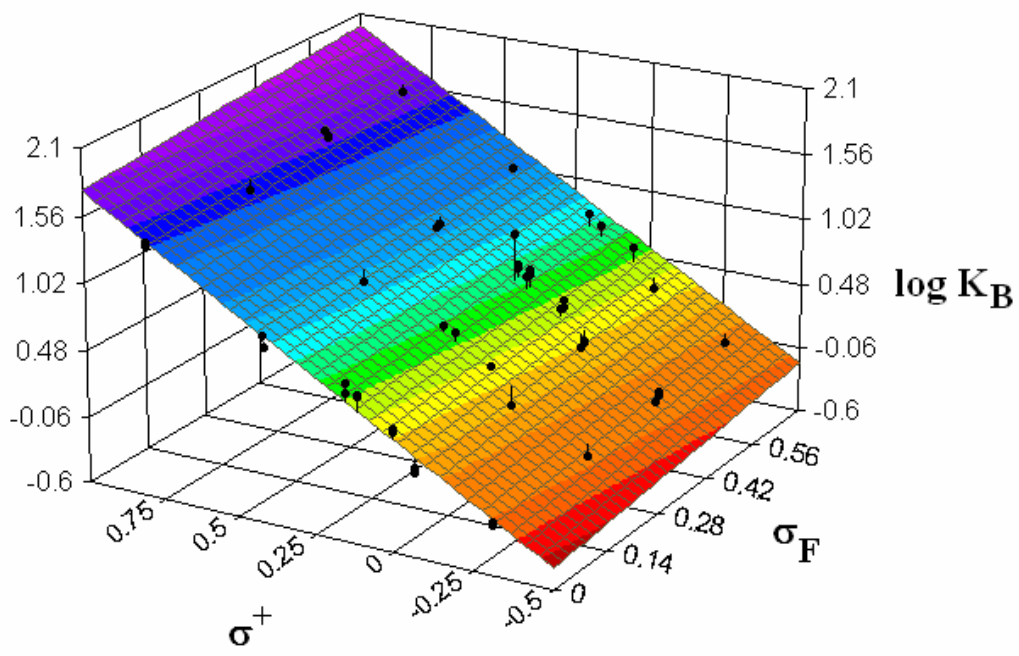

Figure 2. Plots of $\log \mathrm{K}_{\mathrm{B}}$ for 48-54B (•) vs Hammett parameters $\sigma^{+}$and $\sigma_{\mathrm{F}}$

The observed values of both $\rho_{\mathrm{F}}^{\mathrm{X}}$ (inductive) and $\rho_{\mathrm{R}}^{\mathrm{X}}$ (resonance) are positive. Positive values mean that EW substituents increase the relative proportion of the ring form both inductively and by resonance. Interestingly, somewhat more positive $\rho$ values are observed for the equilibrium $\mathbf{B}=\mathbf{A}$, indicating that the sensitivity of the equilibrium in question to substituent $\mathrm{X}$ depends on the orientation of the phenyl ring at position 1 (a disubstitution effect). The positive values for all of the observed $\rho$ 's indicate that EW substituents on both phenyl rings increase the relative proportion of the ring form for both equilibria studied. Good correlations of $\log \mathrm{K}$ with $\sigma^{+}$show that both inductive and resonance effects are usually significant. For excellent reasons, this can be stated to be the normal behaviour of the substituent dependence of the ring-chain equilibria. The origin of this effect is now understood. ${ }^{49}$ As regards substituents $\mathrm{X}$, the present results are in harmony with the above concept. In contrast with the above behaviour, in the case of a phenyl substituent on $\mathrm{C}-1$, the sensitivities of the $\mathrm{K}$ values for the $c$ is and trans isomers differ. For the equilibrium $\mathbf{C}=\mathbf{A}$, no significant dependence on substituent $\mathrm{Y}$ was observed. For the equilibrium $\mathbf{B}=\mathbf{A}$, a positive value of $\rho_{\mathrm{F}}^{\mathrm{Y}}(0.32)$ was found, but there was no significant dependence on resonance parameter $\rho_{R}$. Accordingly, the present results show for the first time that aromatic ring substituents which are not attached to a phenyl ring situated between two heteroatoms can have a systematic effect on the relative proportions of the ring tautomers. The diminished inductive sensitivity, as compared with that of substituent X, reflects the fact that the substituent in question is situated farther away from the reaction centre. In summary, the equilibrium $\mathbf{B}=\mathbf{A}$ seems to be somewhat more sensitive to both substituent $\mathrm{X}$ and substituent $\mathrm{Y}$ than the equilibrium $\mathbf{C}=\mathbf{A}$. The origins of these substituent effects and their connections with stereoelectronic effects caused by the electron donation of the nitrogen lone 
pair (potential anomeric effects) ${ }^{50}$ are discussed below with the aid of the donation energies calculated for the minimum energy conformations.

Table 7. Multiple linear regression analysis of $\log \mathrm{K}$ values for 48-54 and for 60-66

\begin{tabular}{|c|c|c|c|c|c|c|c|}
\hline & & $\mathrm{k}$ & $\rho_{\mathrm{F}}^{\mathrm{Y}}$ & $\rho_{\mathrm{R}}^{\mathrm{Y}}$ & \multicolumn{2}{|c|}{$\rho^{X}, \rho_{F}^{X}$ and $\rho_{R}^{X}, \rho^{R}$} & $\mathrm{r}$ \\
\hline & $48-54 B=48-54 A$ & 0.32 & 0.33 & $-{ }^{\mathrm{a}}$ & \multicolumn{2}{|c|}{1.44} & 0.980 \\
\hline Acc. to Eq. 2 & $48-54 C=48-54 A$ & -0.53 & ${ }^{\mathrm{a}}$ & $-{ }^{\mathrm{a}}$ & \multicolumn{2}{|c|}{1.30} & 0.971 \\
\hline \multirow{2}{*}{ Acc. to Eq. 3} & $48-54 B=48-54 A$ & 0.34 & 0.30 & $-{ }^{\mathrm{a}}$ & 1.17 & 1.87 & 0.992 \\
\hline & $48-54 \mathrm{C}=48-54 \mathrm{~A}$ & -0.53 & $-^{\mathrm{a}}$ & $-{ }^{\mathrm{a}}$ & 1.08 & 1.66 & 0.981 \\
\hline Acc. to Eq. 6 & $60-66 B=60-66 C$ & 0.48 & 0.22 & $-{ }^{\mathrm{a}}$ & \multicolumn{2}{|c|}{7.97} & 0.919 \\
\hline
\end{tabular}

${ }^{\mathrm{a}}$ Insignificant (significance value $>0.05$ )

In order to prove the validity of Eqs 2 and 3, linear regression analysis was carried out by plotting $\log \mathrm{K}_{\text {calc. }}$ (calculated by applying the parameters of Eq. 2 or 3 ) against $\log \mathrm{K}$ determined experimentally (Figure 3).

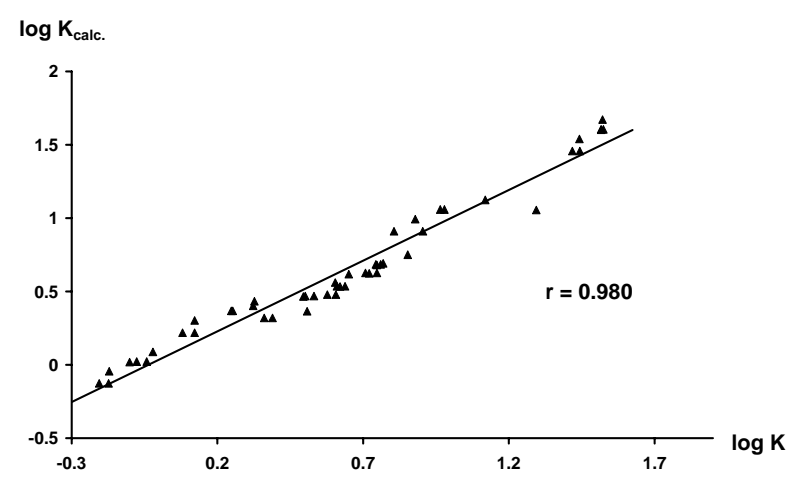

$a$

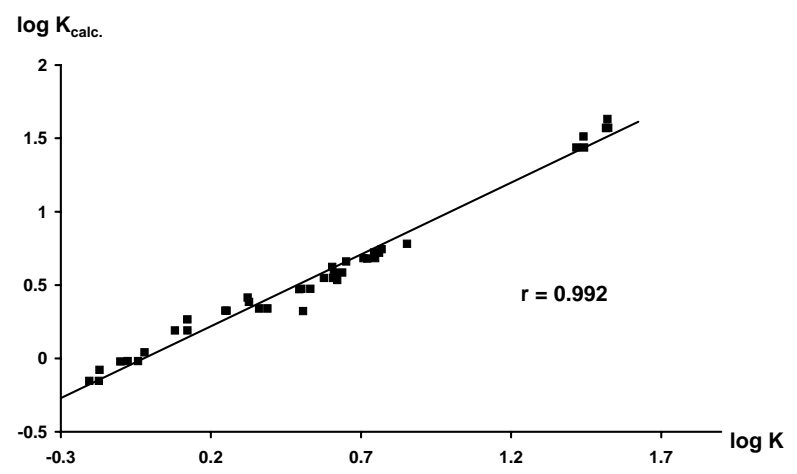

$b$

Figure 3. $a$ : Plots of $\log \mathrm{K}_{\text {calc. }}$ (calc. via Eq. 2) vs $\log \mathrm{K}$ (experimental) for 48-54B. $b$ : Plots of $\log \mathrm{K}_{\text {calc. }}$ (calc. via Eq. 3) vs $\log \mathrm{K}$ (experimental) for 48-54B

\section{Hansch analysis of the donation energies for the rigid model structures}

Donation energy calculations were performed with conformationally rigid models in order to clarify the potential connections between the anomeric effect and the relative stabilities of the cis and trans isomers. The conformational search protocol involved PM3 geometry minimization, followed by optimization at the ab initio level, using the HF/6-31G* base set for all of the compounds. The final conformations, with $48 \mathrm{aB}$ and $48 \mathrm{aC}$ as examples, are shown in Figure 4. Ab initio calculations were performed by second-order perturbative analysis of the Fock matrix in the NBO base, ${ }^{51-54}$ where the energy of donation $(\mathrm{kcal} / \mathrm{mol})$ of a lone pair to a given antibonding orbital could be calculated. We considered that, by comparison with the experimental findings, the factors governing the relative stability of the cis and trans isomers, and the substituent sensitivity of the ${ }^{13} \mathrm{C}$ NMR chemical shifts, could be evaluated more reliably. 


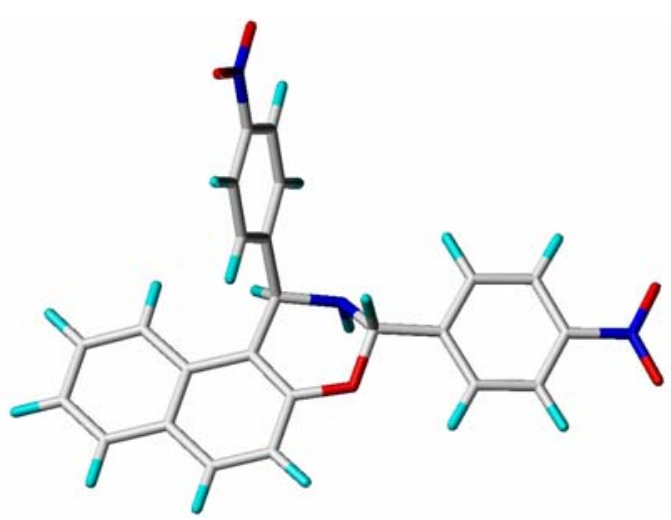

48aB

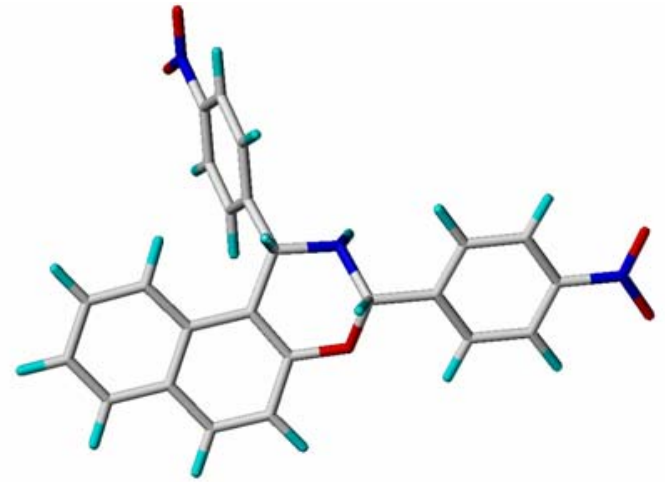

$48 \mathrm{aC}$

Figure 4. Final predominant minimum energy molecular structures for $\mathbf{4 8 a B}$ and $\mathbf{4 8 a C}$, obtained by using ab initio $\mathrm{HF} / 6-31 \mathrm{G}^{*}$ calculations.

In the present calculated model conformations, the nitrogen lone pair can overlap with six different vicinal antibonding orbitals associated with $\mathrm{C} 1\left(\sigma^{*}{ }_{\mathrm{Cl}-\mathrm{H}}, \sigma^{*}{ }_{\mathrm{Cl}-\mathrm{Cl}}\right.$, and $\left.\sigma^{*}{ }_{\mathrm{C} 1-\mathrm{C} 10 \mathrm{~b}}\right)$ or with $\mathrm{C} 3\left(\sigma^{*}{ }_{\mathrm{C} 3-\mathrm{H}}, \sigma^{*}{ }_{\mathrm{C} 3-\mathrm{C} 1}\right.$ " and $\left.\sigma^{*}{ }_{\mathrm{C} 3-\mathrm{O} 4}\right)$. The results of Hansch analysis of the energy values as DV according to Eq. 2 are given in Table 8.

Table 8. Multiple linear regression analysis of overlapping energy values according to Eq. 2 for $\mathbf{4 8 - 5 4}$

\begin{tabular}{|c|c|c|c|c|c|c|}
\hline & Overlapping & $\mathrm{k}$ & $\rho_{\mathrm{F}}^{\mathrm{Y}}$ & $\rho_{\mathrm{R}}^{\mathrm{Y}}$ & $\rho^{\mathrm{X}}$ & $\mathrm{r}$ \\
\hline \multirow{5}{*}{ B } & $n_{\mathrm{N}} \rightarrow \sigma_{\mathrm{C} 1-\mathrm{C} 1}^{*}$ & 3.13 & 0.34 & 0.37 & -0.13 & 0.983 \\
\hline & $n_{\mathrm{N}} \rightarrow \sigma^{*}{ }_{\mathrm{C} 1-\mathrm{C} 10 \mathrm{~b}}$ & 8.94 & $-^{\mathrm{a}}$ & $-^{\mathrm{a}}$ & -0.25 & 0.915 \\
\hline & $n_{\mathrm{N}} \rightarrow \sigma_{\mathrm{C} 3-\mathrm{O} 4}$ & 20.31 & -0.36 & -0.24 & -0.16 & 0.956 \\
\hline & $n_{\mathrm{N}} \rightarrow \sigma_{\mathrm{C} 3-\mathrm{C} 1}^{*}$ & 1.10 & -0.11 & -0.07 & 0.12 & 0.909 \\
\hline & $n_{\mathrm{N}} \rightarrow \sigma_{\mathrm{C} 3-\mathrm{H}}$ & 1.42 & 0.09 & 0.09 & -0.05 & 0.865 \\
\hline \multirow{5}{*}{ C } & $n_{\mathrm{N}} \rightarrow \sigma_{\mathrm{C} 1-\mathrm{H}}$ & 4.49 & $-^{\mathrm{a}}$ & $-^{\mathrm{a}}$ & -0.13 & 0.799 \\
\hline & $n_{\mathrm{N}} \rightarrow \sigma_{\mathrm{C} 1-\mathrm{C} 10 \mathrm{~b}}$ & 8.70 & 0.09 & 0.15 & -0.25 & 0.942 \\
\hline & $n_{\mathrm{N}} \rightarrow \sigma_{\mathrm{C} 3-\mathrm{O} 4}$ & 20.82 & -0.72 & -0.61 & -0.10 & 0.984 \\
\hline & $n_{\mathrm{N}} \rightarrow \sigma^{*}{ }_{\mathrm{C} 3-\mathrm{C} 1}$ & 1.07 & $--^{\mathrm{a}}$ & $-^{\mathrm{a}}$ & -0.08 & 0.819 \\
\hline & $n_{\mathrm{N}} \rightarrow \sigma_{\mathrm{C} 3-\mathrm{H}}^{*}$ & 1.62 & -0.08 & $-{ }^{\mathrm{a}}$ & $-{ }^{\mathrm{a}}$ & 0.642 \\
\hline
\end{tabular}

${ }^{\mathrm{a}}$ Insignificant (significance value $>0.05$ )

Significant overlapping of the nitrogen lone pair was observed in the trans forms $\mathbf{B}$ (to $\sigma^{*}{ }_{\mathrm{C} 1-\mathrm{Cl} 1}, \sigma^{*}{ }_{\mathrm{C} 1-\mathrm{C} 10 \mathrm{~b}}$ and $\left.\sigma^{*}{ }_{\mathrm{C} 3-\mathrm{O} 4}\right)$ and in the $\mathrm{cis}$ forms $\mathbf{C}$ (to $\sigma^{*}{ }_{\mathrm{C} 1-\mathrm{H}}, \sigma^{*}{ }_{\mathrm{C} 1-\mathrm{C} 10 \mathrm{~b}}$ and $\left.\sigma^{*}{ }_{\mathrm{C} 3-\mathrm{O} 4}\right)$. As concerns the donation energies, the clearest difference between the cis and trans forms is that, for the trans form, there is no significant $n_{\mathrm{N}} \rightarrow \sigma_{\mathrm{C} 1-\mathrm{H}}^{*}$ donation, but there is a significant $n_{\mathrm{N}} \rightarrow \sigma^{*} \mathrm{Cl}-\mathrm{Cl} 1$ donation. On the other hand, for the cis form there is no $n_{\mathrm{N}} \rightarrow \sigma^{*} \mathrm{Cl}-\mathrm{Cl}$ ' donation, but there is a significant $n_{\mathrm{N}} \rightarrow \sigma_{\mathrm{C} 1-\mathrm{H}}^{*}$ donation. Further, while the $n_{\mathrm{N}} \rightarrow \sigma_{\mathrm{C} 1-\mathrm{H}}^{*}$ donation energy detected for the cis form does not depend on the substituent $\mathrm{Y}$, the $n_{\mathrm{N}} \rightarrow \sigma_{\mathrm{C} 1-\mathrm{Cl} 1}$, donation energy 
detected for the trans form exhibits a clear substituent dependence on Y, both inductive and resonance effects being important. As for the $n_{\mathrm{N}} \rightarrow \sigma^{*}{ }_{\mathrm{Cl}-\mathrm{C} 10 \mathrm{~b}}$ donation, for the cis form there is a slight dependence on substituent $\mathrm{Y}$, but for the trans isomer no analogous dependence was observed. However, the sums of the different significant donation energies listed above are relatively close to each other: for $\mathrm{X}=\mathrm{Y}=\mathrm{H}$, they are 34.98 and 36.80 (in other words, the sums of the k values in Table 3) for the trans and cis isomers, respectively. It should be noted that the cis isomers exhibit somewhat larger donation energy sums. This is contrary to the idea that an anomeric effect controls the marked stability difference between the cis and trans series.

For the trans forms (B), the overlapping energy for $n_{\mathrm{N}} \rightarrow \sigma^{*}{ }_{\mathrm{C} 1-\mathrm{Cl}}$, was clearly dependent on substituent $\mathrm{Y}\left(\rho_{\mathrm{F}}^{\mathrm{Y}}=0.34\right.$ and $\rho_{\mathrm{R}}^{\mathrm{Y}}=0.37$; Table 8). On the other hand, for the cis forms $(\mathbf{C})$, the overlapping energy for $n_{\mathrm{N}} \rightarrow \sigma^{*}$ C1-C10b was substituent-dependent, but to an essentially smaller extent $\left(\rho_{\mathrm{F}}^{\mathrm{Y}}=0.09\right.$ and $\rho_{\mathrm{R}}^{\mathrm{Y}}=0.15$; Table 8). Thus, the extent of the effect of substituent $\mathrm{Y}$ on the donation energies seems to depend on the configuration. In both cases, electron donation/withdrawal by both inductive and resonance mechanisms is important, but the sensitivity to the resonance effect is slightly higher. The positive values of both $\rho_{\mathrm{F}}^{\mathrm{Y}}$ and $\rho_{\mathrm{R}}^{\mathrm{Y}}$ mean that EW substituents increase the value of the DV. It is generally thought that the mechanism of the anomeric effect is the overlapping between an occupied lone pair orbital and an antibonding orbital of an adjacent polar bond. According to this interpretation, electron density is transferred from $\mathrm{N}-2$ to the $\mathrm{C} 1-\mathrm{C} 1$ ' antibonding orbital. This can be explained as follows. In the case of $n_{\mathrm{N}} \rightarrow \sigma^{*}{ }_{\mathrm{Cl}-\mathrm{Cl} 1}$ overlapping, the positive $\rho_{\mathrm{F}}^{\mathrm{Y}}$ and $\rho_{\mathrm{R}}^{\mathrm{Y}}$ values can be understood in terms of the contribution of the corresponding double bond - no-bond resonance structure $\boldsymbol{e}$ (Scheme 23). EW substituents stabilize structure $\boldsymbol{e}$ both inductively and by direct resonance. The stabilization of resonance structure $\boldsymbol{e}$ results in an increase in the donation energy in question as compared with that of the parent compound, and consequently positive $\rho$ values are observed.

Both $\mathbf{B}$ and $\mathbf{C}$ possess a half-chair structure. Scheme 22 gives the relevant conformations due to nitrogen/ring inversions. It is generally thought that in 1,3-oxazine systems the equatorial orientation of the substituent attached to the O-C-N carbon is favoured. ${ }^{5,56}$ The 1,3-axialpseudo-axial orientations (cis II and IV) of the cis forms are highly unfavoured due to the severe steric interaction, and their presence can be neglected. Hence, the equatorial-pseudo-equatorial orientations (cis I and III) preponderate in the cis forms. As a result of the equatorial preponderance of 3-phenyl substituents (trans I and III), the trans forms exhibit 1-phenyl pseudo-axial orientations. ${ }^{55,56}$ Thus, the minimum energy conformations used in the NBO 
analysis (trans I and cis I, cf. Figure 4) are relevant model structures. In the orientation trans I (see Scheme 22), overlap between the nitrogen lone pair and the sigma antibonding orbital of the $\mathrm{C} 1-\mathrm{C} 1$ ' bond is possible, even if it is not as favoured as it could be in the orientation trans III. In cis I, the spatial orientations of the nitrogen lone pair and the $\mathrm{C} 1-\mathrm{C} 1$ ' antibonding orbital do not allow overlap. Accordingly, the calculations did not indicate any significant $n_{\mathrm{N}} \rightarrow \sigma^{*}{ }_{\mathrm{Cl} 1 \mathrm{Cl}}$, donation for the cis isomers. Interestingly, for trans I the dependence of the overlapping energy of $n_{\mathrm{N}} \rightarrow \sigma^{*}{ }_{\mathrm{C} 1-\mathrm{Cl}}$, on substituent $\mathrm{Y}$ is clearly significant $\left(\rho_{\mathrm{F}}^{\mathrm{Y}}=0.34\right.$ and $\rho_{\mathrm{R}}^{\mathrm{Y}}=0.37$; Table 8$)$, the overlapping increasing with EW substituents. As concerns the $\sigma^{*}{ }_{\mathrm{C} 1-\mathrm{C} 10 \mathrm{~b}}$ orbital, the favourable overlapping of the nitrogen lone pair is possible in orientations I, which possess an equatorial nitrogen lone pair orientation for both the cis and the trans isomers. The calculated donation energies are about three times greater than those for $n_{\mathrm{N}} \rightarrow \sigma^{*}{ }_{\mathrm{Cl}-\mathrm{Cl}}$, donation in the case of the trans isomers. However, in contrast with the above, the dependence on substituent $\mathrm{Y}$ is small for the cis isomers and insignificant for the trans isomers. The differences between the calculated substituent-dependent stereoelectronic effects (anomeric effects) at C-1 can therefore be understood on a conformational basis.

The largest values of the overlapping energies observed for our compounds are connected with the $n_{\mathrm{N}} \rightarrow \sigma^{*}{ }_{\mathrm{C} 3-\mathrm{O} 4}$ transmission. However, the donation energies in question for both the cis and the trans series are very close to each other. Hence, this anomeric effect can not explain the stability differences between the isomers. For both the trans $(\mathbf{B})$ and the cis forms $(\mathbf{C})$, the overlapping energy for $n_{\mathrm{N}} \rightarrow \sigma^{*}{ }_{\mathrm{C} 3-04}$ was clearly dependent on substituent Y (B: $\rho_{\mathrm{F}}^{\mathrm{Y}}=-0.36$ and $\rho_{\mathrm{R}}^{\mathrm{Y}}=-0.24 ; \mathbf{C}: \rho_{\mathrm{F}}^{\mathrm{Y}}=-0.72$ and $\rho_{\mathrm{R}}^{\mathrm{Y}}=-0.61$, Table 8). Reverse behaviour (values of $\rho<0$ ) means that the sensitivity of the process in question is diminished by an electron-donating (ED) substituent. Since both the inductive and resonance sensitivities in question exhibit a reverse substituent dependence, the value of the donation energy is decreased on ED substitution. It can be assumed that the deviations in the half-chair structure itself between the cis and trans isomers are small. Thus, the different magnitudes of the $\rho$ values indicate that the substituent dependence of the donation energy in question is dependent on the orientation of the substituted phenyl ring at $\mathrm{C}-1$, the eq'-Ph-N-C-O pathway being able to transmit the effect of substituent $\mathrm{Y}$ more efficiently than the ax'-Ph-N-C-O pathway. The variation in the substituent dependence of the $n_{\mathrm{N}} \rightarrow \sigma^{*}{ }_{\mathrm{C} 3-\mathrm{O} 4}$ donation energy can be explained by comparison with $n_{\mathrm{N}} \rightarrow \sigma^{*}{ }_{\mathrm{C} 1-\mathrm{Cl} 1}$, transfer (B: $\rho_{\mathrm{F}}^{\mathrm{Y}}=0.34$ and $\rho_{\mathrm{R}}^{\mathrm{Y}}=0.37 ; \mathrm{C}: \rho_{\mathrm{F}}^{\mathrm{Y}}$ and $\rho_{\mathrm{R}}^{\mathrm{Y}}$, not significant), if we neglect the contributions of the $n_{\mathrm{N}} \rightarrow \sigma^{*}{ }_{\mathrm{C} 3-\mathrm{C} 1}$ " and $n_{\mathrm{N}} \rightarrow \sigma^{*} \mathrm{C} 3-\mathrm{H}$ transformations for which the donation energy values are small and for which the $\rho_{\mathrm{F}}^{\mathrm{Y}}$ and $\rho_{\mathrm{R}}^{\mathrm{Y}}$ values are in most cases significant, but relatively small. The 
donation ability of one nitrogen lone pair is limited as regards the number and extent of different donations. The routes giving the maximum stabilization of the molecular structure prevail. For the donation $n_{\mathrm{N}} \rightarrow \sigma^{*}{ }_{\mathrm{C} 1-\mathrm{Cl}}$, observed for the trans isomer, both the $\rho_{\mathrm{F}}^{\mathrm{Y}}$ and $\rho_{\mathrm{R}}^{\mathrm{Y}}$ values are positive. This means that EW substituents increase the value of the donation energy. In contrast, for $n_{\mathrm{N}} \rightarrow \sigma^{*}{ }_{\mathrm{C} 3-\mathrm{O} 4}$ both $\rho_{\mathrm{F}}^{\mathrm{Y}}$ and $\rho_{\mathrm{R}}^{\mathrm{Y}}<0$. This means that EW substituents decrease the value of the donation energy. This decrease compensates the increase in $n_{\mathrm{N}} \rightarrow \sigma^{*}{ }_{\mathrm{Cl} 1-\mathrm{Cl} 1}$. These two effects compete. As a consequence, the absolute values of $\rho_{\mathrm{F}}^{\mathrm{Y}}$ and $\rho_{\mathrm{R}}^{\mathrm{Y}}$ for $n_{\mathrm{N}} \rightarrow \sigma^{*}{ }_{\mathrm{C} 3-\mathrm{O} 4}$ donation for the trans isomer are only about half those observed for the cis isomer. The $n_{\mathrm{N}} \rightarrow \sigma^{*}{ }_{\mathrm{C} 3-\mathrm{O} 4}$ transmission also seems to be sensitive to substituent $\mathrm{X}$, but to an essentially smaller extent than above. It has been shown by Neuvonen et al. that an increase in the contribution of $n_{\mathrm{N}} \rightarrow \sigma^{*}{ }_{\mathrm{C} 3-\mathrm{O} 4}$ donation facilitates the ring opening in ring-chain tautomerism. ${ }^{49}$

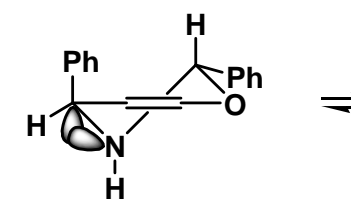

trans I

什

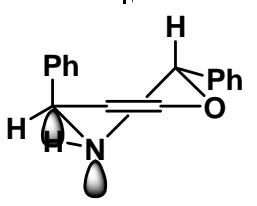

trans III

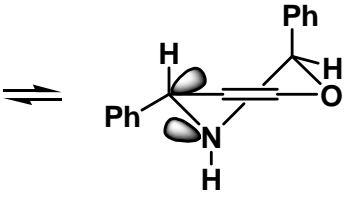

trans II

什

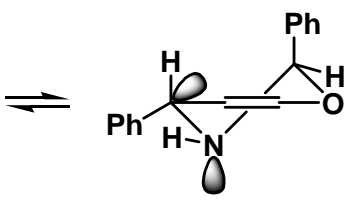

trans IV

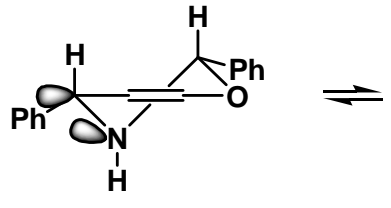

cis I

任

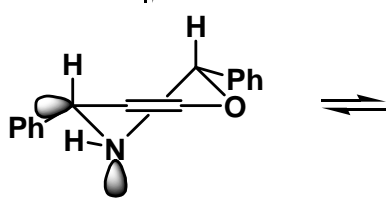

cis III

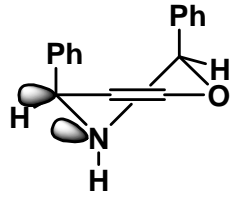

cis II

什

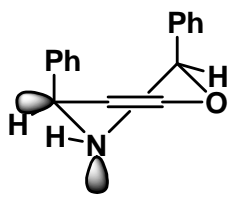

cis IV

Scheme 22

\section{Influences of the substituents on the ${ }^{13} \mathrm{C}$ NMR chemical shifts of compounds 48-54}

The ${ }^{13} \mathrm{C}$ NMR chemical shift changes induced by phenyl substituents (SCS) on C-2 have been analysed by several different dual substituent parameter approaches. ${ }^{49,57-63}$ The best correlation was obtained with the equation SCS $=\rho_{\mathrm{F}} \sigma_{\mathrm{F}}+\rho_{\mathrm{R}} \sigma_{\mathrm{R}} \cdot{ }^{54}$ For all the studied 1,3heterocyclic systems, negative $\rho_{\mathrm{F}}$ values were observed, indicating reverse behaviour of the electron density on $\mathrm{C}-2$. $^{49}$

To check the previous hypothesis, the chemical shifts of C-1 and C-3 were measured in $\mathrm{CDCl}_{3}$. Chemical shift changes induced by an aryl substituent (SCS) for a given compound were calculated as the differences in ${ }^{13} \mathrm{C}$ chemical shift for the substituted relative to the unsubstituted $(\mathrm{X}=\mathrm{H}, \mathrm{Y}=\mathrm{H})$ compound.

$$
\mathrm{SCS}=\rho_{\mathrm{F}}^{\mathrm{Y}} \sigma_{\mathrm{F}}^{\mathrm{Y}}+\rho_{\mathrm{R}}^{\mathrm{Y}} \sigma_{\mathrm{R}}^{\mathrm{Y}}+\rho_{\mathrm{F}}^{\mathrm{X}} \sigma_{\mathrm{F}}^{\mathrm{X}}+\rho_{\mathrm{R}}^{\mathrm{X}} \sigma_{\mathrm{R}}^{\mathrm{X}}
$$


The multiple regression analysis data obtained via Eq. 4 for C-1 and C-3 are presented in Table 9.

Table 9. Multiple linear regression analysis of chemical shifts for 48-54 according to Eq. 4

\begin{tabular}{||c|c|c|c|c|c|c||}
\hline & & $\rho_{\mathrm{F}}^{\mathrm{Y}}$ & $\rho_{\mathrm{R}}^{\mathrm{Y}}$ & $\rho_{\mathrm{F}}^{\mathrm{X}}$ & $\rho_{\mathrm{R}}^{\mathrm{X}}$ & $\mathrm{r}$ \\
\hline \multirow{3}{*}{ For C-1 } & $\mathbf{A}$ & -1.81 & $-^{\mathrm{a}}$ & $-^{\mathrm{a}}$ & 0.45 & 0.967 \\
& $\mathbf{B}$ & -1.12 & 0.75 & $-^{\mathrm{a}}$ & $-^{\mathrm{a}}$ & 0.982 \\
& $\mathbf{C}$ & -1.51 & 0.60 & -0.49 & $-^{\mathrm{a}}$ & 0.983 \\
\hline \multirow{3}{*}{ For C-3 } & $\mathbf{A}$ & 1.74 & 2.31 & -2.96 & $-^{\mathrm{a}}$ & 0.977 \\
& $\mathbf{B}$ & $--^{\mathrm{a}}$ & 0.44 & -1.56 & -0.56 & 0.968 \\
& $\mathbf{C}$ & -0.53 & -0.30 & -1.88 & -0.44 & 0.987 \\
\hline
\end{tabular}

${ }^{\mathrm{a}}$ Insignificant ( significance value $>0.05$ )

The trans isomers $\mathbf{B}$ exhibit low-field (i.e. high-frequency) C-1 ${ }^{13} \mathrm{C}$ NMR chemical shifts as compared with those of the $c i s$ isomers $\mathbf{C}, \Delta \mathrm{SCS}$ being about $3 \mathrm{ppm}$. The values of $\rho_{\mathrm{F}}^{\mathrm{Y}}$ and $\rho_{\mathrm{R}}^{\mathrm{Y}}$ for $\mathrm{C}-1$ seem to depend on the configuration. The trans isomers exhibit somewhat less negative $\rho_{\mathrm{F}}^{\mathrm{Y}}$ values, but slightly more positive $\rho_{\mathrm{R}}^{\mathrm{Y}}$ values. Thus, the sensitivity to the inductive effect is somewhat stronger within the cis series. It was shown above that the sensitivity to the anomeric effect was larger in the trans series.

The anomeric effect can explain the differences in sensitivity of the ${ }^{13} \mathrm{C}$ NMR chemical shifts of $\mathrm{C}-1$ to substituent $\mathrm{Y}$ between the trans and the cis series. A significant $n_{\mathrm{N}} \rightarrow \sigma^{*} \mathrm{Cl}-\mathrm{Cl}$, donation was observed in the trans series, but not in the cis series. The valence bond representation of the anomeric effect is the double bond - no-bond resonance structure (Scheme 23). For the trans isomers, the resonance structure $\boldsymbol{e}$ and therefore the $s p^{2}$ character of $\mathrm{C}-1$ are more prominent as compared with those for the cis isomers. Typically, the $s p^{2}$ hybridized carbons exhibit lower-field ${ }^{13} \mathrm{C}$ NMR chemical shifts than those of the $s p^{3}$ hybridized carbons. Therefore, the trans series exhibit low-field C-1 shifts. If a substituent-dependent stereoelectronic effect $n_{\mathrm{N}} \rightarrow \sigma^{*} \mathrm{Cl}-\mathrm{Cl} 1$ is present in the trans form, the absolute value of $\rho_{\mathrm{F}}^{\mathrm{Y}}$ has to be decreased because the phenyl substituents cause an opposite dependence in the carbon chemical shifts. Since EW substituents stabilize resonance form $\boldsymbol{e}$, the $s p^{2}$ character of C-1 is increased. As a consequence, a less negative $\rho_{\mathrm{F}}^{\mathrm{Y}}$ value is observed. Unexpectedly, both the trans and cis isomers exhibit positive $\rho_{\mathrm{R}}^{\mathrm{Y}}$ values. Instead, they give negative $\rho_{\mathrm{R}}^{\mathrm{X}}$ values, analogously as observed earlier for 1,3-O,N-heterocycles. $\rho_{\mathrm{R}}$ values are measures of prevailing resonance interactions. In principle, there are two possible mechanisms for the resonance interaction of a side-chain-substituted benzene derivative (a $\mathrm{C}=\mathrm{N}$ double bond as an example). Direct (normal) 
resonance is based on an interaction of type $\boldsymbol{b}$. A resonance-induced polar effect, which is indirect resonance, is based on an interaction of type $c$.

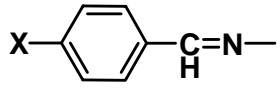

a

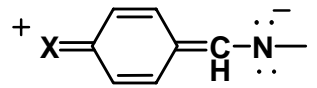

b

mechanism of direct resonance

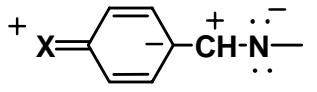

c

mechanism of resonanceinduced polar effect

In direct resonance, ED substituents increase the electron density at the probe site $(\mathrm{C}-1)$ resulting in upfield ${ }^{13} \mathrm{C}$ NMR chemical shifts (i.e. smaller shift values) and consequently in $\rho_{\mathrm{R}}>$ 0. In contrast, in resonance-induced polar effects, ED substituents decrease the electron density at the probe site $(\mathrm{C}-1)$, resulting in $\rho_{\mathrm{R}}<0$. The observed positive $\rho_{\mathrm{R}}^{\mathrm{Y}}$ values indicate the operation of direct resonance. This can be understood by the appearance of the double bond no-bond structure $\boldsymbol{f}$, which is sensitive to resonance interaction and corresponding to $n_{\mathrm{N}} \rightarrow \sigma_{\mathrm{C1}}^{*}$ C10b' donation (see above). In summary, the behaviour of the ${ }^{13} \mathrm{C}$ NMR chemical shifts of C-1 can be nicely explained on the basis of the anomeric effect directed on C-1.

The values of $\rho_{\mathrm{F}}^{\mathrm{X}}$ and $\rho_{\mathrm{R}}^{\mathrm{X}}$ for C-3 also seem to depend on the configuration. The trans isomers exhibit somewhat less negative $\rho_{\mathrm{F}}^{\mathrm{X}}$ values but slightly more negative $\rho_{\mathrm{R}}^{\mathrm{X}}$ values. Accordingly, the sensitivity to the inductive effect is again somewhat stronger for the cis series. For C-1, positive $\rho_{\mathrm{R}}^{\mathrm{Y}}$ values were observed for both the trans and the cis forms (Table 9), whereas for C-3, negative $\rho_{\mathrm{R}}^{\mathrm{X}}$ values were found for both series.

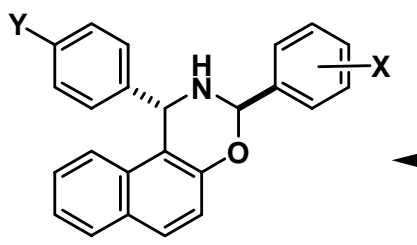

$\boldsymbol{d}$
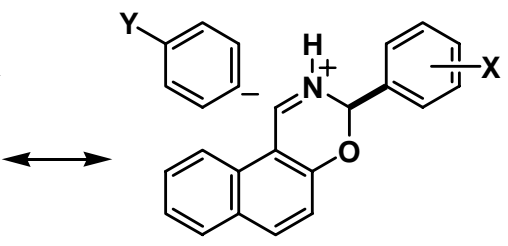

e

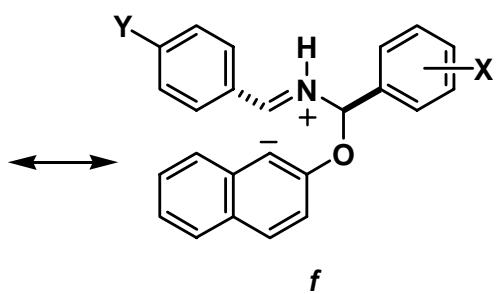

Scheme 23

Table 9 reveals a reverse trend of the inductive substituent effects (i.e. $\rho_{\mathrm{F}}^{\mathrm{Y}}$ for $\mathrm{C}-1$ and $\rho_{\mathrm{F}}^{\mathrm{X}}$ for $\mathrm{C}-3<0$ ) for both the cis and the trans series. This behaviour means that the EW substituents induce upfield ${ }^{13} \mathrm{C}$ NMR chemical shifts as compared with those of the corresponding nonsubstituted derivative. This behaviour is contrary to the well-established idea of a generalized inductive effect, but its appearance is nowadays well documented for many different series of unsaturated side-chain derivatives of substituted benzene. The origin of the reverse trend of the substituent effect is qualitatively satisfactorily understood. On the other hand, the appearance of 
the analogous effect with saturated carbon centres such as those situated between the two heteroatoms in 1,3-O,N-heterocycles has been much less well studied. ${ }^{49}$ The trans and cis series of the present model compounds offer an interesting opportunity to study this type of reversed trend of substituent effect. The negative $\rho_{\mathrm{F}}$ values have been explained by Neuvonen et al. by the concept of the substituent-sensitive polarization of the $\mathrm{N}-\mathrm{C}-\mathrm{O}$ system. ${ }^{49}$ The substituent interaction with the polar $\mathrm{C}-\mathrm{O}$ and/or $\mathrm{C}-\mathrm{N}$ bond results in dipolar induction, as depicted in Figure 5. In consequence, with EW substituents the electron density at the carbon joined to a heteroatom is increased, whereas with ED substituents it is decreased. The idea of substituent interaction with the polar bond (PSI = polar substituent interaction) is, like that of $\pi$-polarization, in conflict with the concept of the generalized inductive effect. Interestingly, the concept of PSI now seems to hold in connection with the polar $(\mathrm{C}-1)-\mathrm{N}$ bonds in the title compounds.
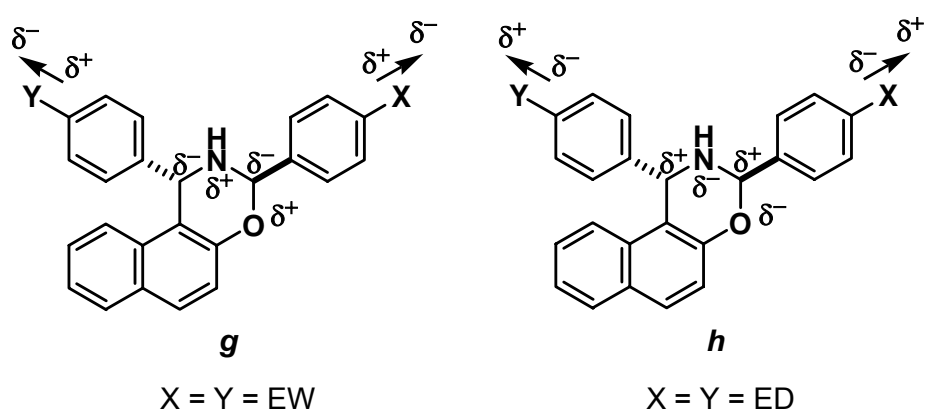

Figure 5. Polar substituent interactions in the trans form

Both the cis and the trans isomers exhibit negative $\rho_{\mathrm{R}}^{\mathrm{X}}$ values, in harmony with the operation of a resonance-induced polar mechanism $(\boldsymbol{c}) .^{49}$

\subsection{Syntheses and ring-chain tautomerism of 3-alkyl-1-arylnaphth[1,2-e][1,3]oxazines}

The ring-chain tautomeric ratio is determined by the free energy difference between the tautomeric forms. Therefore, the observed systematic change in log $\mathrm{K}$ can not be simply related to the energetic changes either in the ring form or in the chain form. To find evidence of the substituent effect in the ring form, the tautomeric system of 3-alkyl-1-aryl-2,3-dihydro- $1 H$ naphth[1,2-e][1,3] oxazines 60-66 was analysed. Condensations of aminonaphthols $45 \mathbf{c}-\mathbf{i}$ with equivalent amounts of aliphatic aldehydes resulted in the naphthoxazine model compounds 6066 (Scheme 24). 
<smiles>NC(c1ccc(I)cc1)c1c(O)ccc2ccccc12</smiles><smiles></smiles>

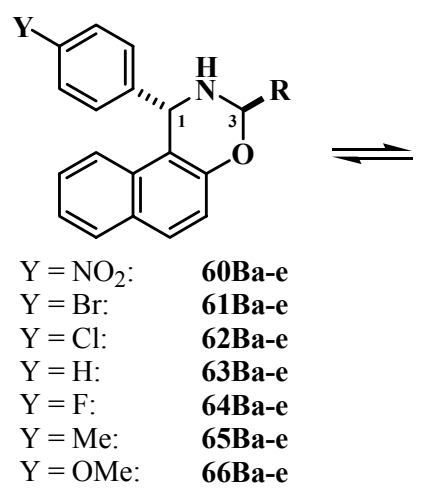<smiles>[R]C=NC(c1ccc(I)cc1)c1c(O)ccc2ccccc12</smiles>

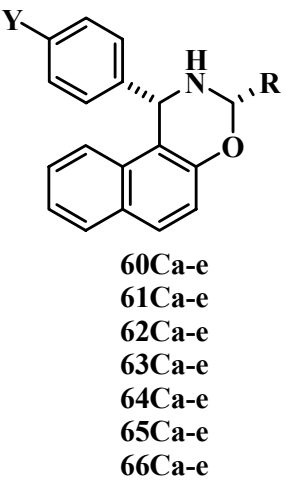

$\mathrm{R}=\mathrm{Me}: \mathbf{a} ;$ Et: b; Pr: $\mathbf{c} ; i \operatorname{Pr}: \mathbf{d} ; t$ Bu: $\mathbf{e}$

\section{Scheme 24}

The ${ }^{1} \mathrm{H}$ NMR spectra of $\mathbf{6 0 - 6 6}$ showed that, in $\mathrm{CDCl}_{3}$ solution at $300 \mathrm{~K}$, the members a-e of each set of compounds 60-66 participated in two-component tautomeric mixtures containing C-3 epimeric naphthoxazines ( $\mathbf{B}$ and $\mathbf{C}$ ). The relative configurations of $\mathbf{B}$ and $\mathbf{C}$ were proved by using NOE measurements. In any set of compounds, chain forms (A) could not be detected. This is in accordance with the results of earlier studies on the condensation products of 2- or 3aminoalkanols and aliphatic carbonyl compounds, in which branching of the chain in 2-alkyl substituents proved to stabilize the cyclic tautomers. ${ }^{64}$

The epimerization constants were calculated from the ratio of the ring forms $\left(K_{R}=[B] /[C]\right)$. To find a linear equation to describe the influence of the alkyl substituents on log $\mathrm{K}_{\mathrm{R}}$, three different alkyl substituent parameters were studied: $\mathrm{E}_{\mathrm{s}}$ (calculated from the hydrolysis or aminolysis ${ }^{65}$ of esters) and two other steric parameters independent of any kinetic data: $v$ (derived from the van der Waals radii ${ }^{66,67}$ ) and $\mathrm{V}^{\mathrm{a}}$ (the volume of the portion of the substituent that is within $0.3 \mathrm{~nm}$ of the reaction centre ${ }^{68}$ ). Good correlations were found with all three alkyl substituent parameters. The linear regression analysis data for series 60-66 are given in Table 10 . As the best correlations were observed $v s$ the Meyer parameters $\left(\mathrm{V}^{\mathrm{a}}, \mathrm{Eq} .5\right)$, this was used for the further examinations (Figure 6). 
Table 10. Linear regression analysis data with different alkyl substituent parameters for series 60-66

\begin{tabular}{||c|c|c|c|c||}
\hline $\begin{array}{c}\text { Substituent } \\
\text { parameter }\end{array}$ & Series & Intercept & Slope & $\begin{array}{c}\text { Correlation } \\
\text { coefficient }\end{array}$ \\
\hline & 60a-e & 0.63 & 8.62 & 0.922 \\
& 61a-e & 0.40 & 9.82 & 0.963 \\
$\mathrm{~V}^{\mathrm{a}}$ & 62a-e & 0.62 & 7.58 & 0.957 \\
& 63a-e & 0.54 & 6.36 & 0.966 \\
& 64a-e & 0.51 & 8.39 & 0.987 \\
& 65a-e & 0.51 & 7.42 & 0.904 \\
& 66a-e & 0.53 & 7.61 & 0.898 \\
\hline & 60a-e & 0.65 & -0.24 & -0.975 \\
& 61a-e & 0.48 & -0.24 & -0.899 \\
$\mathrm{E}_{\mathrm{s}}$ & 62a-e & 0.66 & -0.19 & -0.955 \\
& 63a-e & 0.48 & -0.24 & -0.899 \\
& 64a-e & 0.59 & -0.19 & -0.876 \\
& 65a-e & 0.52 & -0.20 & -0.951 \\
& 66a-e & 0.57 & -0.19 & -0.882 \\
\hline & 60a-e & 0.67 & 0.51 & 0.982 \\
& 61a-e & 0.49 & 0.52 & 0.914 \\
& 62a-e & 0.68 & 0.42 & 0.965 \\
& 63a-e & 0.59 & 0.35 & 0.959 \\
& 64a-e & 0.61 & 0.42 & 0.889 \\
& 65a-e & 0.54 & 0.44 & 0.961 \\
& 66a-e & 0.59 & 0.42 & 0.898 \\
\hline
\end{tabular}

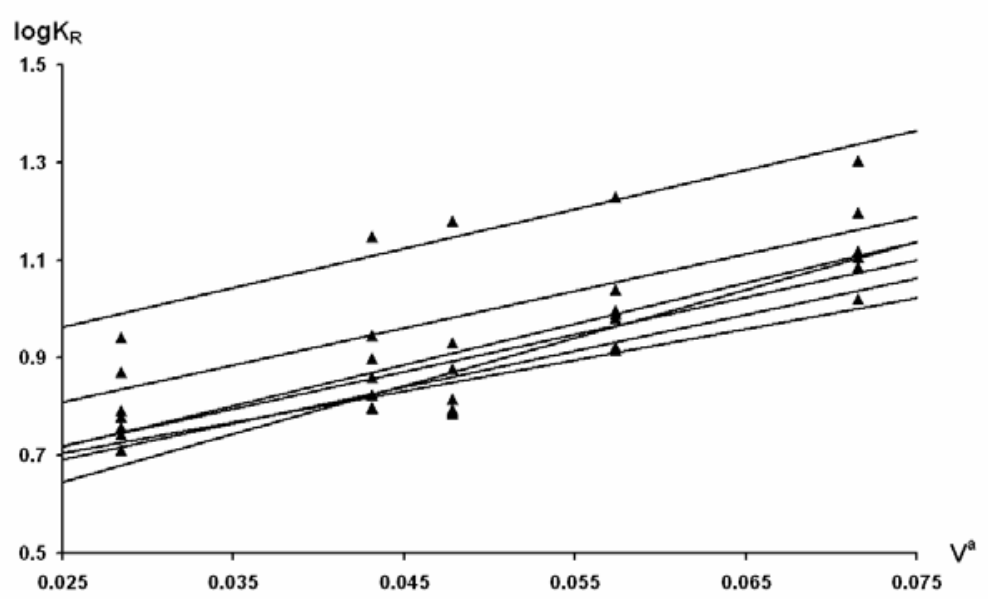

Figure 6. Plots of $\log \mathrm{K}_{\mathrm{R}}\left(\right.$ in $\left.\mathrm{CDCl}_{3}\right)$ for 60-66a-e ( $\left.\mathbf{\Delta}\right)$ vs Meyer parameter $\mathrm{V}^{\mathrm{a}}$

$$
\log \mathrm{K}_{\mathrm{R}}=0.55+7.88 \mathrm{~V}^{\mathrm{a}}
$$

To study the common influence of the aryl substituents at position 1 and the alkyl substituents at position 3, multiple linear regression analysis of $\log K_{R}$ as dependent variable was performed according to Eq. 6. The analysis results are listed in Table 7.

$$
\log K_{R}=k+\rho_{F}^{Y} \sigma_{F}^{Y}+\rho_{R}^{Y} \sigma_{R}^{Y}+\rho^{R} V^{a}
$$


The significant dependence of $\log K_{R}$ on the inductive effect $\left(\sigma_{F}\right)$ of substituent $Y$ for 60 66, together with the $\sigma_{\mathrm{F}}$ dependence of $\log \mathrm{K}$ for $\mathbf{4 8 - 5 4}$, led us to conclude that only the free energy of the trans forms is influenced by the inductive effect of substituent $\mathrm{Y}$, which can be explained by the anomeric effect influenced quantitatively by $\mathrm{Y}$. The $\rho_{\mathrm{F}}^{\mathrm{Y}}$ value obtained via Eq. 6 is relatively close to that obtained according to Eq. 3 for the equilibrium $\operatorname{trans}=$ chain $(\mathbf{B}=\mathbf{A})$. This supports the validity of the $\rho_{\mathrm{F}}^{\mathrm{Y}}$ values, indicating that these parameters reflect the pure contribution of $Y$.

\subsection{Syntheses and ring-chain tautomerism of 2,4-diarylnaphth[2,1-e][1,3]oxazines}

A further aim was to examine the applicability of Eq. 2 in the case of a new model system, the 2,4-diaryl-3,4-dihydro-2H-naphth[2,1-e][1,3]oxazines, which are regioisomers of the previously studied model compounds 46-54.

2-( $\alpha$-Aminobenzyl)-1-naphthols, the starting materials for the synthesis of the target naphth $[2,1-e][1,3]$ oxazine model compounds, were prepared in a manner similar to that for their regioisomeric 1-( $\alpha$-aminobenzyl)-2-naphthol derivatives, by Betti aminoalkylation of 1naphthol. ${ }^{5}$ The condensation of 1-naphthol (6) and benzaldehyde or substituted benzaldehydes in the presence of ammonia, and subsequent acidic hydrolysis, furnished aminonaphthol hydrochlorides 68a-g in moderate yields (Scheme 25). In consequence of the close analogy to 1-( $\alpha$-aminobenzyl)-2-naphthols, which are known as "Betti bases", the regioisomeric compounds 68a-g can be referred as to "reverse Betti bases".<smiles>Oc1cccc2ccccc12</smiles>

6

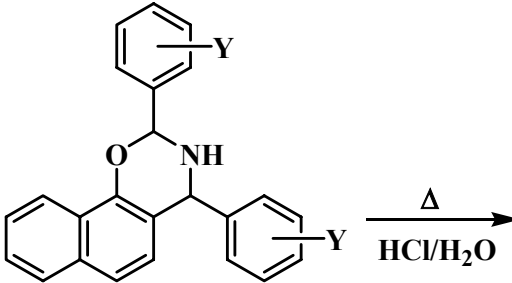

67a-g

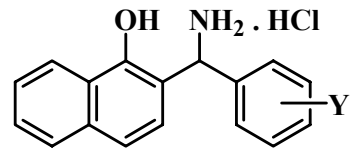

68a-g

$\mathrm{Y}=\mathrm{NO}_{2}(m): \mathbf{a} ; \operatorname{Br}(m): \mathbf{b} ; \operatorname{Br}(p): \mathbf{c} ; \mathrm{Cl}(p): \mathbf{d} ; \mathrm{H}: \mathbf{e} ; \operatorname{Me}(p): \mathbf{f} ; \mathrm{OMe}(p): \mathbf{g}$

\section{Scheme 25}

In contrast with the regioisomeric 1-( $\alpha$-aminobenzyl)-2-naphthols, which are relatively stable crystalline substances, the bases of $\mathbf{6 8 a - g}$ proved to be quite unstable comnpounds, which were therefore liberated in situ in the further transformations. The naphthoxazine model compounds 69-75 were prepared by condensations of aminonaphthol hydrochlorides 68a-g with equivalent amounts of aromatic aldehydes in the presence of $\mathrm{Et}_{3} \mathrm{~N}$ (Scheme 26). The ${ }^{1} \mathrm{H}$ NMR spectra of 69-75 proved that, in $\mathrm{CDCl}_{3}$ solution at $300 \mathrm{~K}$, the members a-g of each set of 
compounds 69-75 formed three-component tautomeric mixtures, containing C-2 epimeric oxazines (B and $\mathbf{C}$ ) besides the open-chain tautomer (A). Because of the very similar NMR spectroscopic characters of 2,4-diaryl-3,4-dihydro- $2 H$-naphth[2,1-e][1,3]oxazines 69-75, the relative configurations of the major $(\mathbf{B})$ and minor $(\mathbf{C})$ ring-closed tautomers were determined and conformational analysis was performed only for compounds 70a and $69 \mathrm{~g}$. The NOESY spectra of compound $\mathbf{7 0 a}$ proved that, similarly to 1,3-diaryl-2,3-dihydro-1H-naphth[1,2e][1,3]oxazines, the major ring-closed tautomer contains the 2,4-diaryl substituents in the trans position (B). 2D spectroscopic analysis of $69 \mathrm{~g}$ revealed that the configuration of the azomethine double bond is $E$.

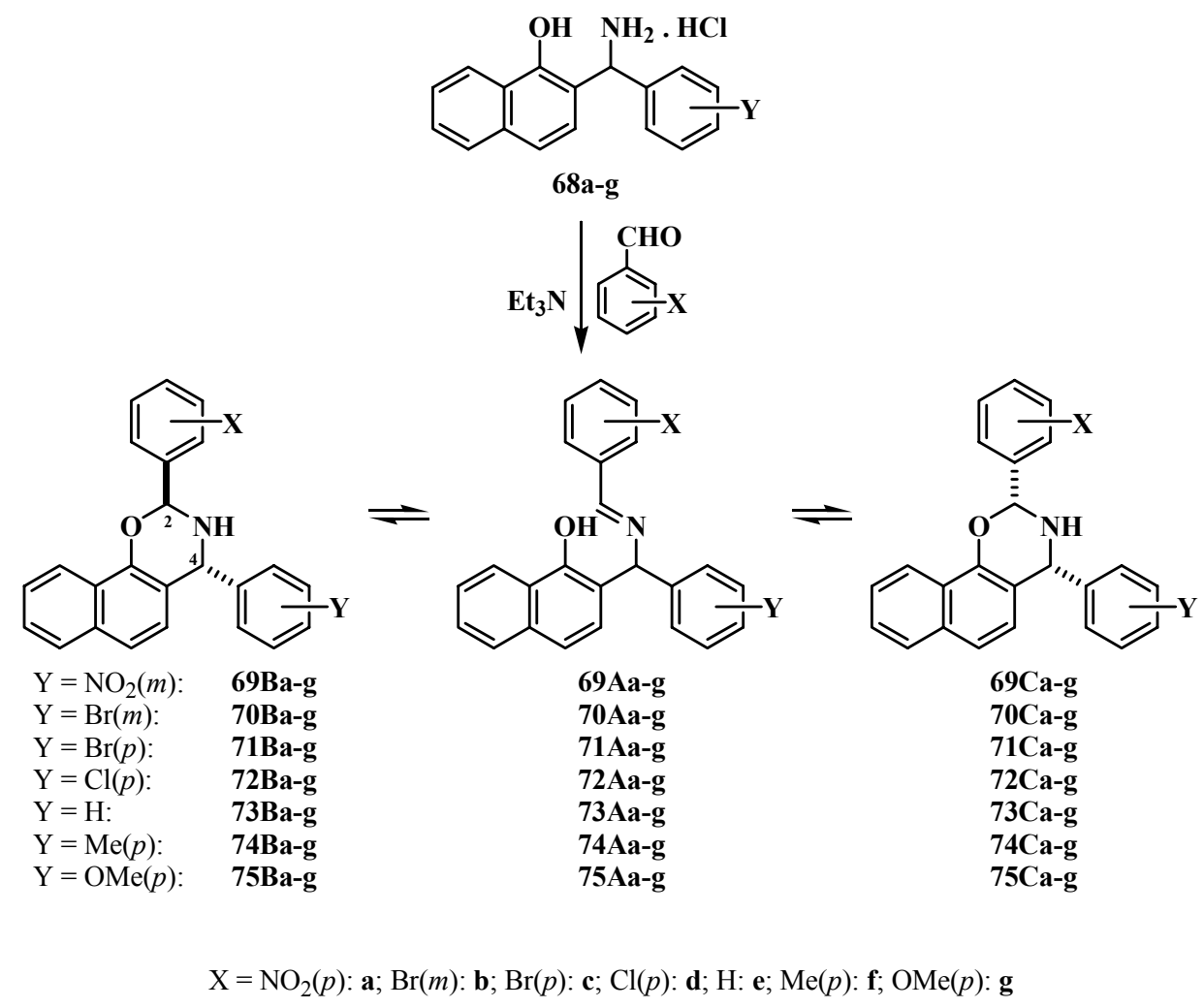

Scheme 26

The proportions of the chain (A) and diastereomeric ring forms (B and $\mathbf{C}$ ) in the tautomeric equilibria of 69-75 $\left(\mathrm{K}_{\mathrm{X}}\right)$ were determined by integration of the well-separated O-CHAr-N (ring) and $\mathrm{N}=\mathrm{CHAr}$ (chain) proton singlets from the ${ }^{1} \mathrm{H}$ NMR spectra. When Eq. 1 was applied to the $\log \mathrm{K}_{\mathrm{X}}$ values, good linear correlations were obtained $v_{s}$ the Hammett-Brown parameter $\sigma^{+}$of the substituent $X$ on the 2-phenyl group for compounds 69-75 (Figure 7, Table 11). 

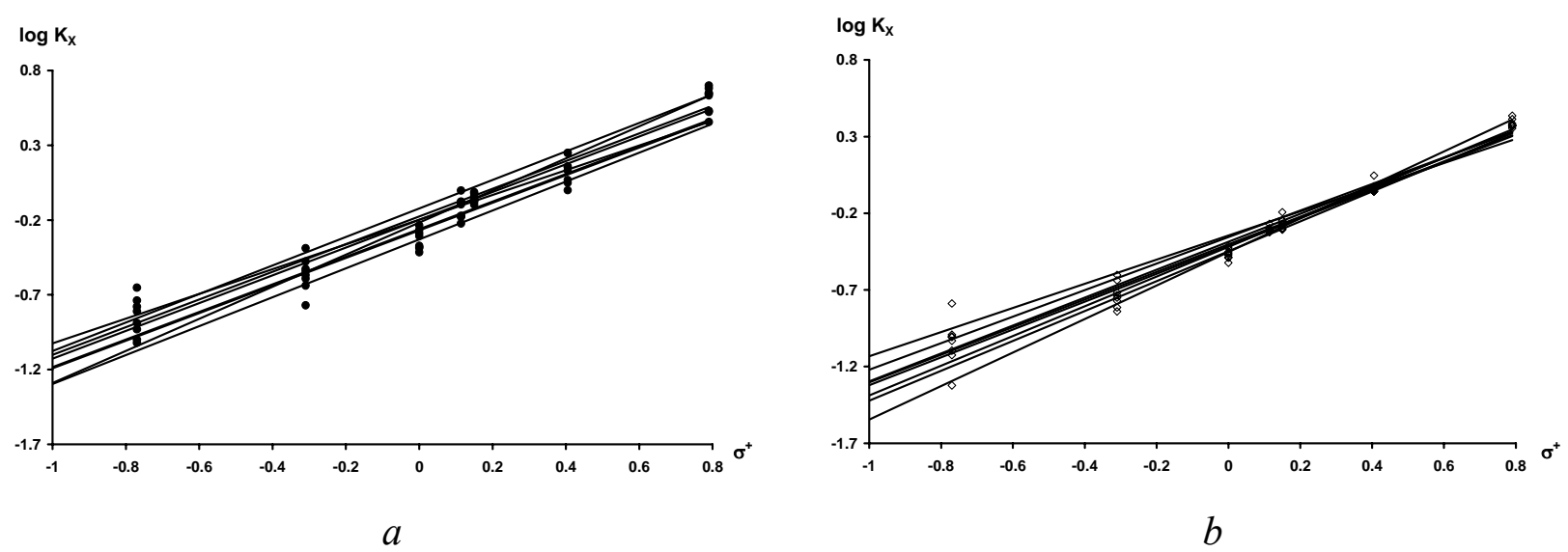

Figure 7. $a$ : Plots of $\log \mathrm{K}_{\mathrm{X}}$ for 69-75B (•) vs Hammett-Brown parameter $\sigma^{+}$. $b$ : Plots of $\log \mathrm{K}_{\mathrm{X}}$ for $\mathbf{6 9 - 7 5 C}$ ( ) vs Hammett-Brown parameter $\sigma^{+}$

For each series, the value of $\rho$ was found to be positive, as is customary among 2-aryl-1,3$O, N$ heterocycles. The plots for the equilibria containing C-2 epimeric ring forms of 69-75 (B-A and $\mathbf{C - A}$ ) proved to be practically parallel, which points to the fact that 2,4-diaryl substituents in the ring forms of 2,4-diaryl-3,4-dihydro-2H-naphth[2,1-e][1,3]oxazines do not influence the value of $\rho$ (Table 11).

Table 11. Linear regression data on compounds $69-75$ and the oxazines 51,57 and 58

\begin{tabular}{||c|c|c|c|c|c||}
\hline Equilibrium & No. of points & Slope $(\rho)$ & Intercept & $\begin{array}{c}\text { Correlation } \\
\text { coefficient }\end{array}$ & $\mathrm{c}_{\mathrm{s}}$ \\
\hline $\mathbf{6 9 A}=\mathbf{6 9 B}$ & 7 & 0.95 & -0.12 & 0.992 & 0.03 \\
$\mathbf{6 9 A}=\mathbf{6 9 C}$ & 7 & 0.97 & -0.45 & 0.994 & -0.30 \\
$\mathbf{7 0 A}=\mathbf{7 0 B}$ & 7 & 1.07 & -0.22 & 0.997 & -0.07 \\
$\mathbf{7 0 A}=\mathbf{7 0 C}$ & 7 & 1.09 & -0.45 & 0.998 & -0.30 \\
$\mathbf{7 1 A}=\mathbf{7 1 B}$ & 7 & 0.93 & -0.18 & 0.977 & -0.03 \\
$\mathbf{7 1 A}=\mathbf{7 1 C}$ & 7 & 0.91 & -0.41 & 0.988 & -0.26 \\
$\mathbf{7 2 A}=\mathbf{7 2 B}$ & 7 & 0.93 & -0.20 & 0.981 & -0.05 \\
$\mathbf{7 2 A}=\mathbf{7 2 C}$ & 7 & 0.91 & -0.39 & 0.991 & -0.24 \\
$\mathbf{7 3 A}=\mathbf{7 3 B}$ & 7 & 0.92 & -0.27 & 0.981 & -0.12 \\
$\mathbf{7 3 A}=\mathbf{7 3 C}$ & 7 & 0.90 & -0.40 & 0.994 & -0.25 \\
$\mathbf{7 4 A}=\mathbf{7 4 B}$ & 7 & 0.97 & -0.33 & 0.984 & -0.18 \\
$\mathbf{7 4 A}=\mathbf{7 4 C}$ & 7 & 0.97 & -0.42 & 0.994 & -0.27 \\
$\mathbf{7 5 A}=\mathbf{7 5 B}$ & 7 & 0.92 & -0.26 & 0.991 & -0.11 \\
$\mathbf{7 5 A}=\mathbf{7 5 C}$ & 7 & 0.86 & -0.36 & 0.994 & -0.21 \\
$\mathbf{5 7 A}=\mathbf{5 7 B}$ & 7 & 0.74 & -0.15 & 0.984 & - \\
$\mathbf{5 8 A}=\mathbf{5 8 B}$ & 7 & 0.82 & -0.66 & 0.995 & -0.51 \\
$\mathbf{5 1 A}=\mathbf{5 1 B}$ & 7 & 1.05 & 0.51 & 0.986 & 0.66 \\
$\mathbf{5 1 A}=\mathbf{5 1 C}$ & 6 & 0.98 & -0.35 & 0.983 & -0.20 \\
\hline \hline
\end{tabular}

${ }^{\mathrm{a}}$ Relative ring stability constant: see the text. ${ }^{\mathrm{b}}$ Data from ref. 9 
Table 11 shows that an annelated naphthalene ring decreases the stability of the ring form; this was observed for all naphthoxazines having trans (69-75B: $\left.\mathrm{c}_{\mathrm{s}}=-0.18-0.03\right)$ or cis (69-75C: $\left.\mathrm{c}_{\mathrm{s}}=-0.30--0.21\right)$ diaryl substituents. The differences between the $\mathrm{c}_{\mathrm{s}}$ values for the trans and cis series are smaller than that found for regioisomeric naphthoxazines $\left(\mathbf{5 1 B}: \mathrm{c}_{\mathrm{s}}=0.66, \mathbf{5 1 C}\right.$ : $\mathrm{c}_{\mathrm{s}}=-0.20$ ), which can be explained by the less unfavourable steric arrangement of the diaryl substituents in 69-75.

While the inductive effect of substituent $\mathrm{Y}$ (characterized by substituent parameter $\sigma_{\mathrm{F}}$ ) was found to be significant as concerns the tautomeric equilibrium constant according to Eq. 2 for the 1,3-diaryl-substituted naphthoxazines 48-54, our aim was to study the applicability of Eq. 2 for the present model compounds 71-75. The significance level was taken as 0.05 . The linear regression analysis of Eq. 2 in Table 12 shows that the trans $=$ chain $(B=\mathbf{A})$ equilibrium constants are significantly influenced by the inductive effect $\left(\sigma_{\mathrm{F}}\right)$ of substituent $\mathrm{Y}$ on the 4phenyl ring. This means that for the trans $=$ chain $(B=\mathbf{A})$ equilibria the equilibrium constant can be described by applying a double substituent parameter treatment, and a plane can be fitted to the data points with data error $r=0.971$ (Figure 8).

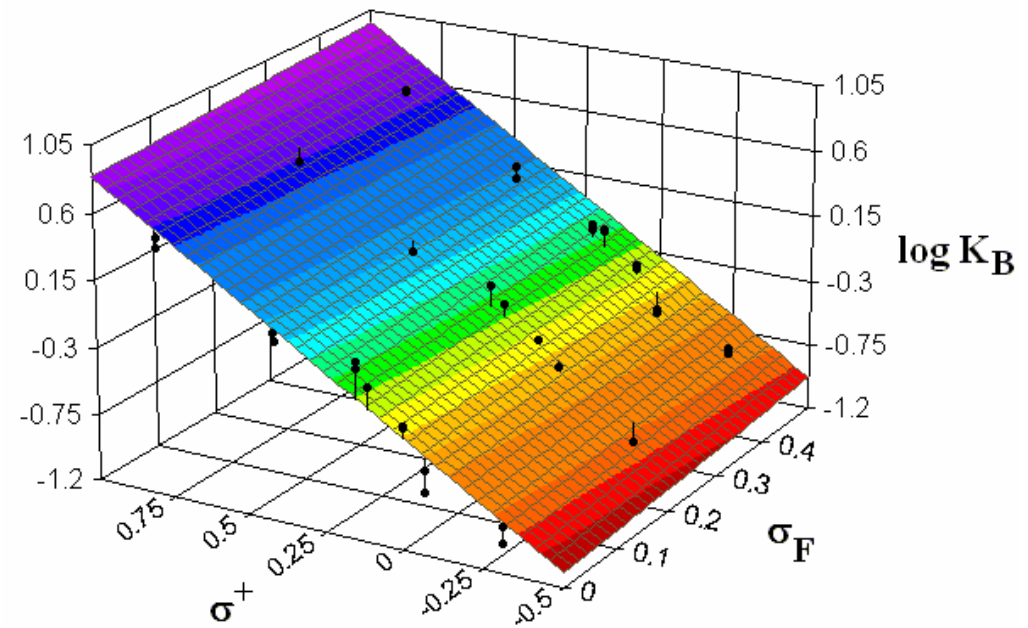

Figure 8. Plots of $\log \mathrm{K}_{\mathrm{B}}$ for 71-75B (•) vs Hammett parameters $\sigma^{+}$and $\sigma_{\mathrm{F}}$

The double substituent dependence of $\log \mathrm{K}$ for the trans-chain equilibria is related to the relative configurations of C-2 and C-4 and thereby the spatiality of the model compound. This observation is in accordance with the concept of the stereoelectronically mediated substituent effect. ${ }^{50}$ The present results are in harmony with those found for the ring-chain tautomerism of 1,3-diarylnaphth[1,2-e][1,3] oxazines 48-54. The positive value of $\rho_{\mathrm{F}}^{\mathrm{Y}}(0.28)$ shows that aromatic ring substituents not attached to a phenyl ring situated between two heteroatoms can also have a systematic effect on the relative proportions of the ring tautomers. It can be concluded that equilibrium $\mathbf{B}=\mathbf{A}$ seems to be somewhat more sensitive to both substituent $\mathrm{X}$ and substituent $\mathrm{Y}$ 
than is equilibrium $\mathbf{C}=\mathbf{A}$. These substituent effects can be explained in terms of a stereoelectronic effect related to the relative configuration of C-4.

For a better understanding of the ring-chain tautomeric process, multiple linear regression analysis of Eq. 3 was performed (Table 12). Both $\rho_{\mathrm{F}}^{\mathrm{X}}$ (inductive) and $\rho_{\mathrm{R}}^{\mathrm{X}}$ (resonance) are positive, i.e. both the inductive and resonance effects of EW substituents increase the proportion of the ring form (the normal behaviour of the substituent dependence of the ring-chain equilibria).

Table 12. Multiple linear regression analysis of $\log \mathrm{K}$ values for 71-75

\begin{tabular}{|c|c|c|c|c|c|c|c|}
\hline & & $\mathrm{k}$ & $\rho_{\mathrm{F}}^{\mathrm{Y}}$ & $\rho_{\mathrm{R}}^{\mathrm{Y}}$ & \multicolumn{2}{|c|}{$\rho^{X}$ or $\rho_{F}^{X} \rho_{R}^{X}$} & $\mathrm{r}$ \\
\hline \multirow{2}{*}{ Acc. to Eq. 2} & $71-75 A \rightleftharpoons 71-75 B$ & -0.44 & 0.28 & $-{ }^{\mathrm{a}}$ & \multicolumn{2}{|c|}{1.29} & 0.971 \\
\hline & $71-75 \mathrm{~A} \rightleftharpoons 71-75 \mathrm{C}$ & -0.58 & ${ }^{\mathrm{a}}$ & $-{ }^{\mathrm{a}}$ & \multicolumn{2}{|c|}{1.27} & 0.965 \\
\hline \multirow{2}{*}{ Acc. to Eq. 3} & $71-75 A \rightleftharpoons 71-75 B$ & -0.46 & 0.25 & $-{ }^{\mathrm{a}}$ & 1.15 & 1.62 & 0.984 \\
\hline & $71-75 \mathrm{~A} \rightleftharpoons 71-75 \mathrm{C}$ & -0.58 & $-^{\mathrm{a}}$ & $-{ }^{\mathrm{a}}$ & 1.05 & 1.66 & 0.976 \\
\hline
\end{tabular}

${ }^{\mathrm{a}}$ Insignificant (significance value $>0.05$ )

The validity of the parameters of Eqs 2 and 3 was checked by means of regression analysis of the $\log \mathrm{K}_{\text {calc. }}$ values (calculated by applying the parameters of Eq. 2 or 3 ) against $\log \mathrm{K}$ determined from the ${ }^{1} \mathrm{H}$ NMR spectra (Figure 9).

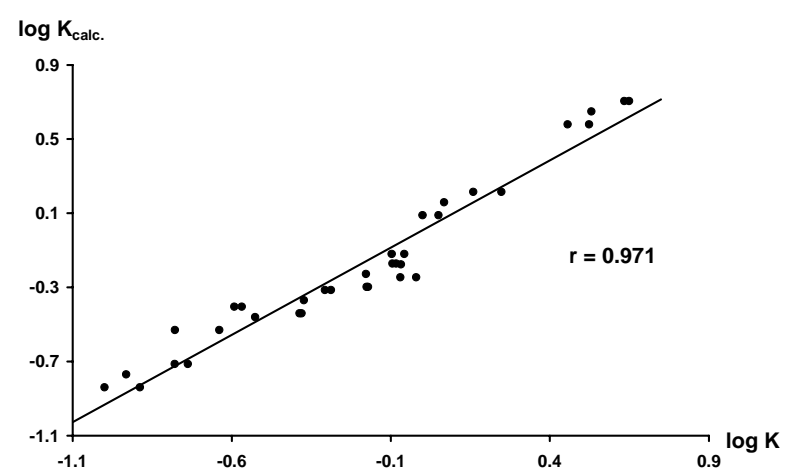

$a$

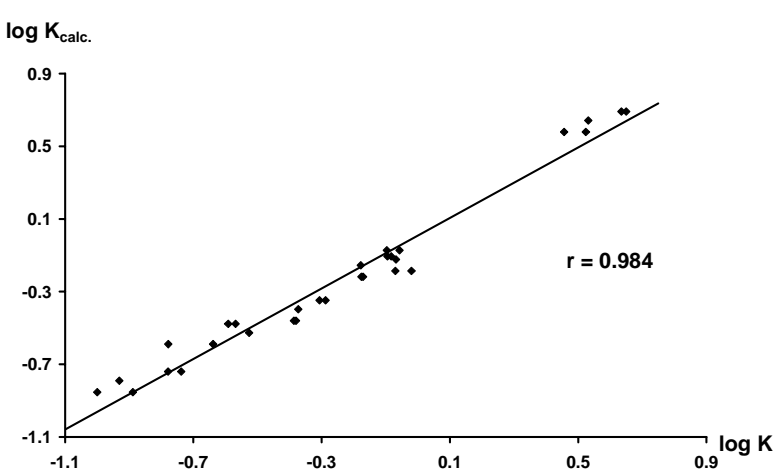

$b$

Figure 9. $a$ : Plots of $\log \mathrm{K}_{\text {calc. }}$ (calculated by applying Eq. 2) vs $\log \mathrm{K}$ (experimental) for 71-75B. $b$ : Plots of $\log \mathrm{K}_{\text {calc. }}$ (calculated by applying Eq. 3) vs $\log \mathrm{K}$ (experimental) for 71-75B

\subsection{Transformations of $\alpha$-aminobenzylnaphthol derivatives}

Application of the Betti base (45f) in the ring-closure reactions toward naphthalenecondensed heterocyclic derivatives has not been thoroughly investigated. The few publications that have appeared on this field focus on the reactions of $\mathbf{4 5 f}$ with aldehydes.

In the first stage of the transformations of compounds $45 \mathrm{f}, 55$ and $68 \mathrm{e}$ toward heterocyclic derivatives a one-carbon segment with $s p^{2}$ configuration was inserted between the hydroxy and amino groups. 
When aminonaphthols 45f, 55 and 68e were treated with phosgene in the presence of $\mathrm{Et}_{3} \mathrm{~N}$, the corresponding naphthalene-condensed 1,3-oxazin-2ones (76, 77 and 90) were formed in each case (Schemes 27 and 30). The similar ring closures of the analogous 2-(aminomethyl)phenol were investigated recently. ${ }^{69}$ The reactions of $\mathbf{4 5 f}, \mathbf{5 5}$ and $\mathbf{6 8 e}$ with ethyl benzimidate in boiling EtOH gave the desired 1,3-oxazine derivative (78) only with the unsubstituted aminophenol 55; for the phenyl-substituted regioisomers $45 \mathbf{f}$ and $\mathbf{6 8 e}$, only decomposition of the starting aminonaphthols could be observed (Scheme 27). While the preparation of dihydro-1,3-oxazine derivatives by the ring closure of amino alcohols with imidates is well known in the literature, ${ }^{70}$ compound $\mathbf{7 8}$ was the first aminophenol, for which this transformation was successfully accomplished.

For the preparation of 2-phenylimino-substituted 1,3-oxazines, aminonaphthols $\mathbf{4 5 f}, \mathbf{5 5}$ and 68e were reacted with phenyl isothiocyanate. In the cases of 1-substituted 2-naphthols $\mathbf{4 5 f}$ and 55, the corresponding thiourea derivatives 79 and 80 were formed in good yields. Thioureas 79 and $\mathbf{8 0}$ were converted with methyl iodide to the corresponding $S$-methyl isothiourea derivatives, treatment of which with methanolic $\mathrm{KOH}$ gave the corresponding 2-arylimino-substituted 1,3oxazines 81 and 82 via methyl mercaptan elimination (Scheme 27). While this type of ring closure is well known among $N$-thiocarbamoyl-substituted aminoalcohols, ${ }^{71}$ as far as we are aware, compounds $\mathbf{8 1}$ and $\mathbf{8 2}$ are the first 2-arylimino-substituted 1,3-oxazine derivatives formed from $\mathrm{N}$-thiocarbamoyl-substituted aminophenols in this way. Endocyclic-exocyclic tautomerism of the $\mathrm{C}=\mathrm{N}$ bond was not investigated.

The ring closures of $N$-unsubstituted aminonaphthols 45f, 55 and 68e with oxo compounds (i.e. the insertion of a one-carbon segment with $s p^{3}$ configuration) result in naphthalenecondensed 1,3-oxazines with a ring-chain tautomeric character. If the oxo compound used in this reaction contains another functional group capable of reacting with the amino group of the naphthoxazine formed, the tautomeric equilibrium can be shifted completely toward the ringclosed form by this second ring closure, resulting in nitrogen-bridged heterocycles. This principle was successfully applied earlier in the domino ring-closure reactions of $N$-unsubstituted aminoalcohols or aminophenols with $\gamma$ - or $\delta$-oxoacids. ${ }^{72,73}$ 


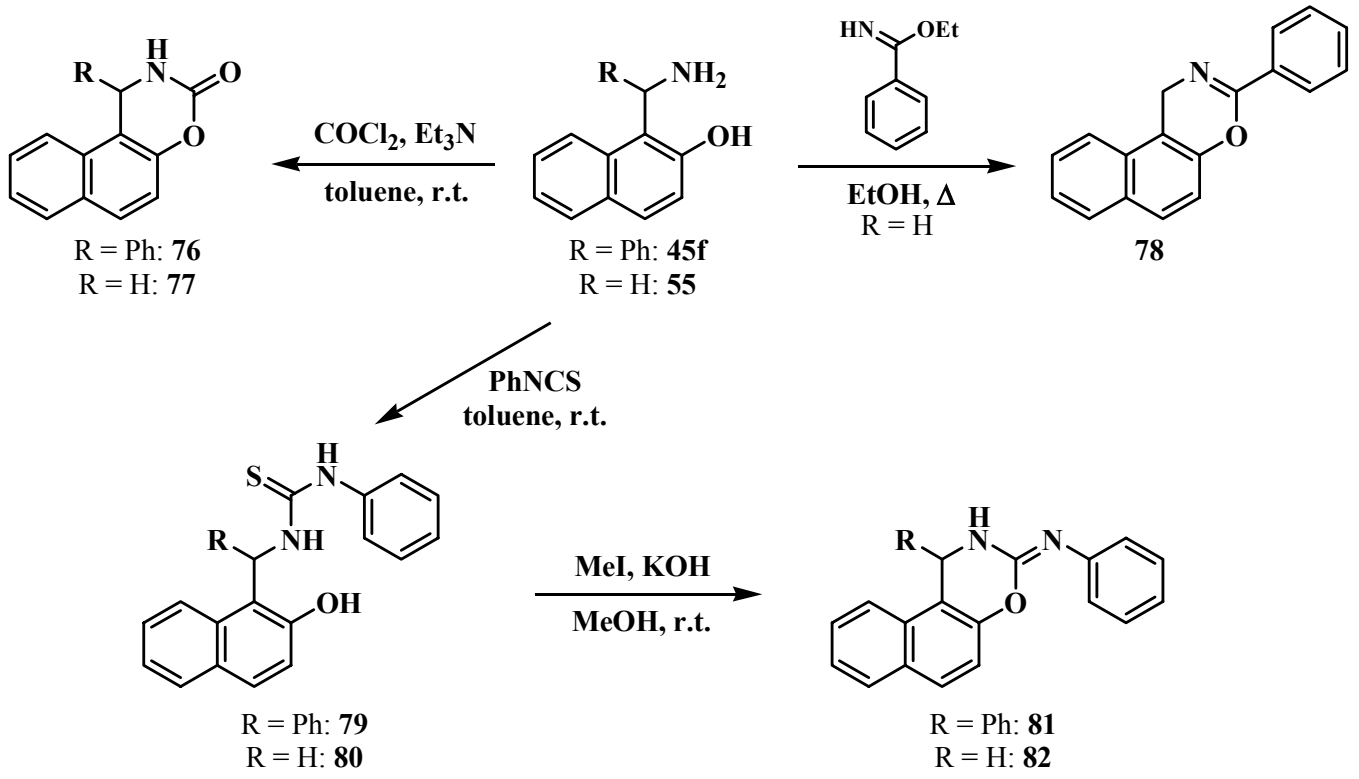

Scheme 27

The reactions of aminonaphthols 45f, 55 and 68e with 2-carboxybenzaldehyde, performed under mild conditions (r.t.), gave the corresponding isoindole-condensed naphthoxazines 83,84 and 91 (Schemes 28 and 30). According to the NMR measurements, pentacycles 83 and 91 were formed with practically complete stereoselectivity, with the relative configuration depicted in the Schemes; no minor diastereomers could be detected even in the crude products. Similarly high diastereoselectivities are often observed in analogous ring closures of aminoalcohols and are explained as a result of the kinetic control governing the second ring closures of the cyclic tautomeric intermediates. ${ }^{6,74}$

The analogous reactions of compounds $45 \mathrm{f}, 55$ and $68 \mathrm{e}$ with levulinic acid could not be accomplished under mild conditions; only the corresponding pyrrolonaphthoxazine (85) could be obtained in the case of the unsubstituted aminonaphthol 55 (Scheme 28). Elevated temperature again caused decomposition of aminonaphthols $45 \mathrm{f}$ and $68 \mathrm{e}$ instead of cyclization.
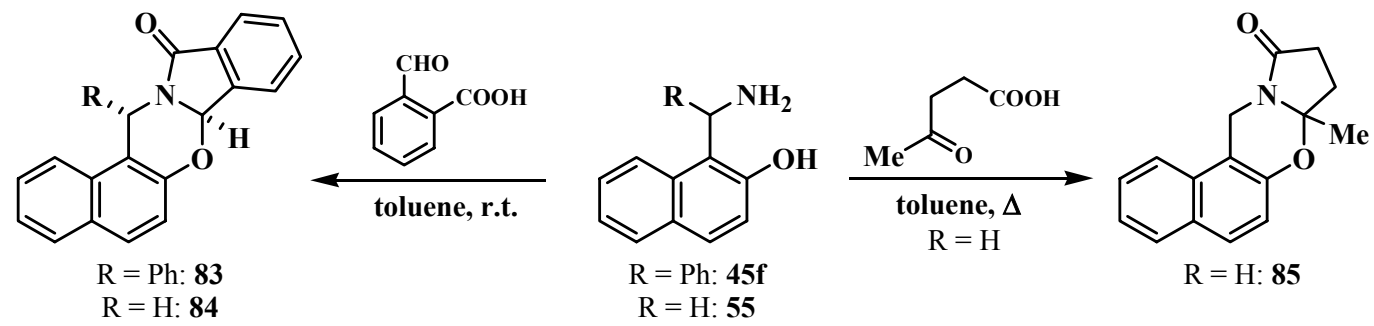

Scheme 28

A complete shift of the ring-chain tautomeric equilibrium of 1,3-O,N-heterocycles can be achieved by another transformation. If the oxo compound contains another functional group (e.g. $\mathrm{OH})$ capable of coupling with the amino group of the ring-closed tautomers via an appropriate agent, this reaction can also be a second ring closure with another aldehyde. This type of 
transformation was exploited earlier in the preparation of 1,3-O,N-heterocycle-condensed 1,3oxazines by subsequent cyclization of aminoalcohols with salicylaldehyde and another aldehyde. $^{75-77}$

When aminonaphthols $\mathbf{4 5 f}$ and $\mathbf{5 5}$ were reacted with salicylaldehyde, crystalline condensation products $(\mathbf{8 6}, \mathbf{8 7})$ were formed. The NMR measurements showed that the tautomeric equilibrium of $\mathbf{8 7}$ in $\mathrm{CDCl}_{3}$ at $300 \mathrm{~K}$ was practically totally shifted toward the open form (87A), while the phenyl-substituted compound $\mathbf{8 6}$ was found to participate under similar conditions in a three-component tautomeric equilibrium involving the trans (86B: $56.7 \%)$ and the cis (86C: $8.5 \%$ ) cyclic diastereomers besides the Schiff base (86A: 34.8\%). These data are in accordance with earlier observations on the predominance of the open form in the tautomeric equilibria of the condensation products of 1,2- and 1,3-aminoalcohols and salicylaldehyde, which is explained by the stabilization due to the strong intramolecular hydrogen bonds. ${ }^{75,76}$

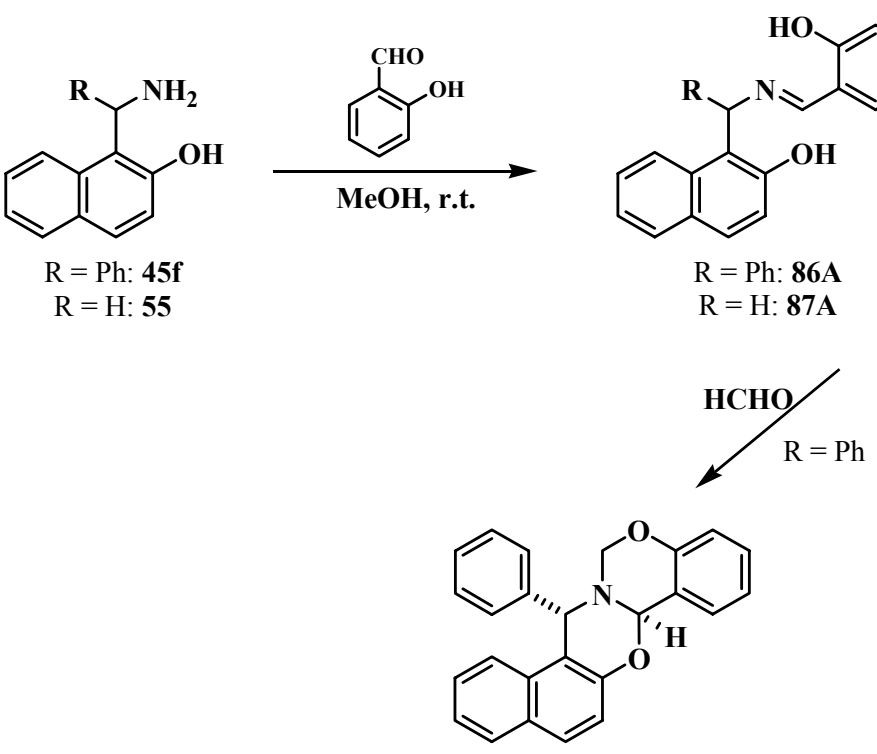

88
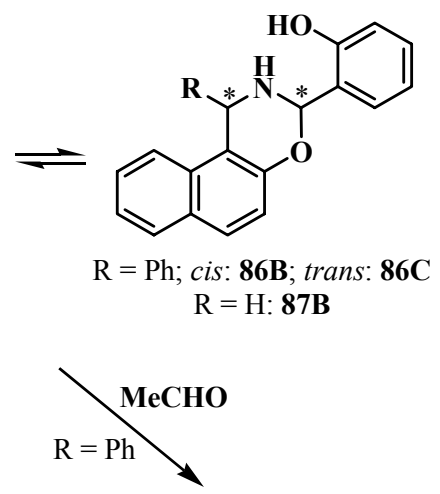

89

Scheme 29

Treatment of compound $\mathbf{8 6}$ with $40 \%$ formalin or ethanolic acetaldehyde solution resulted in the formation of phenyl-substituted naphthoxazinobenzoxazines $\mathbf{8 8}$ and $\mathbf{8 9}$ as crystalline products, whereas the similar transformations of $\mathbf{8 7}$ failed. The difference in cyclization behaviour between 86 and 87 can be explained on the basis of the better crystallization ability of the pentacyclic products $(\mathbf{8 8}$ and $\mathbf{8 9})$ formed from $\mathbf{8 6}$, which caused a continuous shift of the tautomeric equilibrium toward the predominant cyclic tautomer $(\mathbf{8 6 B}){ }^{75,76}$ In contrast, Stankevich et al. related the successful formation of oxazolobenzoxazines in analogous reactions to the increased proportion of the cyclic form in the tautomeric equilibria of the 2-(ohydroxyphenyl)oxazolidine intermediates. ${ }^{77}$ According to the NMR data, pentacycles $\mathbf{8 8}$ and $\mathbf{8 9}$ 
were formed with high stereoselectivity (de $\sim 100 \%$ ) with the relative configuration depicted in Scheme 29.<smiles>O=C1NC(c2ccccc2)c2ccc3ccccc3c2O1</smiles>

90<smiles>NC(c1ccccc1)c1ccc2ccccc2c1O</smiles>

$68 \mathrm{e}$

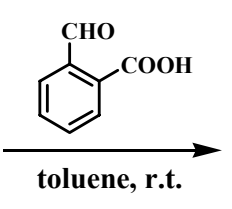

toluene, r.t.<smiles>O=C1c2ccccc2[C@H]2Oc3c(ccc4ccccc34)C(c3ccccc3)N12</smiles>

91

Scheme 30

The relative configurations of the diastereomer for $83,86,88,89$ and 91 were deduced from the NOESY spectra, in which the cross-peak for the protons of the chiral C-atoms proves their trans arrangement for all the compounds.

The structures were also confirmed by molecular modelling. The conformational protocol comprised a stochastic search using the Merck Molecular Force Field (MMFF94) and a subsequent minimization of the resulting low-energy conformations at the ab initio level, using the HF/3-21G* basis set for all the compounds $\mathbf{8 3}, \mathbf{8 6}, \mathbf{8 8}, \mathbf{8 9}$ and $\mathbf{9 1}$. The resulting structures proved to be rigid, since no minor conformation was found within the $6 \mathrm{kcal} / \mathrm{mol}$ energy window. The final conformations for $\mathbf{8 3}, \mathbf{8 8}, \mathbf{8 9}$ and $\mathbf{9 1}$ are shown in Figure 10. 
<smiles>CC1C(C)C(C)C(C2C3C4C(C)C(C)C(C)C3C3(C)CC5C(C)C(I)C6C(C)C(C)C(C)C(C)C6C5C(C)C(C4C)C23)C(C)C1C</smiles>

83

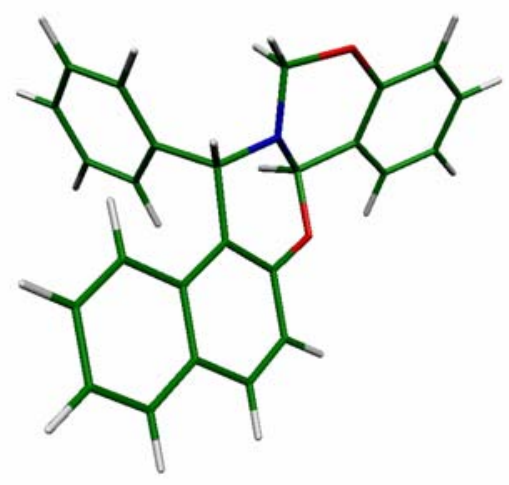

88

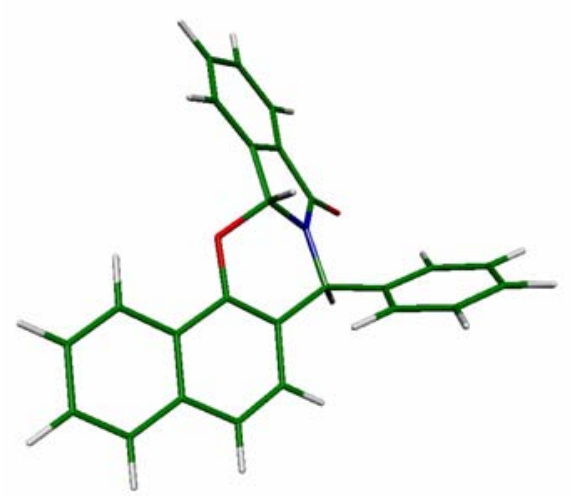

91

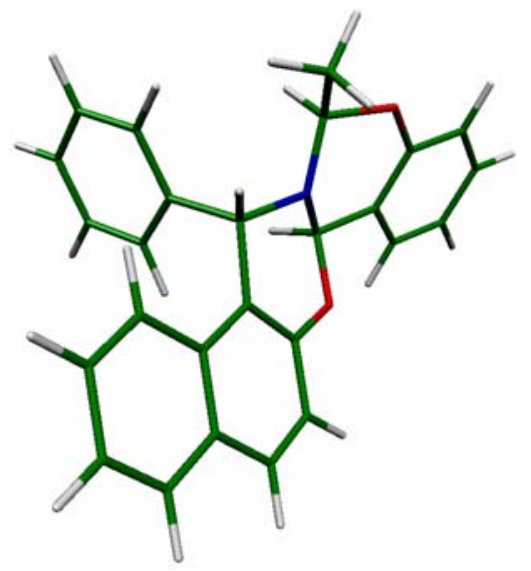

89

Figure 10. Final predominant minimum energy molecular structures for $\mathbf{8 3}, \mathbf{8 8}, \mathbf{8 9}$ and $\mathbf{9 1}$, obtained by using ab initio $\mathrm{HF} / 3-21 \mathrm{G}^{*}$ calculations.

\subsection{Methods}

Details of the syntheses, physical and analytical data on the new compounds described in the thesis, and descriptions of the NMR spectroscopic analyses of the tautomeric equilibria can be found in the experimental sections of the enclosed publications. 


\section{SUMMARY}

1. By using Betti's classical procedure (starting from 2-naphthol), 1-[ $\alpha$-amino(Y-substitutedbenzyl)]-2-naphthols (45a-i) were prepared. The analogous transformation of 1-naphthol led

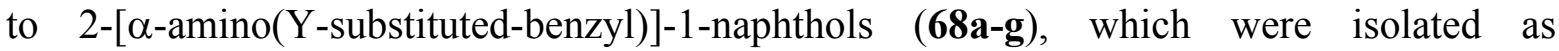
hydrochloride salts.

2. The reactions of 1-[ $\alpha$-amino(Y-substituted-benzyl)]-2-naphthols (45a-i) and substituted benzaldehydes led to 1,3-diaryl-2,3-dihydro- $1 H$-naphth[1,2-e][1,3]oxazines (46-54) which at $300 \mathrm{~K}$ in $\mathrm{CDCl}_{3}$ proved to be three-component tautomeric mixtures containing $\mathrm{C}-3$ epimeric naphthoxazines $(\mathbf{B}>\mathbf{C})$ besides the open tautomer $(\mathbf{A})$. The influence of aryl substituents at position 3 on the ring-chain tautomeric equilibria could be described by the Hammett equation.

3. In order to examine the influence of aryl substituents at positions 1 and 3 on the ring-chain equilibria of 1,3-diaryl-2,3-dihydro-1 $H$-naphth[1,2-e][1,3]oxazines (48-54), multiple linear regression analysis of Eqs 2 and 3 was performed. The significant dependence of $\log \mathrm{K} v s$ the inductive parameter $\sigma_{\mathrm{F}}^{\mathrm{Y}}$ of substituent $\mathrm{Y}$ for the trans $=$ chain $(\mathbf{B}=\mathbf{A})$ tautomeric equilibria was explained with the aid of the anomeric effect in the trans ring form. The multiple linear regression analysis of the chemical shifts of C-1 and C-3 for the cis and trans diastereomers revealed a significant dependence on $\sigma_{\mathrm{F}}^{\mathrm{Y}}$. The differences between the intercepts could be explained nicely in terms of the anomeric effect in the trans ring form. For a deeper examination of this phenomenon, the donation energies of the nitrogen lone pairs to vicinal antibonding orbitals were calculated by using NBO molecular modelling calculations. The calculations showed that the donation energy values are strongly influenced by the relative configuration of C-1 and C-3.

4. To find evidence of the substituent effect in the ring form, the tautomeric system of 3-alkyl1-aryl-2,3-dihydro- $1 H$-naphth[1,2-e][1,3]oxazines 60-66 was analysed. Condensations of aminonaphthols 45a-i with equivalent amounts of aliphatic aldehydes resulted in the naphthoxazine model compounds 60-66, which at $300 \mathrm{~K}$ in $\mathrm{CDCl}_{3}$ proved to be twocomponent tautomeric mixtures containing C-3 epimeric naphthoxazines $(\mathbf{B}>\mathbf{C})$. The 
epimerization constant was calculated from the ratio of the diastereomers $\left(K_{R}=[\mathbf{B}] /[\mathbf{C}]\right)$. The influence of alkyl substituents on $\log K_{R}$ could be described in terms of their Meyer parameters $\mathrm{V}^{\mathrm{a}}$. The results of multiple linear regression analysis of the $\log \mathrm{K}_{\mathrm{R}}$ values reveal a significant dependence on the inductive effect of substituent $Y\left(\sigma_{F}\right)$, which can improve the anomeric effect in the trans ring form.

5. The ring-closure reactions of aminonaphthols 68a-g with equivalent amounts of aromatic aldehydes resulted in 2,4-diaryl-3,4-dihydro-2H-naphth[2,1-e][1,3]oxazines (69-75), which in $\mathrm{CDCl}_{3}$ at $300 \mathrm{~K}$ formed three-component tautomeric mixtures containing major $(\mathbf{B})$ and minor $(\mathbf{C})$ ring-closured epimeric forms beside the open chain form $(\mathbf{A})$, and they proved to be good model compounds for study of the double substituent influence on the tautomeric eqilibria. Systematic quantitative investigations on the ring-chain tautomeric equilibria of 2,4-diarylnaphth[2,1-e][1,3] oxazines demonstrated an analogous inductive influence on the trans $=$ chain $(\mathbf{B}=\mathbf{A})$ tautomeric equilibria.

6. By simple or domino ring-closure reactions of 1-( $\alpha$-aminobenzyl)-2-naphthol (45f), 1-aminomethyl-2-naphthol (55) and 2-( $\alpha$-aminobenzyl)-1-naphthol (68e) with phosgene, ethyl benzimidate, 2-carboxybenzaldehyde, levulinic acid, salicylaldehyde/formalin or salicylaldehyde/acetaldehyde, naphth[1,2-e][1,3]oxazine and naphth[2,1-e][1,3]oxazine derivatives were prepared. All of the nitrogen-bridged polycyclic derivatives of $\mathbf{4 5 f}$ and $\mathbf{6 8 e}$ with several centres of asymmetry were formed with nearly total diastereoselectivity. Considerable differences were found in the ring-closing abilities of the unsubstituted and phenyl-substituted aminonaphthols $\mathbf{4 5 f}$ and $\mathbf{5 5}$ and the regioisomeric compounds $\mathbf{4 5 f}$ and $68 \mathrm{e}$. 


\section{ACKNOWLEDGEMENTS}

This work was carried out in the Institute of Pharmaceutical Chemistry, University of Szeged, during the years 1999-2003.

I would like to express my warmest thanks to Professor Ferenc Fülöp, head of the Institute, for his guidance of my work, his inspiring ideas, his useful advice and his constructive criticism.

My warmest thanks are due to my supervisor, Dr. László Lázár, for his continuous support and interest in my activities. His advice and help have been invaluable during all stages of my work.

I am greatly indebted to Professor Erich Kleinpeter, Department of Chemistry, University of Potsdam, for providing me with the opportunity to work for 7 months in his research group.

I would like to thank Dr. Tamás Martinek and Anasztázia Hetényi for helpful discussions concerning the NMR assignments.

I am grateful to Dr. David Durham for revising the English language of all the English publications and the manuscripts.

I owe very much to my family, my colleagues and my friends for creating all the circumstances enabling me to carry out this work. Without their help, this thesis could not have been prepared. 


\section{REFERENCES}

1 Betti, M. Gazz. Chim. Ital., 1900, 30 II, 310.

2 Betti, M. Gazz. Chim. Ital., 1901, 31 II, 377.

3 Betti, M. Gazz. Chim. Ital., 1901, 31 II, 170.

4 Betti, M. Gazz. Chim. Ital., 1901, 31 II, 191.

5 Betti, M. Org. Synth. Coll. Vol., 1941, 1, 381.

6 Lázár, L.; Fülöp, F. Eur. J. Org. Chem., 2003, 3025.

7 Valters, R. E.; Flitsch, W. Ring-Chain Tautomerism; Plenum Press: New York, 1985.

8 Valters, R. E.; Fülöp, F.; Korbonits, D. Adv. Heterocyclic Chem., 1996, 66, 1.

9 Fülöp, F.; Pihlaja, K.; Mattinen, J.; Bernáth, G. J. Org. Chem., 1987, 52, 3821.

10 Star, A.; Fuchs, B. J. Org. Chem., 1999, 64, 1166.

11 Hetényi, A.; Szakonyi, Z.; Klika, K. D.; Fülöp, F.; Pihlaja, K. J. Org. Chem., 2003, 68, 2175.

12 Milman, B. L.; Potekhin, A. A. Khim. Get. Soedin., 1973, 902.

13 Fülöp, F.; Lázár, L.; Bernáth, G.; Sillanpää, R.; Pihlaja, K. Tetrahedron, 1993, 49, 2115.

14 Göblyös, A.; Lázár, L.; Evanics, F.; Fülöp, F. Heterocycles, 1999, 51, 2431.

15 Ray, F. E.; Moomaw, W. A. J. Am. Chem. Soc., 1933, 55, 749.

16 Kharasch, M. S.; Howard, L. B. J. Am. Chem. Soc., 1934, 56, 1370.

17 Smith, H. E.; Cooper, N. E. J. Org. Chem., 1970, 35, 2212.

18 Möhrle, H.; Miller, C.; Wendisch, D. Chem. Ber., 1974, 107, 2675.

19 Hanumanthu, P.; Ratman, C. V. Ind. J. Chem., 1977, 15B, 1019.

20 Jin, J.; Wen, Z.; Long, J.; Wang, Y.; Matsuura, T.; Meng, J. Synth. Commun., 2000, 30, 829.

21 Hassner, A.; Cromwell, N. H.; Davis, S. J. J. Am. Chem. Soc., 1957, 79, 230.

22 Littman, J. B.; Brode, W. R. J. Am. Chem. Soc., 1930, 52, 1655.

23 Brode, W. R.; Littman, J. B. J. Am. Chem. Soc., 1931, 53, 1531.

24 Dilthey, W.; Steinhorn, H. J. prakt. Chem., 1932, 133, 219.

25 Seshadri, S.; Cherian, A. L.; Pandit, P. Y. Indian J. Chem., 1969, 7, 1080.

26 Grumbach, H-J.; Arend, M.; Risch, N. Synthesis, 1996, 883.

27 Saidi, M. R.; Azizi, N.; Naimi-Jamal, M. R. Tetrahedron Lett., 2001, 42, 8111.

28 Betti, M. Gazz. Chim. Ital., 1906, 36 II, 392.

29 Betti, M. Gazz. Chim. Ital., 1906, 36 II, 666.

30 Cardellicchio, C.; Ciccarella, G.; Naso, F.; Schingaro, E.; Scordari, F. Tetrahedron: Asymmetry, 1998, 9, 3667. 
31 Cardellicchio, C.; Ciccarella, G.; Naso, F.; Perna, F.; Tortorella, P. Tetrahedron, 1999, 55, 14685.

32 Palmieri, G. Tetrahedron: Asymmetry, 2000, 11, 3361.

33 Cimarelli, C.; Mazzanti, A.; Palmieri, G.; Volpini, E. J. Org. Chem., 2001, 66, 4759.

34 Cimarelli, C.; Palmieri, G.; Volpini, E. Tetrahedron: Asymmetry, 2002, 13, 2417.

35 Boga, C.; Di Martino, E.; Forlani, L. J. Chem. Res. (S), 2001, 219.

36 Saidi, M. R.; Azizi, N. Tetrahedron: Asymmetry, 2003, 14, 389.

37 Ji, J-X.; Qiu, L-Q.; Yip, C. W.; Chan, A. S. C. J. Org. Chem., 2003, 68, 1589.

38 Desai, N. C.; Shukla, H. K..; Langalia, N. A.; Thaker, K. A. J. Indian Chem. Soc., 1984, 61, 711.

39 Liu, D-X.; Zhang, L-C.; Wang, Q.; Da, C-S.; Xin, Z-Q.; Wang, R.; Choi, M. C. K.; Chan, A. S. C. Org. Lett., 2001, 3, 2733.

40 Cimarelli, C.; Palmieri, G.; Volpini, E. Tetrahedron, 2001, 57, 6089.

41 Lu, J.; Xu, X.; Wang, S.; Wang, C.; Hu, Y.; Hu, H. J. Chem. Soc., Perkin Trans. 1, 2002, 2900.

42 Lu, J.; Xu, X.; Wang, C.; He, J.; Hu, Y.; Hu, H. Tetrahedron Lett., 2002, 43, 8367.

43 Wang, Y.; Li, X.; Ding, K. Tetrahedron: Asymmetry, 2002, 13, 1291.

44 Betti, M.; Pratesi, P. Ber., 1930, 63 B, 874.

45 Betti, M.; Pratesi, P. Biochem. Z., 1934, 274, 1.

46 Betti, M. Gazz. Chim. Ital., 1912, 42 I, 288.

47 Duff, J.C.; Bills, E. J. J. Chem. Soc., 1934, 1305.

48 SPSS Advanced Models 9.0, SPSS Inc., Chicago, IL

49 Neuvonen, K.; Fülöp, F.; Neuvonen, H; Koch, A.; Kleinpeter, E.; Pihlaja, K. J. Org. Chem., 2001, 66, 4132.

50 Hetényi, A.; Martinek, T. A.; Lázár, L.; Zalán, Z.; Fülöp, F. J. Org. Chem., 2003, 68, 5705.

51 Salzner, U.; Schleyer, P. R.; J. Org. Chem., 1994, 59, 2138.

52 Cortés, F.; Tenorio, J.; Collera, O.; Cuevas, G. J. Org. Chem., 2001, 66, 2918.

53 Reed, E. A.; Weinstock, R. B.; Weinhold, F. J. Chem. Phys., 1985, 83, 735.

54 Reed, E. A.; Curtiss, L. A.; Weinhold, F. Chem. Rev., 1988, 88, 899.

55 Neuvonen, K.; Pihlaja, K. J. Chem. Soc., Perkin Trans. 2, 1988, 461.

56 Neuvonen, K.; Pohtola, R.; Pihlaja, K. Magn. Reson. Chem., 1989, 27, 725.

57 Ehrenson, S.; Brownlee, R. T. C.; Taft, R. W. Prog. Phys. Org. Chem., 1973, 10, 1.

58 Craik, D. J.; Brownlee, R. T. C. Prog. Phys. Org. Chem., 1983, 14, 1.

59 Reynolds, W. F. Prog. Phys. Org. Chem., 1983, 14, 165. 
60 Kawasaki, A. J. Chem. Soc., Perkin Trans. 2, 1990, 223.

61 Gordon, M. S.; Sojka, S. A.; Krause, J. G. J. Org. Chem., 1984, 49, 97.

62 Neuvonen, K.; Fülöp, F.; Neuvonen, H.; Pihlaja, K. J. Org. Chem., 1994, 59, 5895.

63 Neuvonen, K.; Fülöp, F.; Neuvonen, H; Simeonov, M.; Pihlaja, K. J. Phys. Org. Chem., 1997, 10, 55.

64 Bergmann, E. D.; Gil-Av, E.; Pinchas, S. J. Am. Chem. Soc., 1953, 75, 358.

65 De Tar, D. F.; Delahunty, C. J. Am. Chem. Soc., 1983, 105, 2734.

66 Charton, M. J. Am. Chem. Soc., 1975, 97, 1552.

67 Charton, M. J. Org. Chem., 1976, 41, 2217.

68 Meyer, A., Y.J. Chem. Soc., Perkin Trans. 2, 1986, 1567.

69 Mindl, J.; Hrabik, O.; Sterba, V.; Kavalek, J. Coll. Czech. Chem. Commun., 2000, 65, 1262.

70 Fülöp, F.; Bernáth, G.; Pihlaja, K. Adv. Heterocyclic Chem., 1998, 69, 349.

71 Fülöp, F.; Bernáth, G.; Sohár, P. Tetrahedron, 1985, 41, 5981.

72 Csende, F.; Stájer, G. Heterocycles, 2000, 53, 1379.

73 Ito, T.; Yamazaki, N.; Kibayashi, Synlett, 2001, 10, 1506.

74 Meyers, I.; Downing, S. V.; Weiser, M. J. J. Org. Chem., 2001, 66, 1413.

75 Fülöp, F.; Lázár, L.; Pelczer, I.; Bernáth, G. Tetrahedron, 1988, 44, 2993.

76 Lázár, L.; Fülöp, F.; Bernáth, G.; Kálmán A.; Argay, G. J. Heterocyclic Chem., 1991, 28, 1213.

77 Kukharev, B. F.; Stankevich, V. K.; Klimenko, G. R.; Bayandin, V. V.; Albanov, A. I. Arkivoc, 2003, xiii, 166. 
ANNEX 